UNCLASSIFIED

\begin{tabular}{|c|}
\hline AD NUMBER \\
\hline ADB014580 \\
\hline LIMITATION CHANGES \\
\hline
\end{tabular}

TO:

Approved for public release; distribution is unlimited.

FROM:

Distribution authorized to U.S. Gov't. agencies only; Test and Evaluation; JUL 1976. Other requests shall be referred to Aero-Propulsion Lab., Wright-Patterson AFB, OH 45433-6503.

\title{
AUTHORITY
}

AFWAL ltr 9 Sep 1983 


$$
\text { A0 } 13014580
$$

$$
\begin{aligned}
& \text { Authority: AFWALE } \\
& \text { Hty } 9 \operatorname{sep} 83
\end{aligned}
$$




\section{ADVANCED TURBINE ENGINE SEAL TEST FINAL REPORT}

GENERAL ELECTRIC COMPANY

AIRCRAFT ENGINE GROUP

ADVANCED ENGRG. AND TECH. PROGRAMS DEPT.

CINCINNATI, OHIO 45215

JULY 1976

TECHNICAL REPORT AFAPL-TR-76-40

FINAL REPORT FOR THE PERIOD 28 FEBRUARY 1973 to 29 FEBRUARY 1976

Distribution limited to U.S. Government Agencies only: Test data evaluation; July 1976. Other requests for this document must be referred to AF Aero Propulsion Laboratory (TBC), W-PAFB, Ohio 45433

AIR FORCE AERO PROPULSION LABORATORY AIR FORCE WRIGHT AERONAUTICAL LABORATORIES AIR FORCE SYSTEMS COMMAND WRIGHT-PATTERSON AIR FORCE BASE, OHIO 45433

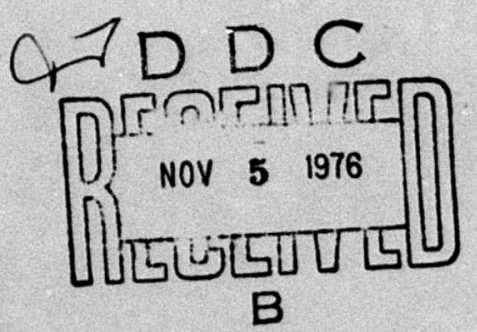




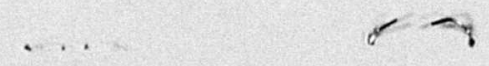

NOTICE

When Government drawings, specifications, or other data are used for any purpose other than in connection with a definitely related Government procurement operation, the United States Government thereby incurs no responsibility nor any obligation whatsoever; and the fact that the Government may have formulated, furnished, or in any way supplied the said drawings, specifications, or other data, is not to be regarded by implication or otherwise as in any manner licensing the holder or any other person or corporation, or conveying any rights or permission to manufacture, use, or sell any patented invention that may in any way be related thereto.

This final report was submitted by the General Electric Company, Aircraft Engine Group, under Contract F33615-73-C-2041. The effort was sponsored by the Air Force Aero Propulsion Laboratory, Air Force Systems Command, Wright-Patterson AFB, Ohio, under Project (3066), with Mr. C.W. Elrod/AFAPL/ TBC as Project Engineer. Mr. A.A. Hauser of the General Electric Company was technically responsible for the work. The General Electric Program Manager was Mr. K.W. Schuning; the Principal Investigators were Mr. D.C. Bryant and Mr. C.H. Gay, Jr.

Distribution limited to U.S. Government agencies only; Test Data Evaluation; Date July 1976. Other requests for this document must be referred to AFAPL/TBC, Air Force Aero Propulsion Laboratory, W-PAFB, Ohio 45433.

This technical report has been reviewed and is approved for publication.

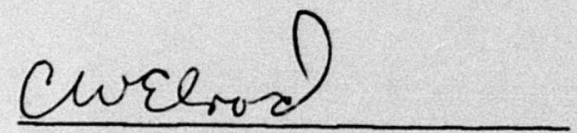

C.W. Elrod

Project Engineer

FOR THE COMMANDER
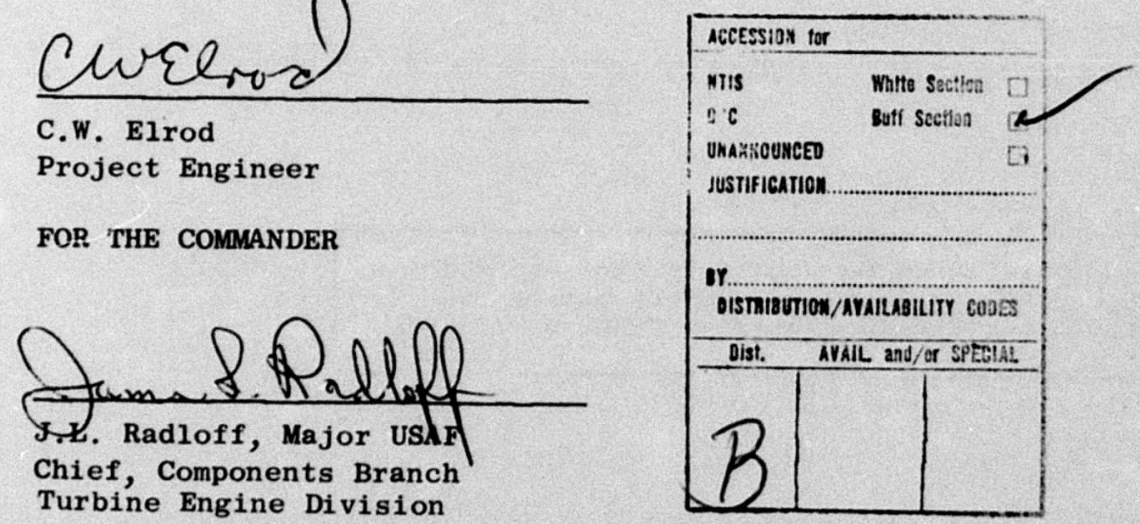

Copies of this report should not be returned unless return is required by security considerations, contractual obligations, or notice on a specific document. 
UNCLASS IF IED

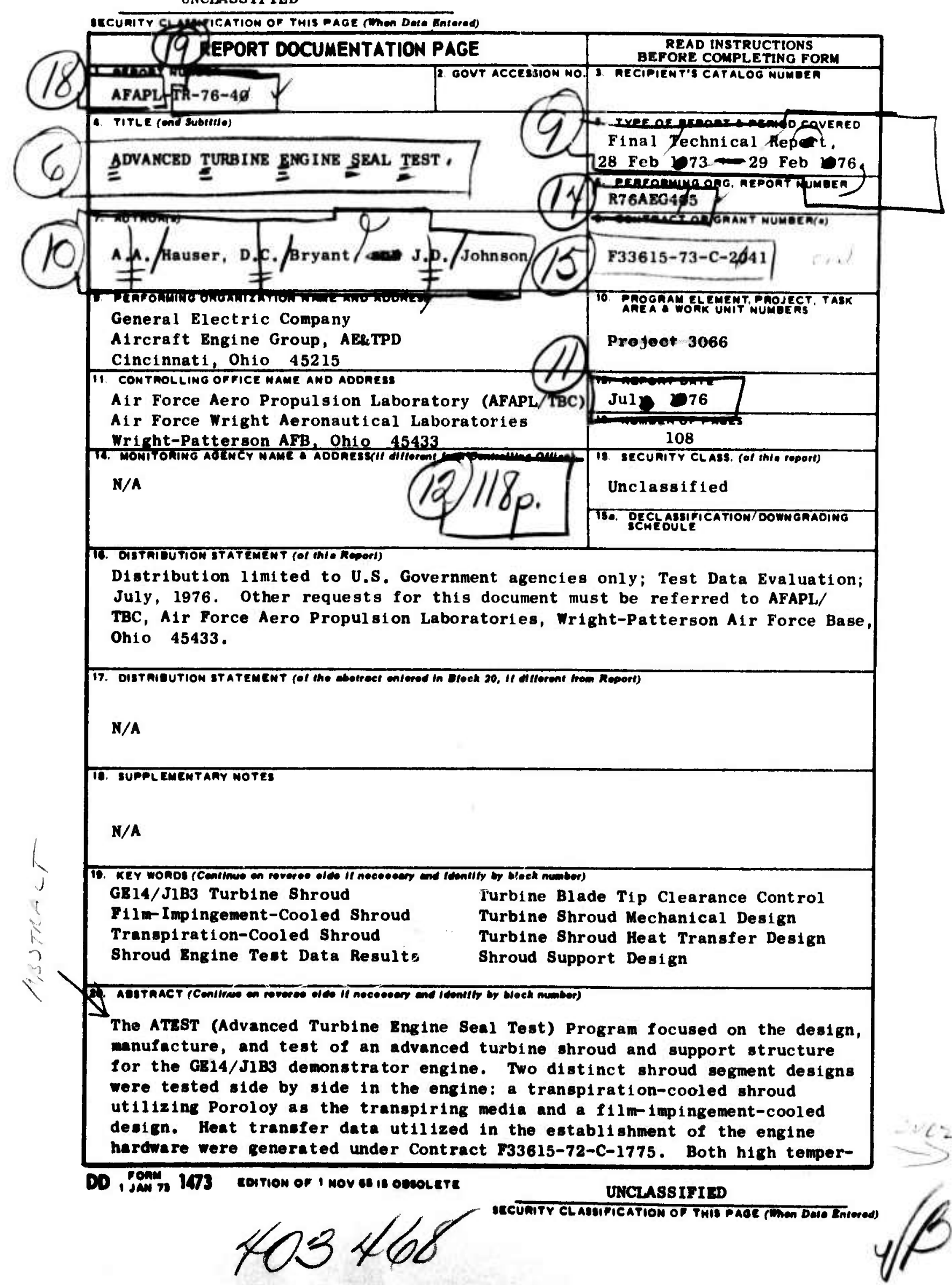


UNCIASSIFIED

secunitr CLASSIFICATION OF THIS PAGE(mom Dete Entered)

ature performance and cyclic endurance testing were performed. Transient and steady-state temperature and pressure data were measured and compared to predicted values.

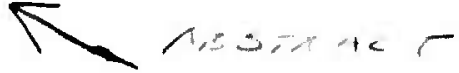




\section{TABLE OF CONTENTS}

Section

Page

1.0 INTRODUCTION

1.1 Background

1.2 Scope

1

2

2.0 SUMMARY

3.0 DESIGN DESCRIPTION

4.0 MANUFACTURE OF HARDWARE

4.1 Transpiration-Cooled Shrouds

4.2 Film-Impingement-Cooled Shrouds

4.3 Shroud Support System Hardware

4.4 Shroud Design Cost Comparison

4.5 Problems and Solutions

4.5.1 Casting Curvature

4.5.2 Sheet Metal Redesign, Film-ImpingementCooled Shrouds

4.5.3 Leakage Flow, F11m-Impingement-Cooled Shrouds

5.0 ASSEMBLY

5.1 Shroud System Assembly

5.2 Shroud ECG Grind

5.3 Shroud Support Si ip Joint Problem

6.1 Location/Purpose

6.2 Clearance Pin Installation

7.0 TEST RESULTS

62

8.0 RESULTS OF TEARDOWN INSPECTION

9.0 CONCLUS IONS

9.1 Mechanical Design Performance

9.2 Cooling Performance 


\section{LIST OF ILLUSTRATIONS}

Figure

Page

1. ATEST Turbine Shroud Assembly.

2. ATEST Turbine Shroud Cooling and Temperature Control Circuits.

3. ATEST Turbine Shroud Assemblies. 9

4. ATEST Film-Impingement-Cooled Shroud Segment. 10

5. ATEST Transpiration-Cooled Shroud. 11

6. ATEST Turbine Shroud End Seal. 14

7. Partially Machined Transpiration-Cooled Shroud Segment $\begin{array}{ll}\text { Casting, Flowpath Side View. } & 16\end{array}$

8. Partially Machined Transpiration-Cooled Shroud Segment Casting, Barkside View.

9. Poroloy Wire Mesh Design. 18

10. Transpiration-Cooled Shroud Segment Assembly Prior to EB Welding.

11. Welded Poroloy Transpiration-Cooled Shroud Segment Before Final Machining.

12. Final Machined Transpiration-Cooled Shroud Segment, Flowpath Surface View.

13. Transpiration-Cooled Shroud Segment, Backside View Featuring the Forward Shroud Hanger.

14. Transpiration-Cooled Shroud Segment, Backside View Fenturine the Aft Shroud Hanger.

15. I iftial Machining of Film-Impingement-Cooled Shroud Segment.

16. Film-Impingement-Cooled Shroud Segment Components Prior to Braze, Backside View.

17. Final Machined Film-Impingcinent-Cooled Shroud Segment, Flowpath Surface View. 
18. Film-Impingement-Cooled Shroud Segment, Backside View Featuring the Aft Shroud Hanger.

19. Film-Impingement-Cooled Shroud Segment, Backside View Featuring the Forward Shroud Hanger.

20. Shroud Support Assembly, Front View.

21. Shroud Support Assembly, Aft View.

22. Shroud Support Assembly, Detail View.

23. Transpiration-Cooled Shroud Casting Drawing.

24. Transpiration-Cooled Shroud Machining Drawing.

25. Film-Impingement-Cooled Shroud Casting Drawing.

26. F11m-Impingement-Cooled Shroud Machining Drawing.

27. Shroud Support.

28. Forward Seal.

29. Outer Support.

30. Shroud Assembly.

31. F11m-Impingement-Cooled Shroud, Assembly Detail Modifications.

32. Leakage Path.

33. Overall View of Shroud Assembly Prior to Overlapping Shim Seal Installation.

34. Close-up View of Shroud Assembly Prior to Installation of Overlapping Shim Seals.

35. Shroud Support and Film-Impingement-Cooled Shroud Segment Instrumentation.

36. Transpiration-Cooled Shroud segment Instrumentation.

37. Instrumented Transpiration-Cooled shroud Segments. 


\section{LIST OF ILLUSTRATIONS (Continued)}

Figure

38. Instrumented Film-Impingement-Cooled Shroud Segments.

Page

39. Instrumented Shroud Locations in Shroud Assembly.

40. Shroud Segment Clearance Pin Installation.

41. Shroud Measured Steady-State Temperatures at Rated $\mathrm{T}_{4}$
Conditions.

42. ATEST Shroud Gas Stream Pressure Instrumentation Locations.

43. Measured Shroud Static Pressure Distributions.

Measured Shroud Support Transient Response

$\left(T_{\text {Rated }}-300^{\circ} \mathrm{F}\right)$

Gas Stream Recovery Temperature on the Shroud Surface.

Shroud Design Static Pressure Distribution.

47. Design Point Cooling Air Pressure Drop Across

Transpiration-Cooled Shroud.

48. Design Point Cooling A1r Pressure Drop Across FilmImpingement-Cooled Shroud.

49. Assumed Streamline Trajectory over the Shroud Surface for the Design of the ATEST Shrouds.

50. Heat Transfer Cuefficient Test Factor for a Shroud Over a Highly Loaded Turbine Blade. 51. Heat Transfer Test Factor Versus Axial Position Along the
Shroud.

52. Transpiration-Cooled Shroud Segment Calculated Steady-

State Design Temperature Distribution at Rated $\mathrm{T}_{4}$.

53. ATEST Film-Impingement-Cooled Shroud Temperature Distribution, Case 1 - Design Point.

54. Shroud Support Cyclic Test Calculated Temperature Response.

55. Instrumented Transpiration-Cooled Shroud Flows.

56.

Inst rumented Film-Impingement-Cooled Shroud Flows. 


\section{LIST OF ILLUSTRATIONS (Concluded).}

Figure

57. Comparison of Shroud Design and Measured Static Pressure Distribution.

58. Comparison of Measured and Predicted Temperatures on the Film-Impingement-Cooled Shrouds.

59. Comparison of Measured and Predicted Temperatures on the Transpiration-Cooled Shrouds.

60. Comparison of Predicted and Measured Shroud Support

Ten. iratures.

61. Shroud Support Transient Response (TRated $-300^{\circ} \mathrm{F}$ ) ,

62. ATEST Shroud Assembly After Test.

63. Transpiration-Cooled Shroud Segment After Test.

64. Film-Impingement-Cooled Shroud Segment After Test.

65. ATEST Shroud Seals Teardown Observations.

66. Typical Rub Pin Weld Crack, Back Side of TranspirationCooled Shroud Segmenits.

67. ATEST Shroud Rub Pin Heights and Mid-Chord Runout.

68. Locations of Nine-Point Runout Check on Shroud Surface.

69. ATEST Shroud Leading Edge Runout.

70. ATEST Shroud Trailing Edge Runout.

71. ATEST Shroud Support Posttest Runout.

72. ATEST Shroud Flow Zones.

73. Shroud Segment LCF Life.

74. Heat Transfer Test Factor Versus Axial Position Along the Shroud. 


\section{LIST OF TABI,ES}

Table

Page:

1. GE14/J1B3 Demonstrator Engine Test Summary.

2. Shroud Design Cycle Conditions.

68

3. Shroud Test Rated $T_{4}$ Demonstrator Conditions.

80

4. Comparison of Actual and Predicted Rotor-Shroud clearances.

96 


\section{SECTION 1.0}

\section{INTRODUCTION}

\subsection{BACKGROUND}

Advanced turbine engine design requirements include operating environments which are $f$ ar more severe for component design than are encountered in current engines. The performance of these gas turbine engines will be improved in part by increasing the cycle gas temperatures and pressures. The gas temperatures in current advanced engines are now at levels where couling is required throughout the high pressure turbine.

Higher turbine inlet temperatures require advanced long-1ife mechanical designs which incorporate advanced materials and heat transfer technology to allow for the high component operating temperatures. This is necessary in order to minimize the engine cycle penalty incurred in the use of bleed alr for component cooling, which will of $\mathrm{fset}$ to some degree the performance gain of the high cycle pressures and temperatures.

The program herein reported relates to the auvancement of turbine blade tip shroud seal technology. The tip shroud seal, like other turbine components, must be designed for long life and effictently cooled. In addition, very close attention must be paid to the shroud system temperature gradients, the transient thermal response of the shroud support, and the effects of these variables on turbine blade tip clearances. The temperature gradients in the shroud system must be controlled so that induced stresses are acceptable. The gradients must be matched with the shroud structural support design so that the shroud surf ace remains parallel to the engine axis during engine operation.

Close tip clearances are necessary to maintain good turbine efficlency; and, therefore, the transient response of the rotor assembly and shroud support system must be matched so that close steady-state clearances can be achieved without causing a severe tip rub during the expansions and contractions of the shroud system which occur during transient accelerations and decelerations. While the severity of a tip rub can be controlled, the shroud segments and their support system must withstand expected tip rubs without signif icantly impairing the structural integrity, destroying the cooling system, or excessively enlarging the operating clearances.

As new seal technology is evolved, it must undergo rigorous testing, both bench-scale and full-scale demonstration, before future engine application can be considered. Furthermore, the seal design must be tested in the operating environment for final proof of 1 ts design validity. 
The cooling effectiveness performance of two turbine shroud cooling concepts was measured in low temperature air turbine testing conducted Design," the results of which are used to design the advanced technology air-cooled, turbulence tip shrouds
which were evaluated in a high temperature program. The results of the shroud design demonstrator engine under this in Reference 2. One of the goals of verify the design analysis predictions and ments made on the turbine shroud components.

\subsection{SCOPE}

The objective of this program was to demonstrate the design performance of two competing seal concepts: a film-impingement-cooled design and generator environment. The program full-scale advanced turbine engine gas cooling effectiveness of these applying modern design analysis methods high temperature applications, and, thus and low temperature cooling data to and mechanical design technology for future higlish advanced shroud cooling

engines.

The complete program consisted of three phases as follows:

- Phase I - Design of Shrouds and the Shroud Support System

- Phase II - Fabrication and Instrumentation of Shrouds and Sup-
port System

- Phase III - Demonstration Test of Shroud Designs

This report summarizes the mechanical and heat transfer design and analysis of the turbine shroud segments and support system, the manuf ing of the hardware, and the results of the demonstracturThese results are compared to predicted compone inerits of the two competing cooling designs and performance levels. The turbine cooling effectiveness data ore also discue low temperature air

The General Electric Company has been engaged for the past several years in the ATEGG (Advanced Turbine Engine Gas Generator) Program to demonstrate advanced component technologies that will be needed to meet
future engine requirements. The GE14/JIB3 eight-stage compressor operating at high gas temperatur a single-stage high pressure turbine variable area $\left(\mathrm{A}_{4}\right)$ turbine nozzle. The demonstrator also incorporates a program were designed for install. The shrouds evaluated under this having a turbine diameter of approximately 27 inches. 
The assembly, test, posttest data evaluation, and component inspections for the Advanced Turbine Engine Seal Test Turbine (ATEST) shroud components are presented in this report. The entire test plan proposed for the hardware procured under this contract was completed with but one build of the GE14/J1B3 high temperature demonstrator sigine. The running times and cyclic testiag completed are shown in Table 1 below.

Table 1. GE14/J1B3 Demonstrator Engine Test Summary.

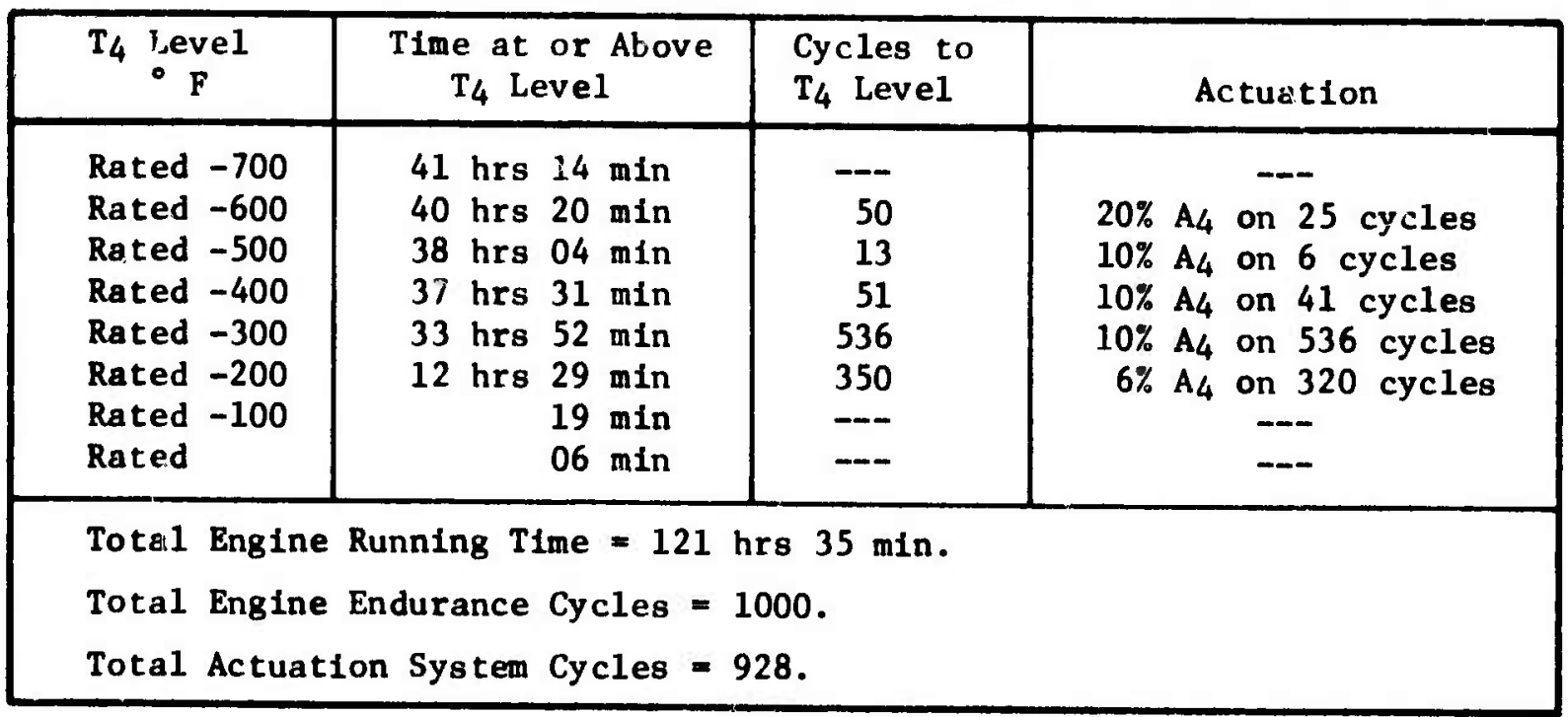

The turbine shroud configuration tested consisted of a total of 22 segments ( 11 transpiration-cooled shrouds and $11 \mathrm{f} 1 \mathrm{~lm}$-impingement-cooled shrouds). These shrouds were installed in an alternating fashion around the circumference of the shroud support.

The puṛpose of the testing was to:

- Evaluate the data obtained in the low temperature a1r turbine test.

- Compare the posttest condition of the transpiration-cooled and film-impingement-cooled shroud segments.

- Verify mechanical design and heat transfer pretest performance predictions. 
- Evaluate the transient response characteristics of the temperature-controlled shroud support system.

The performance and cyclic endurance portions of the demonstrator engine test were successfully completed with no significant problems or distress noted on the turbine shroud components. Both transient and steady-state pressure and temperature measurements on the turbine shroud components and surrounding alr cavities were recorded for evaluation and analysis. Light turbine blade tip rubs which were predicted, were noted on a portion of the $f 11 \mathrm{~m}-1 \mathrm{mpingement-cooled} \mathrm{shroud} \mathrm{segments,} \mathrm{and} \mathrm{approximately}$ half of the unique radial segment spline seals were missing af ter completion of the engine testing. 


\title{
SECTION 3.0
}

\author{
DESIGN DESCRIPTION
}

The ATEST turbine shroud assembly is shown in Figure 1. It consists of an inner and outer shroud support, a forward and aft shroud seal, and 22 shroud segments. The shroud segments attach to the inner shroud support. This assembly is bolte 1 to the main engine structural assembly at the aft flange of the outer stator casing through the outer turbine shroud support. Th1s attachment location was selected to minimize the effect of tolerance accumulation from the rear bearing to enhance the concentricity of the turbine shroud to the turbine rotor.

The outer turbine shroud support was machined from a René 41 forging. The outer flange of this support was designed to be heated by compressor discharge afr to reduce the radial thermal gradient in this part, thereby reducing the thermal stresses and the tendency of the inner flange to rotate forward. This contributes to the reduction of the "coning" or axial t1lting of the shroud support and shroud segments. The heating of this flange is accomplished by c1rculating compressor discharge alr through circumferential manifolds machined in the outer stator casing and forward turbine frame casing flanges. This alr passes through the turbine shroud outer support flange through a serles of oversized bolt holes. It is then circulated through the aft cavity air baffle to achieve temperature uniformity on the shroud support for transient response and roundness control and then used as turbine shroud segment cooling.

The turbine shroud support was machined of forged Rene 41. Th1s material was selected because of its good thermal expansion coefficlent match with that of the Rene 95 turbine disk. This match provides good clearance control at both part- and full-power operation.

The shroud flange was designed with a large radial height to provide roundness control to the assembly. Th1s flange is rigidly attached to the turbine shroud forward seal flange by body-bound bolts to increase the mass of the flange system for a timed support transient response characteristic. The forward seal is preloaded against the stator outer casing to prevent leakage of sooling sir into the gas stream.

The bolt wh1ch dowels the forward seal to the shroud support is shouldered, the shoulder being permitted to translate radially in slots machined into the outer shroud support inner flange. This feature permits relative radial motion to occur between the shroud support and the outer support, making the desired transient and steady-state radial growth of the shroud support independent of the colder engine casing structure. This elongated slot is dimensioned closely on the radial surfaces of the slot to assure uniform radial growth of the shroud support and prevent excessive tangential motion. 


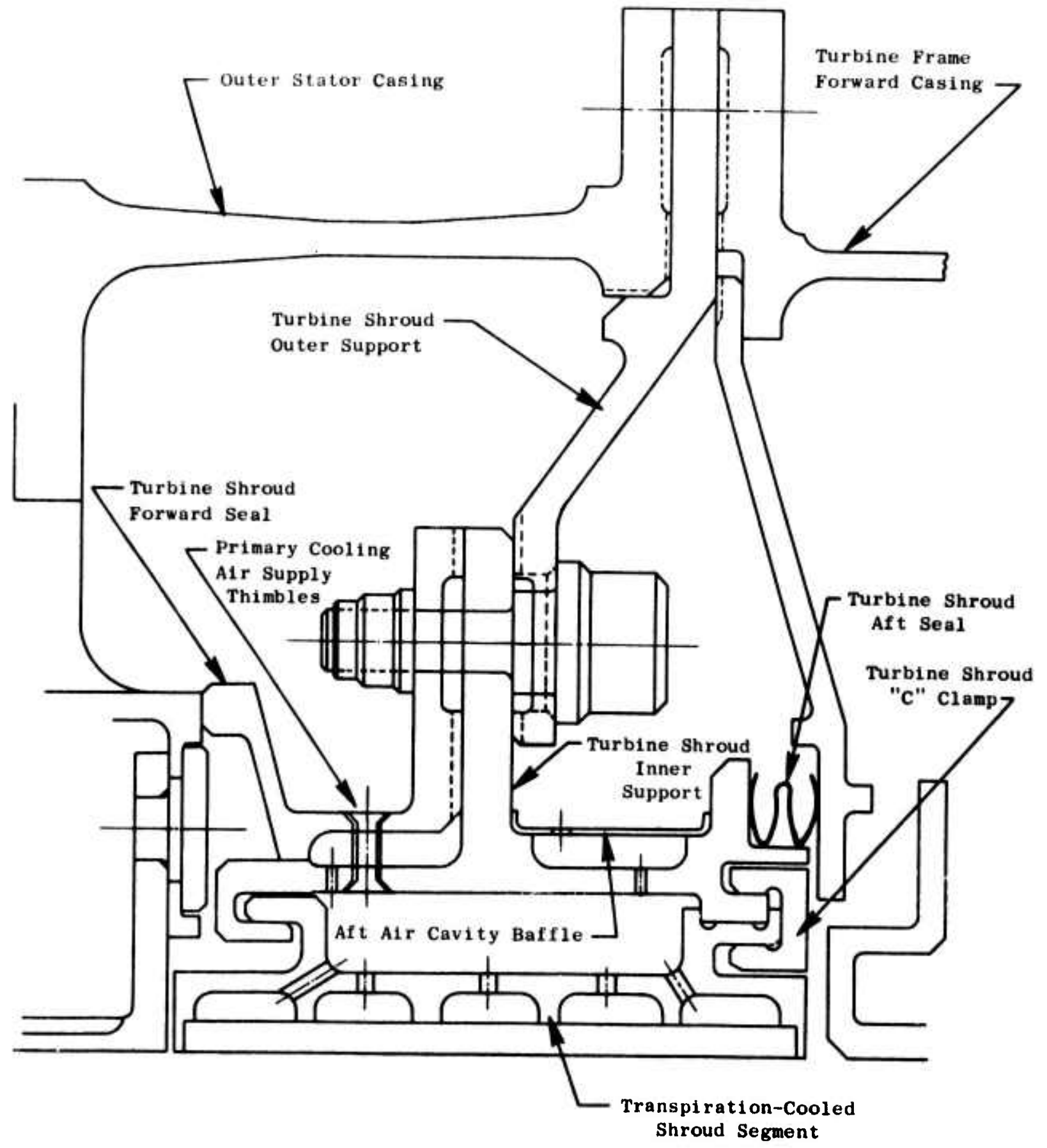

Figure 1. ATEST Turbine Shroud Assembly. 
The shroud support and forward seal flange assembly is temperature controlled in a fashion similar to that of the stator outer casing aft flange. This assures a uniform circumferential temperature distribution for roundness control and helps to provide the destred radial growth transient response characteristic necessary to maintain close shroud-to-turbineblade clearances. Figure 2 illustrates the cooling air circulation paths within the turbine shroud assembly. A sheet metal " $W$ " seal is preloaded into position to prevent cooling air leakage from the turbine shroud aft cavity.

Figure 3 shows the ATEST turbine shroud assembly with the two types of turbine shroud segments which were evaluated: transpiration-cooled and film-impingement-cooled. The film-impingement-cooled shroud is shown in Figure 4. It was cast of MAR-M-509 with IN 600 impingement covers brazed to the cooling-air side of the segment. The forward and at $t$ overhangs of the segment were also film-impingement-cooled with cooling air provided to the sheet metal impingement manifolds, which were brazed to the segment by means of air supply holes drilled through the forward and af shroud attachment hangers.

In this design, jets of cooling air, metered through 0.012-inchdiameter holes in the sheet metal cover, are directed against the back surface of the shroud for impingement cooling. This air then is directed through $\mathrm{f} 1 \mathrm{~lm}$ holes, 0.025 inch diameter in Zone 1 and 0.018 inch diameter in Zones 2, 3, and 4, which are drilled at an angle of approximately 20 degrees to the flowpath surface. The atr accomplishes additional convection cooling as it passes through the holes and then forms an insulating cool air film layer on the flowpath surface. The 0.012 inch diameter impingement hole size was selected to reduce the tendency of hole plugging. A f 11 ter screen, installed upstream of the shroud coolant plenum, was designed to eliminate particulate matter in the cooling stream larger than 0.008 inch diameter. The film hole pattern duplicated the patterns evaluated in the previous Air Turbine Test Program (Contract F33615-72-C-1775).

The transpiration-cooled shroud is shown in Figure 5. It consists of a porous metal flowpath surface which is electron beam welded to a cast MAR-M-509 structural backing member. Porolny (Bendix Corporation trade name) material was used as the porous surface media and was made up of 0.008 -inch-thick by $0.032-1$ nch-wide Hastelloy $X$ wire ribbon. This wire ribbon was wound on a mandrel and sintered in hydrogen at approximately $2000^{\circ} \mathrm{F}$. This spool then was split, rolled flat, and cut into sections sized to fit the shroud.

The flow and structural characteristics of the Poroloy material are determined by the wind angle of the wire, the wire spacing, and the overall thickness of the Poroloy. These parameters were tailored especially for the ATEST application. The Poroloy used in the ATEST turbine shrouds represents the first use of large wire ribbon sizes and large spacings between the ribbon to reduce the deteriorating effects of oxidation and plugging. In addition, the wind angle was selected to maximize the strength of the material to resist bulging due to cooling air pressure loading. 


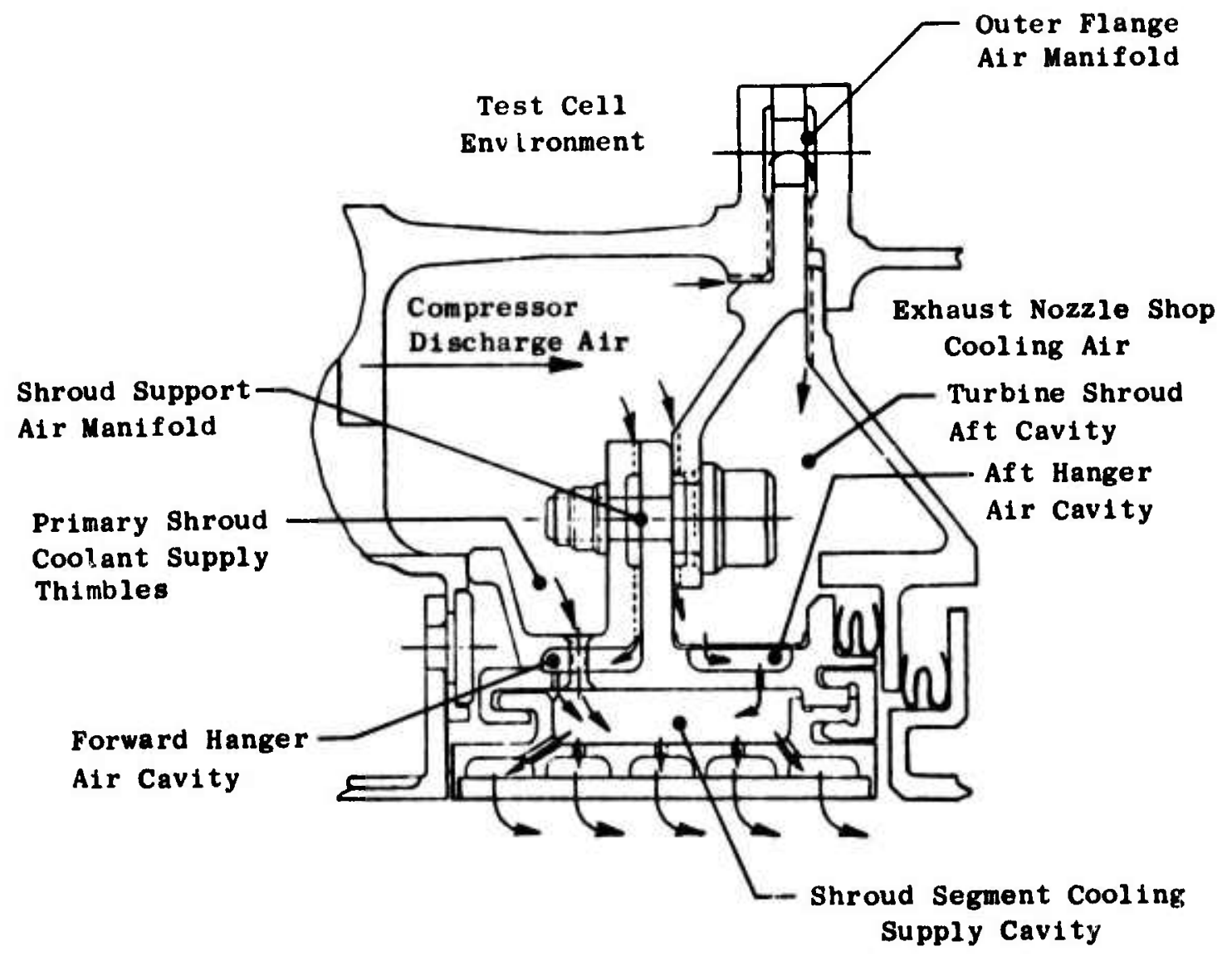

Figure 2. ATEST Turbine Shroud cooling and Temperature Control circuits. 


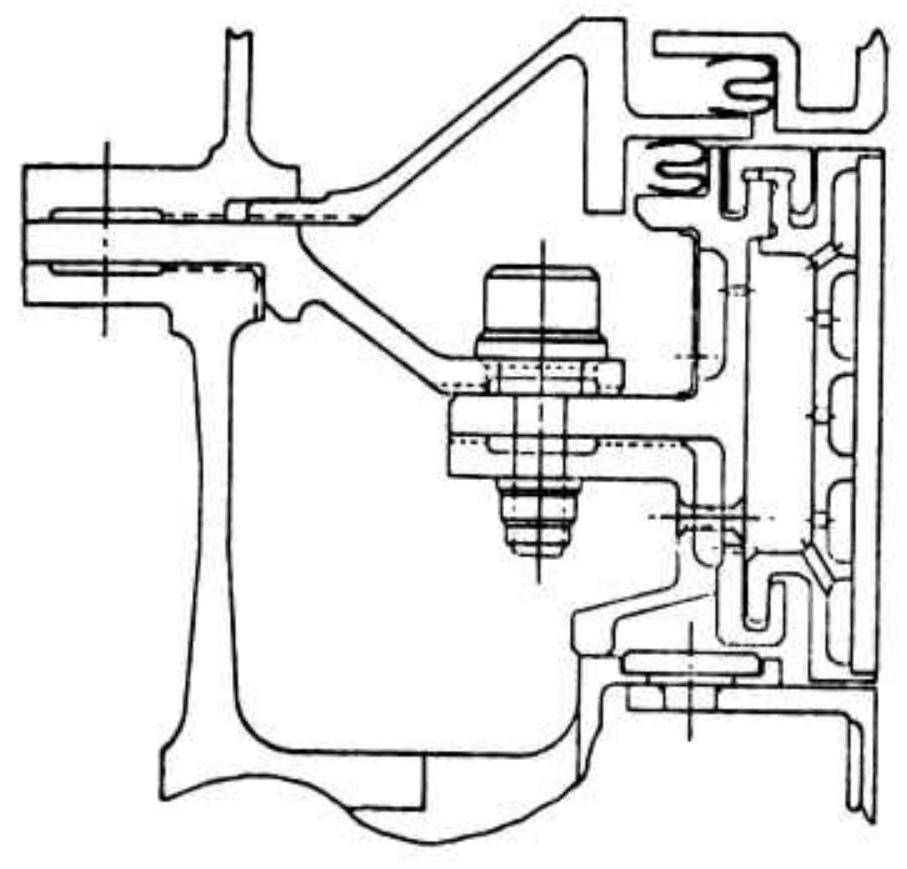

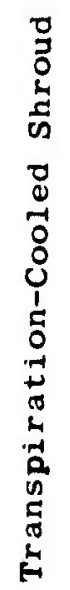

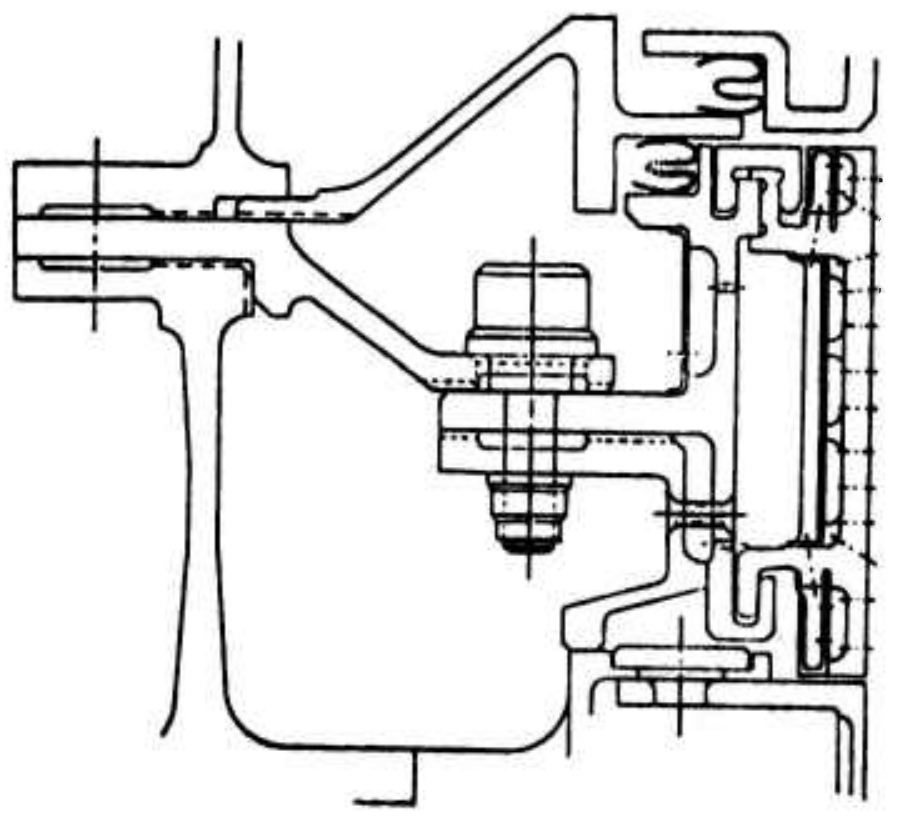

की 


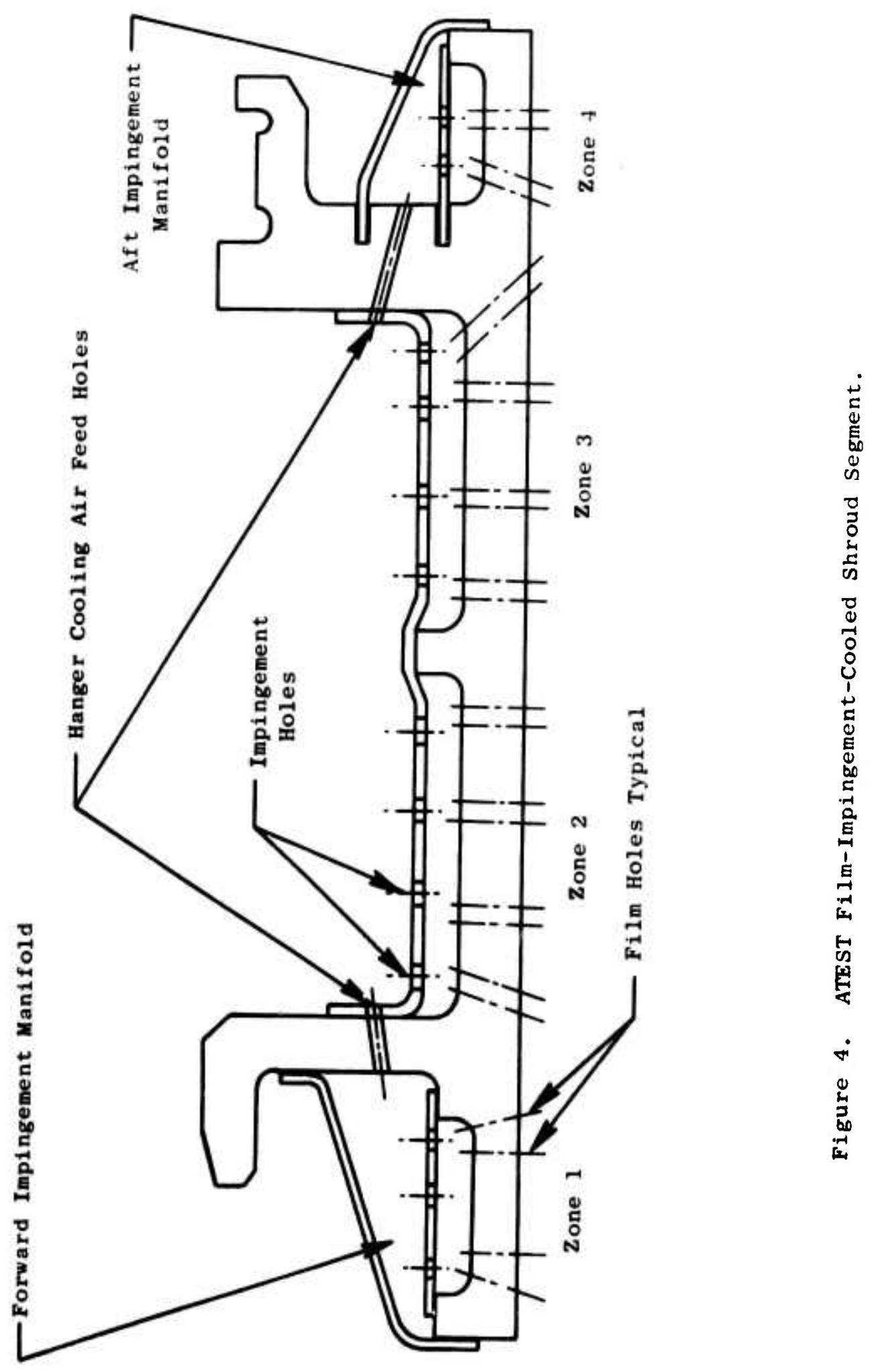



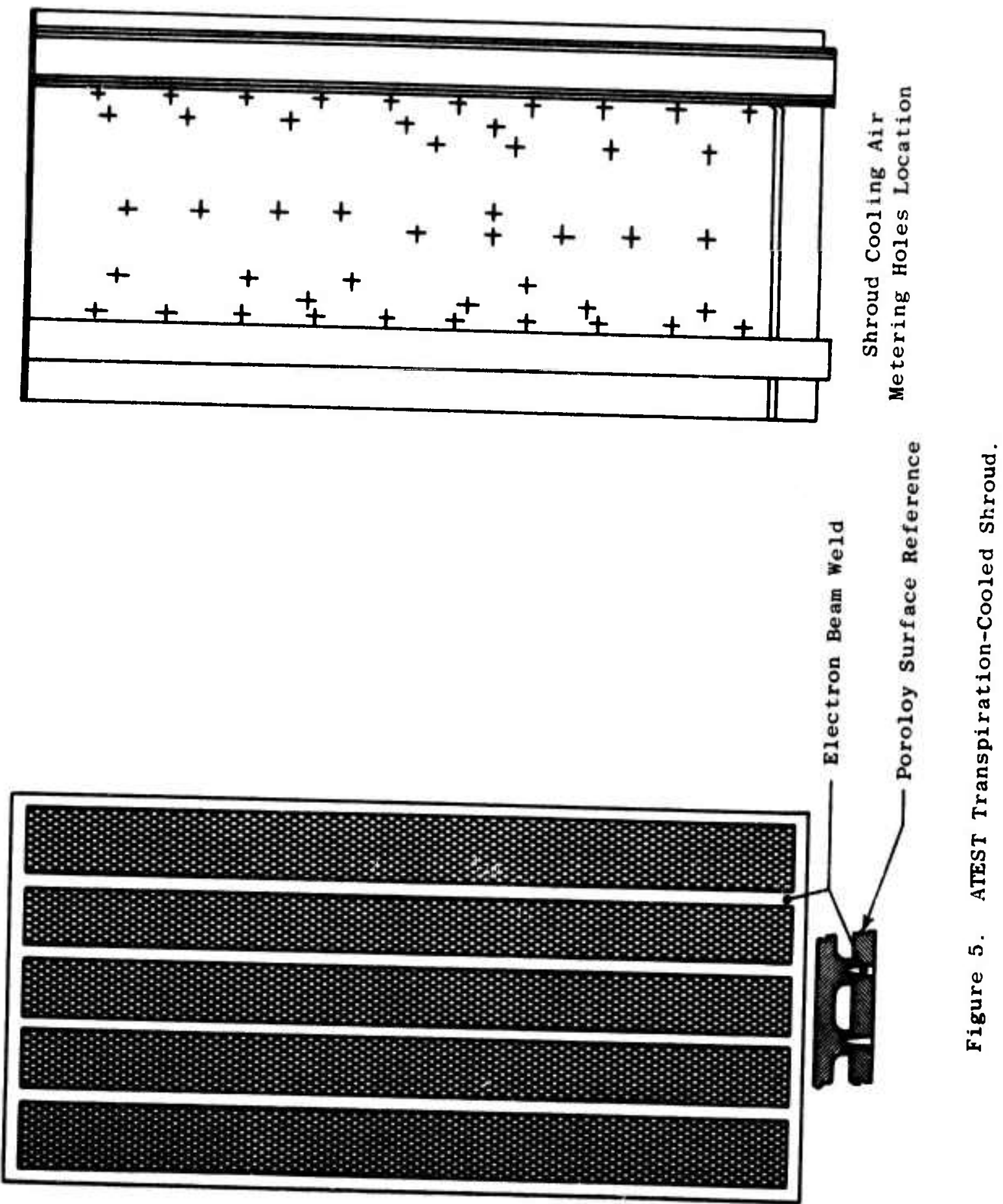
The electron beam weld attaching the Poroloy to the cast MAR-M-509 shroud backing structural member was made along circumferentially running ribs which are integral with the backing member. Axial welds were made along similar ribs at the circumferential ends of the shroud segment to at tach the Poroloy ends. These ribs form chambers into which cooling air is metered via holes drilled into the backing structural member. These holes connect the primary shroud cooling air supply cavity with each of the five cooling zones in the ATEST transpiration-cooled shrouds. These holes were sized in accordance with the local gas stream pressure through the blade row to meter the precise quantity of air needed to satisfy the flow characteristics of the Poroloy material.

The minimum pressure ratio across the supply metering holes is 1.15 to provide a minimum Mach number of 0.45 . This pressure ratio is high enough that, even if all of the Poroloy material were lost in one zone, the total shroud cooling air flow would not increase by more than 17 percent. Such an increase in cooling air flow would not cause severe overheating of the other regions of the shroud. The metering holes were drilled at angles from $45^{\circ}$ to $60^{\circ}$ to the radial to spread the air flow over the entire zone of Poroloy and eliminate impinging directly on small local areas.

of the total cooling air flow to the transpiration-cooled shroud, the metering holes supply 38 percent to the first zone, 26 percent to the second zone, 15 percent to the third zone, 12 percent to the fourth zone, and 9 percent to the $f$ if th zone. The metering hole configurations required to supply these flows with a discharge coefficient of 0.8 based on $f$ low data from simflar conf igurations are:

\begin{tabular}{|c|c|c|c|c|}
\hline Zone & $\begin{array}{c}\text { Number of } \\
\text { Holes/Segment }\end{array}$ & $\begin{array}{l}\text { Hole Dia. } \\
\text { (Inch) }\end{array}$ & $\begin{array}{l}\text { Angle to } \\
\text { Radial } \\
\text { (deg) } \\
\end{array}$ & $\begin{array}{c}{ }^{W} \text { Cool Zone } /{ }^{W} \text { Cool Total } \\
(\%)\end{array}$ \\
\hline 1 & 18 & 0.042 & 60 & 38 \\
\hline 2 & 22 & 0.028 & 60 & 26 \\
\hline 3 & 12 & 0.028 & 60 & 15 \\
\hline 4 & 9 & 0.028 & 60 & 12 \\
\hline 5 & 7 & 0.028 & 45 & 9 \\
\hline
\end{tabular}

The turbine shroud segments were attached to the front (leading edge) of the shroud support by a forward tongue and groove arrangement and to the aft (trailing edge) of the support by a " $c$ " clamp which was machined $f$ rom Rene 41. The " $\mathrm{C}$ " clamp was sized to provide the preload necessary to keep the shroud segments from lifting of $f$ the shroud support mating surface when the segments experienced thermal gradients. This design feature was necessary both for control of shroud assembly roundness and the prevention of excessive shroud segment leakage. 
The abutting shroud segment ends were sealed with a unique radial spline seal design which, while displaying superior sealing performance in bench testing, was found to be less than satisfactory in actual engine testing. This sealing arrangement is shown in Figure 6. Pressure loading forces the spline seals into contact with the smoothly machined shroud segment ends affecting a seal. The advantages possessed by this sealing arrangement were the smooth sealing surfaces and the circumferentially compact side rail retainers which allowed flowpath cooling to be accomplished
clos":r to the segment ends.

Engine testing showed that the radial spline seals operated in a pulsating pressure environment, probably due to the passage of the turbine blades. Although similar seals were used successfully in the demonstrator engine stator outer band segments, this sealing method is not recommended for future shroud application. The vibratory stimulus wore the ends of the seals down, some to the extent that they apparently lost contact and fell out of the grooves as they were missing at engine teardown.

All other shroud assembly components performed as expected with no distress noted on the hardware. The shroud hardware was in sultable condition following the demonstrator engine test for reassembly and further testing. 


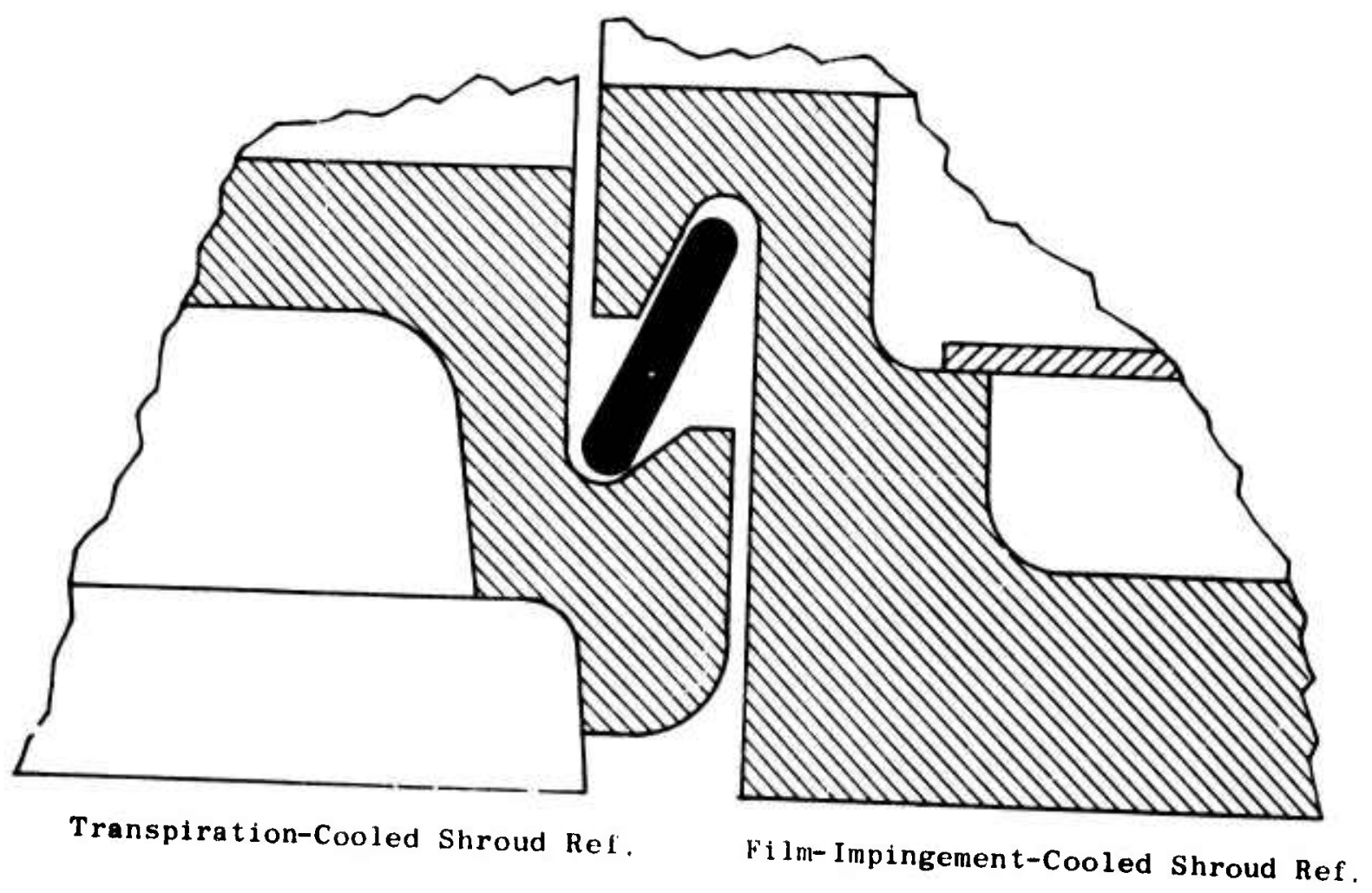

Figure 6. ATEST Turbine Shroud End Seal. 


\subsection{MANUFACTURE OF HARUWARE}

\subsection{TRANSPIRATION-COOLED SHROUDS}

The transpiration-cooled shroud consisted of two main elements, a cast structural backing and a face sheet of wire mesh (Poroloy), which were welded into an Inseparable assembly. The casting of MAR-M-509 (see Figures 7 and 8) Incorporated shroud hangers for attachment to the shroud support and also circumferential ribs that compartmentalized the cooling air in the shroud and provided support for the Poroloy face sheet. The Poroloy material design was a wide mesh weave $(0.008$-inch by 0.031 -inch wire with 0.012 -inch gaps between the wires and cross plys at 58.5 degrees to the ribs). The wire mesh design is shown schematically in Figure 9. This design offered several improved features compared to prior Porcloy shroud mesh designs: (1) a steeper axtal weave angle to resist axial ballooning or bulging of the wires between the shroud rib supports; (2) larger gage wire to keep surface oxidation penetration as a smaller percentage of wire thickness; and, (3) wider spacing of wires to better resist plugging of the alr passages between the wires due to small dirt particles.

The first step in the manufacturing sequence involved drilling afr metering holes in the shroud structural backing member in order to distribute and meter the air to the shroud (Figures 7 and 8). Next, the Poroloy face sheet was cut to fit the face of the shroud casting (Figure 10) and then was electron beam (EB) welded to the casting (FIgure 11). The EB weld was chosen because of Its high precision and low heat generation. The EB weld was set to prectsely weld the Poroloy face sheet to the casting only along the thin shroud backing member edges and ribs: (1) without a wide weld area that would close off areas of the Poroloy to cooling flow; and, (2) without high heating that might distort the casting dimensions. A single structural weld pass was made on each weld line (four ribs plus four edges) as a penetration weld with no f1ller added. Th1s procedure allowed full-strength penetration burn-down and left only a slight depression along the weld 11ne. A second weld pass then was made on each weld line using 0.045-inch-diameter Hastelloy $X$ filler which completely filled the weld line. The weld lines subsequently were ground in the finished part to provide a smooth continuous flowpath surface on the shroud. Prior to fabrication of the shroud segments, a sample shroud plece was welded, cut apart, and evaluated to establish optimum weld settings (distance, power, allgment, and focus).

Inspection of the welds was made on each shroud segment using the relatively new technique of laser holography. Each shroud was mounted in a fixture and vibrated in a fundamental mode. Under vibratior, unsupported Poroloy panels between weld 1 ines deflected. The weld lines along each $r$ ib, If solld Poroloy-to-casting joints, would not leflect but acted rather as a vibratory node. Using laser 11 ght to accentuate this deflection, the adequacy of the Poroloy welds was determined and all shrouds were found to have sound welds. 


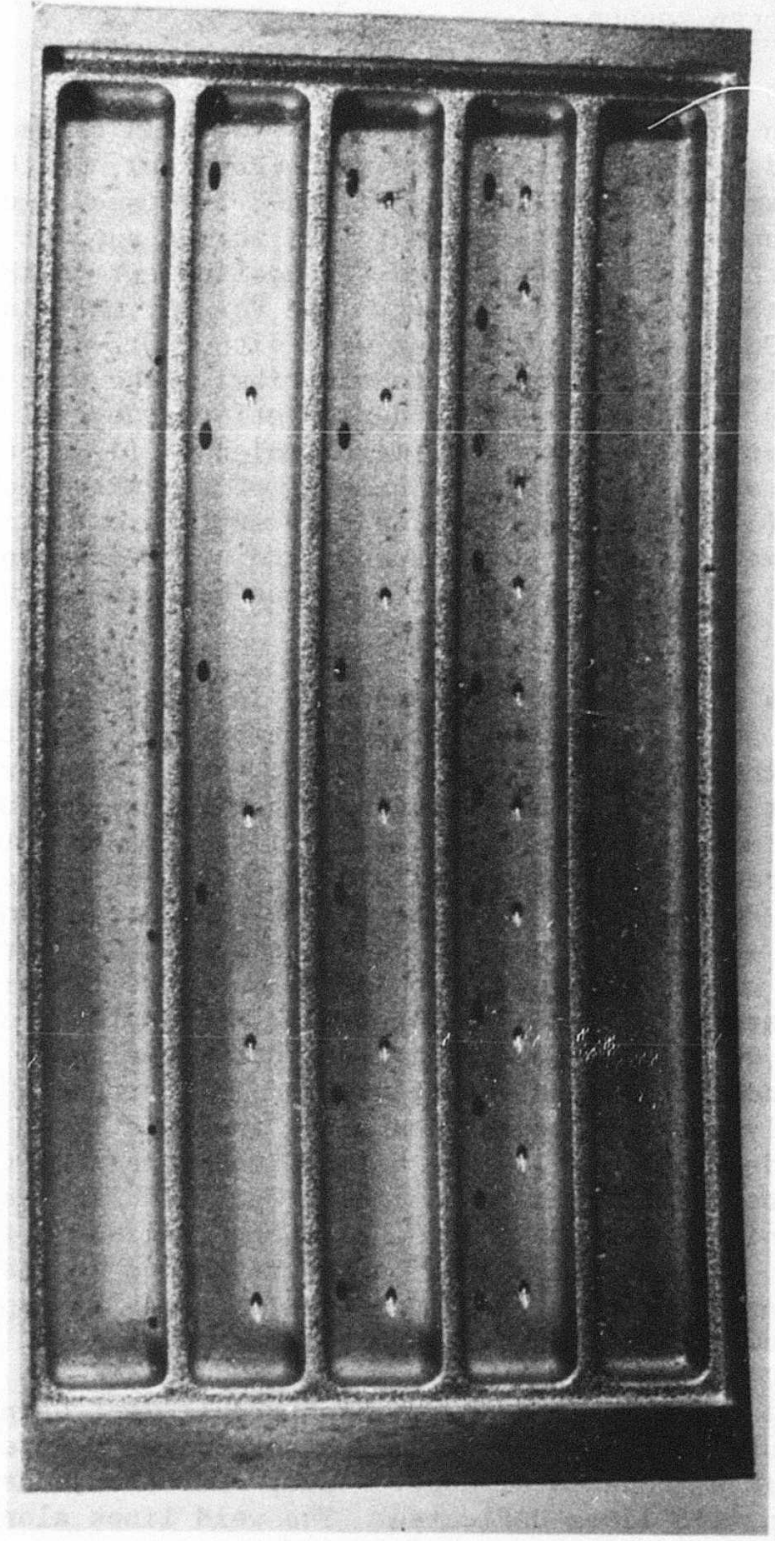

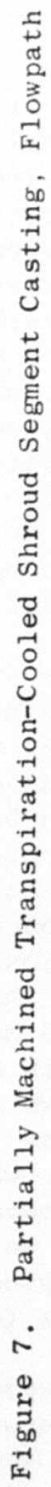




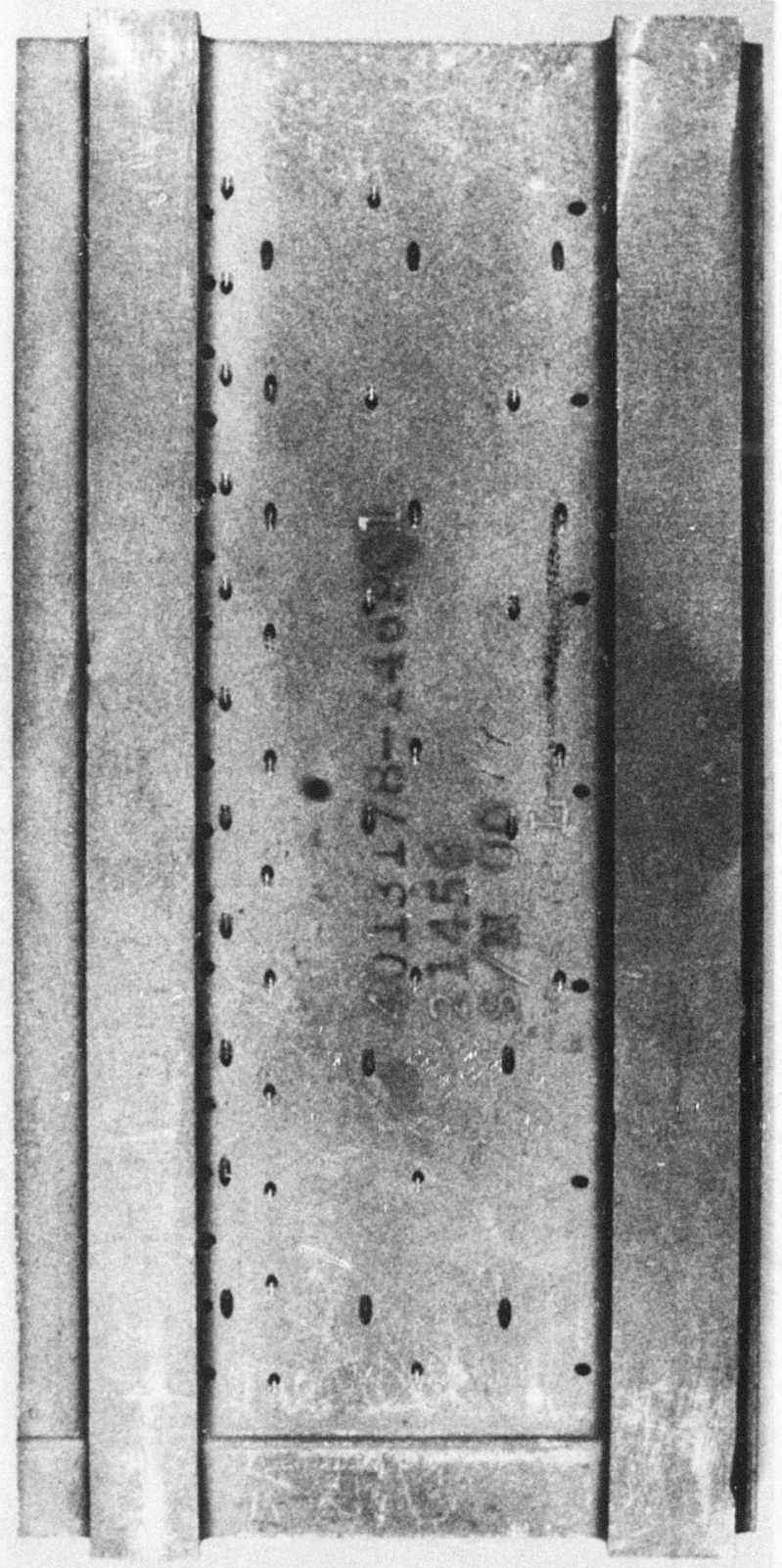

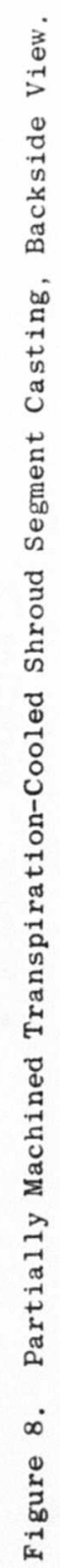



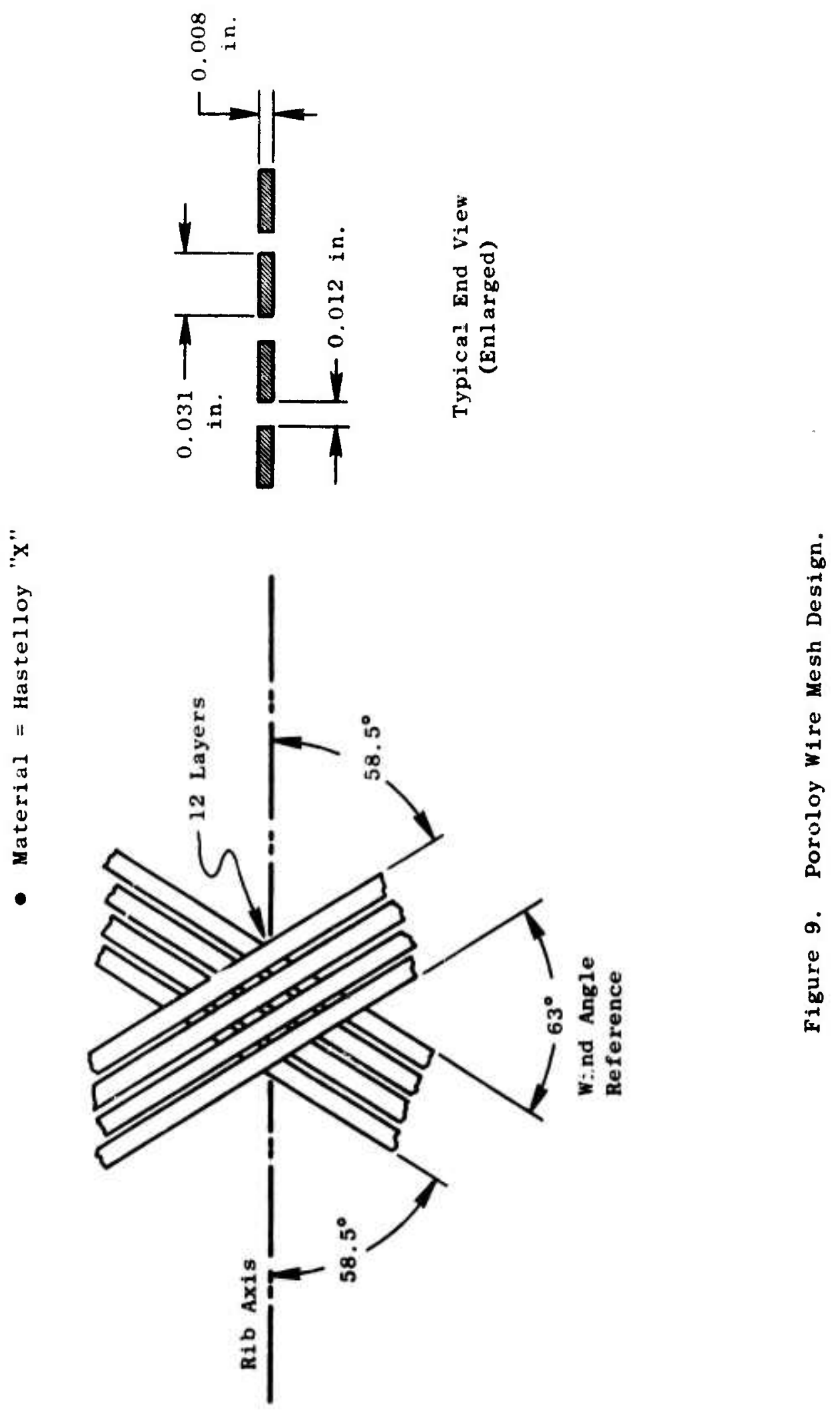


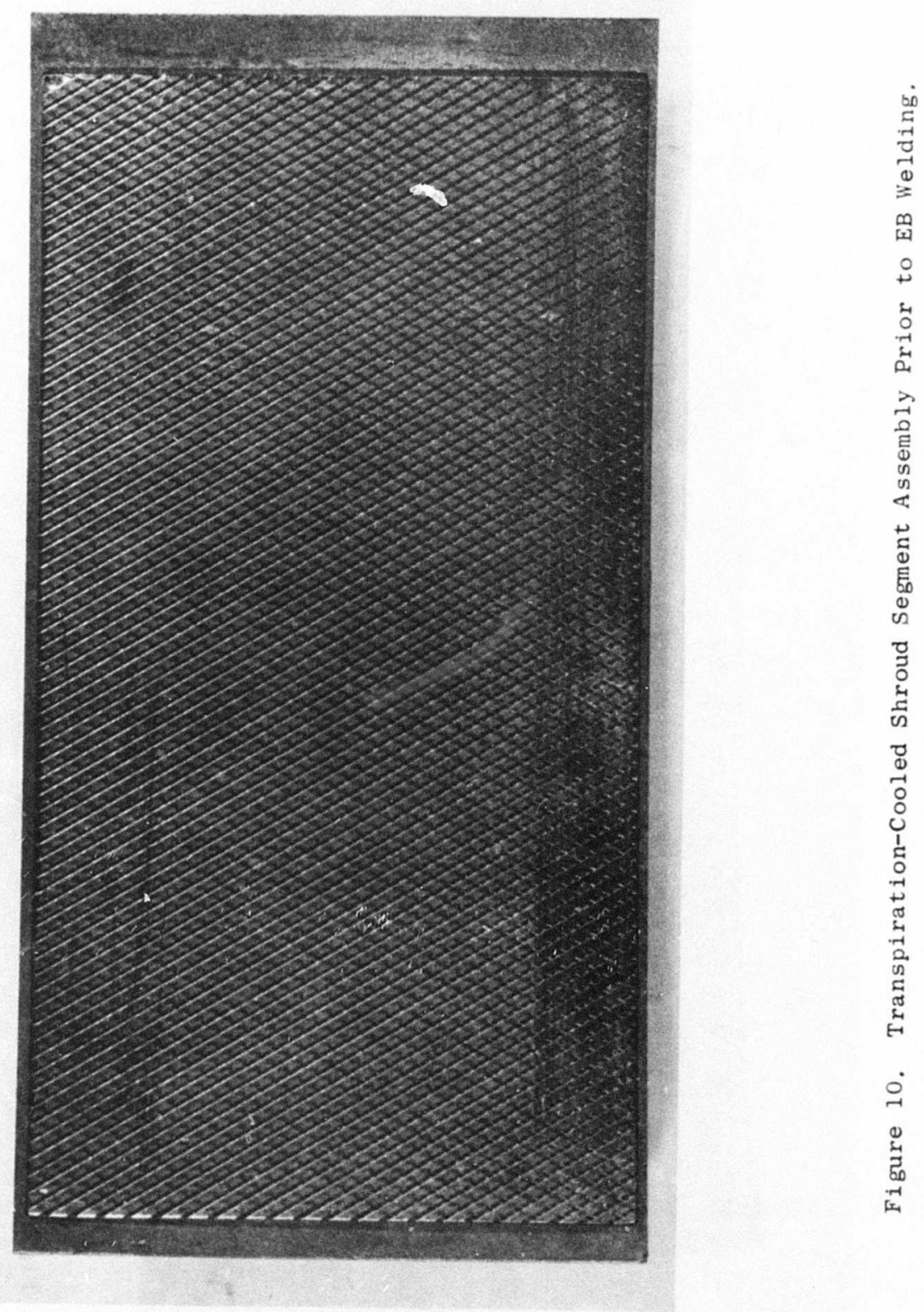




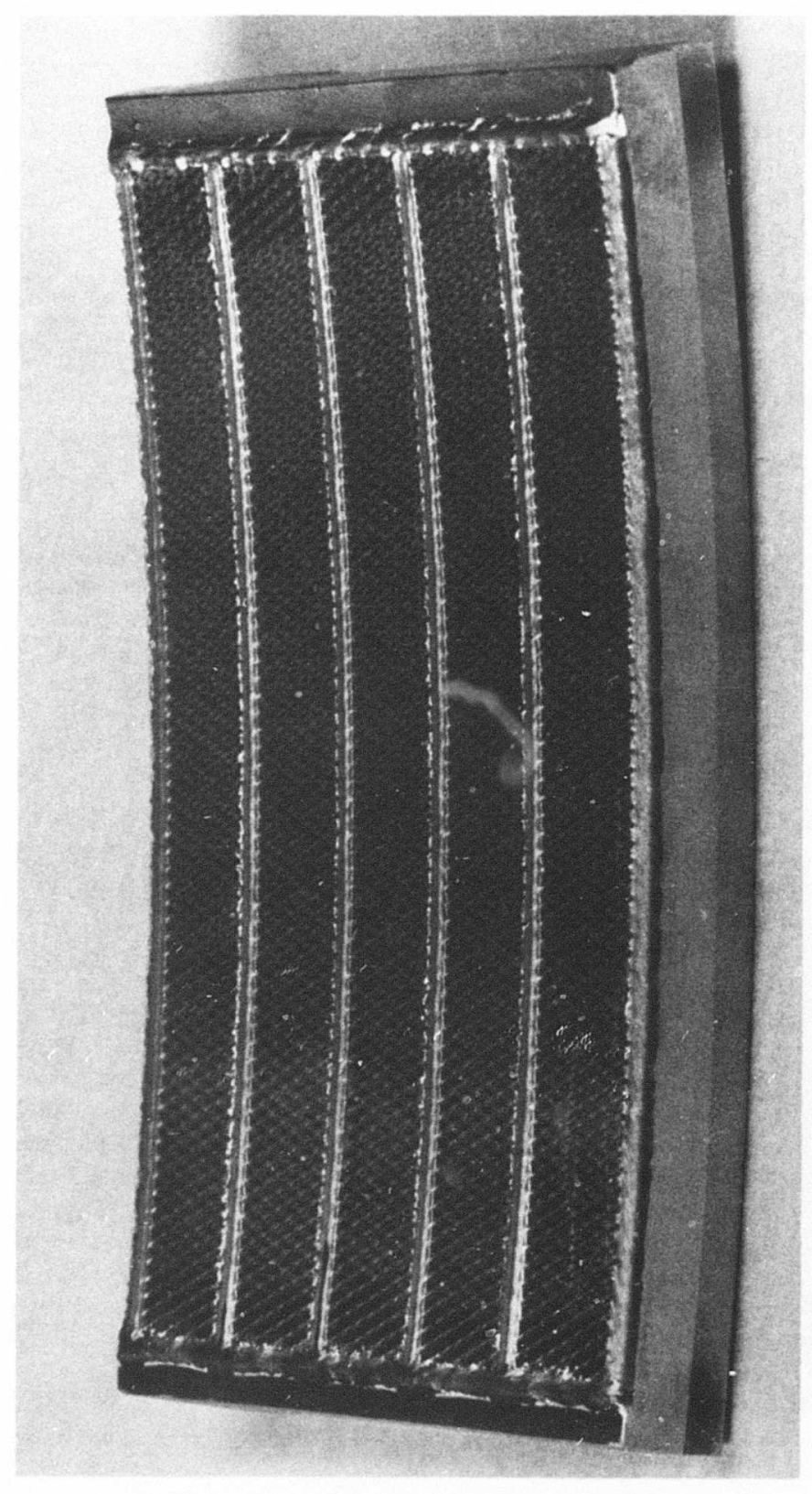

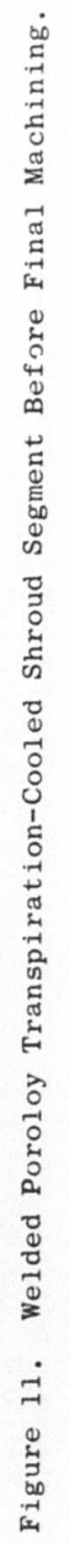


Final machining of the transpiration-cooled shrouds consisted of work on: the forward and aft hangers, the fore and aft sides, the c1rcumferential ends (which also incorporated the spline seal retaining slots), and a tangential positioning slot in the aft hanger. The final machined transpirationcooled shroud is shown in Figures 12, 13, and 14. Flow checks of each shroud were made to ensure that adequate cooling air quantity and pressure margin were provided per design intent. All shrouds successfully passed these flow checks.

\subsection{FILM-IMPINGEMENT-COOLED SHROUDS}

The film-impingement-cooled shroud design consisted of several major elements, a shroud segment casting and sheet metal plates brazed into an Inseparable assembly. The MAR-M-509 casting Incorporated the shroud hangers, the transpiration-cooled shrouds, the ribs, and a definition of the cavity edges that compartmentalized the impingement cocling cavities in the shroud (F1gure 15). Hole drilling of the flowpath casting face was first done (note F1gure 15) in a pattern to provide uniform cooling of the surface. Next, sheet metal impingement plates were fabricated and holes were drilled in them. One small plate was made for each region fore and aft of the shroud hangers and one large plate was made for the center region (see F1gure 16). These plates, made of IN 600 , were brazed to the casting in a vacuum furnace at $2200^{\circ}-2225^{\circ}$ F for five minutes using B28 (Spec B50TF90) braze alloy. Following Inopection of these braze joints, the fore and aft plenum cover places were brazed to the casting in a vacuum furnace at $2125^{\circ}-2150^{\circ} \mathrm{F}$ for five winutes uning GE81 (Spec B50TF81) braze alloy. Th1s brazing integrally Joined the plates to the casting, forming four cooling air chambers sealed at the edges so that cooling alr could be accurately distributed and metered throughout the shroud. Following brazing, supply alr holes were drilled through both hangers into the fore and aft plenums to provide air for impingement In these areas.

Final machining of the f1lm-impingement-cooled shrouds was carried out with a final geometry similar to that of the transpiration-cooled shrouds (F1gures 17, 18 and 19). Flow checks then were carried out on each of the four cooling zones in each shroud to ensure that adequate quantities of coolIng a1r and satisfactory pressure rat1os existed across the impingement plates. Some shrouds were found to have higher-than-design cooling air flows (see Section 4.5 ), but this condition did not pose a risk to component life.

\subsection{SHROUD SUPPORT SYSTEM HARDWARE}

The shroud support system was designed to be compatible with either the transpiration-cooled or f1lm-1mpingement-cooled shrouds. The support assembly consisted of three major components which were designed to provide a round itructural support for the shrouds and to supply shroud cooling air. The system also was designed to be radially and thermally responsive to engine operating conditions in order to minimize turbine 1 ip clearances. The 


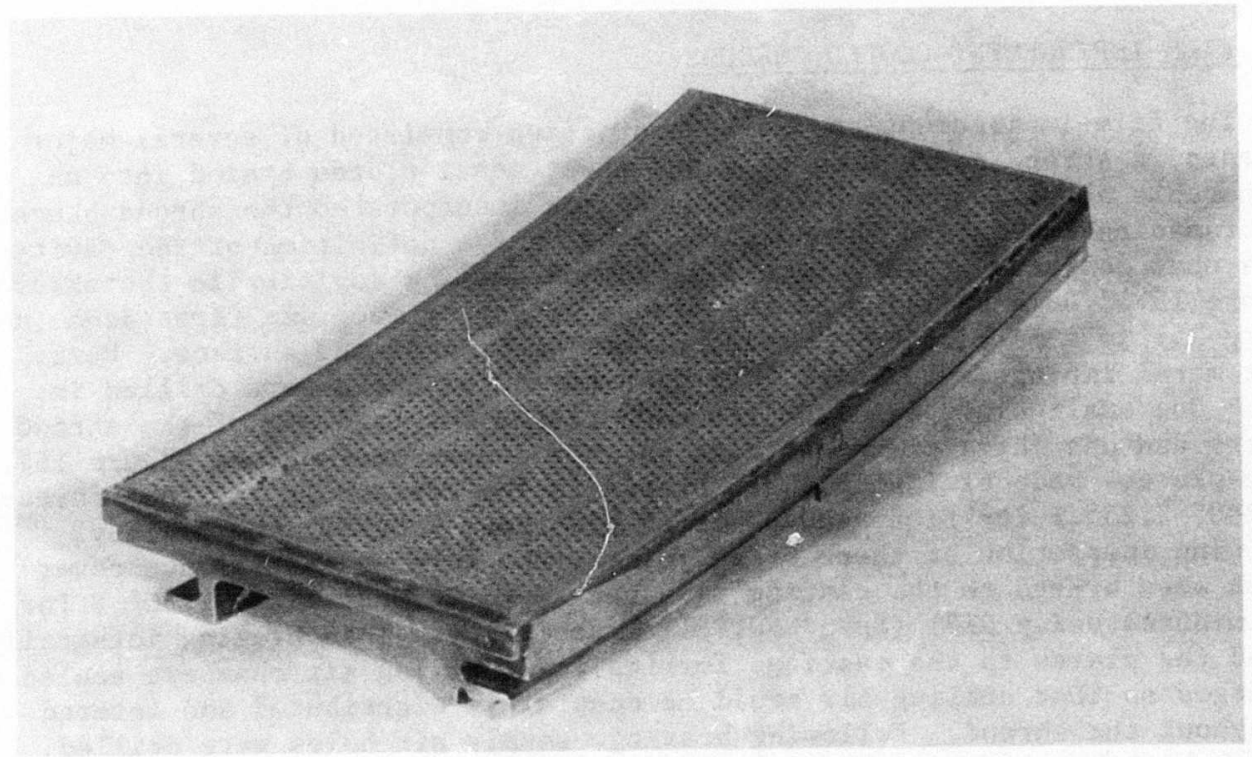

Figure 12. Final Machined Transpiration-Cooled Shroud Segment, Flowpath Surface View. 


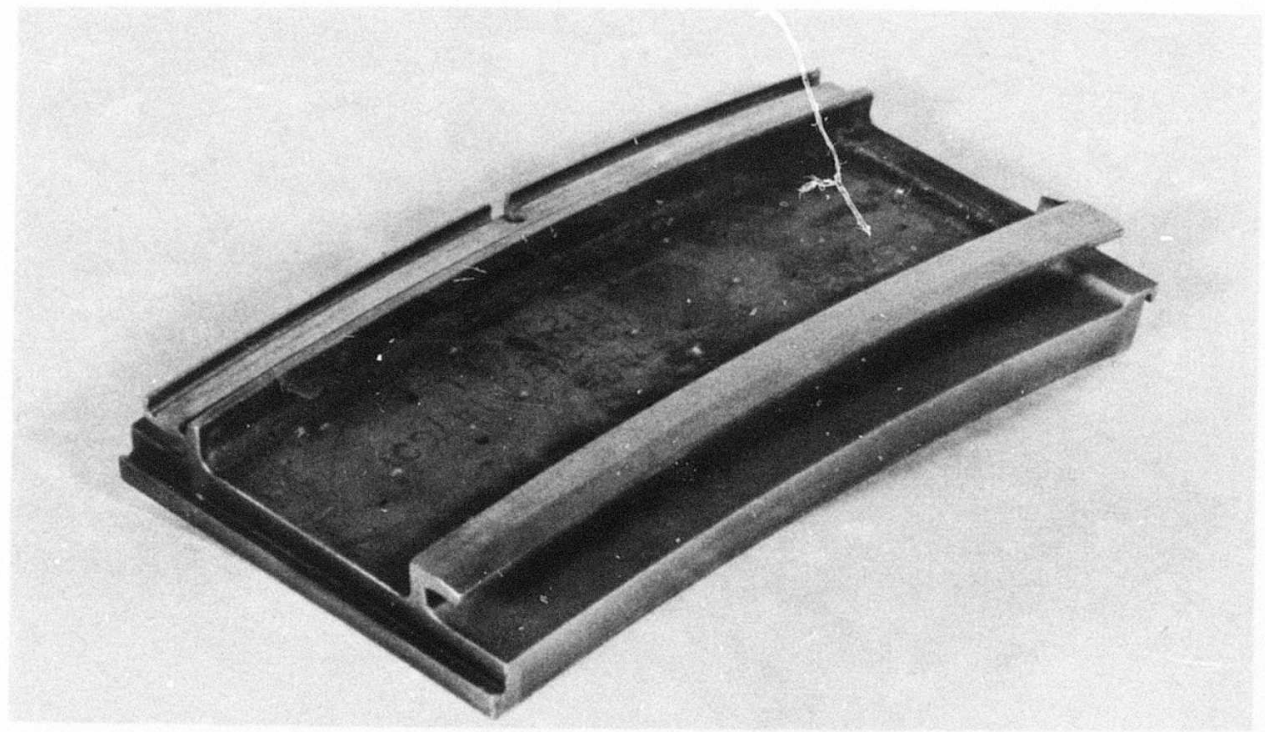

Figure 13. Transpiration-Cooled Shroud Segment, Backside View Featuring the Forward Shroud Hanger. 


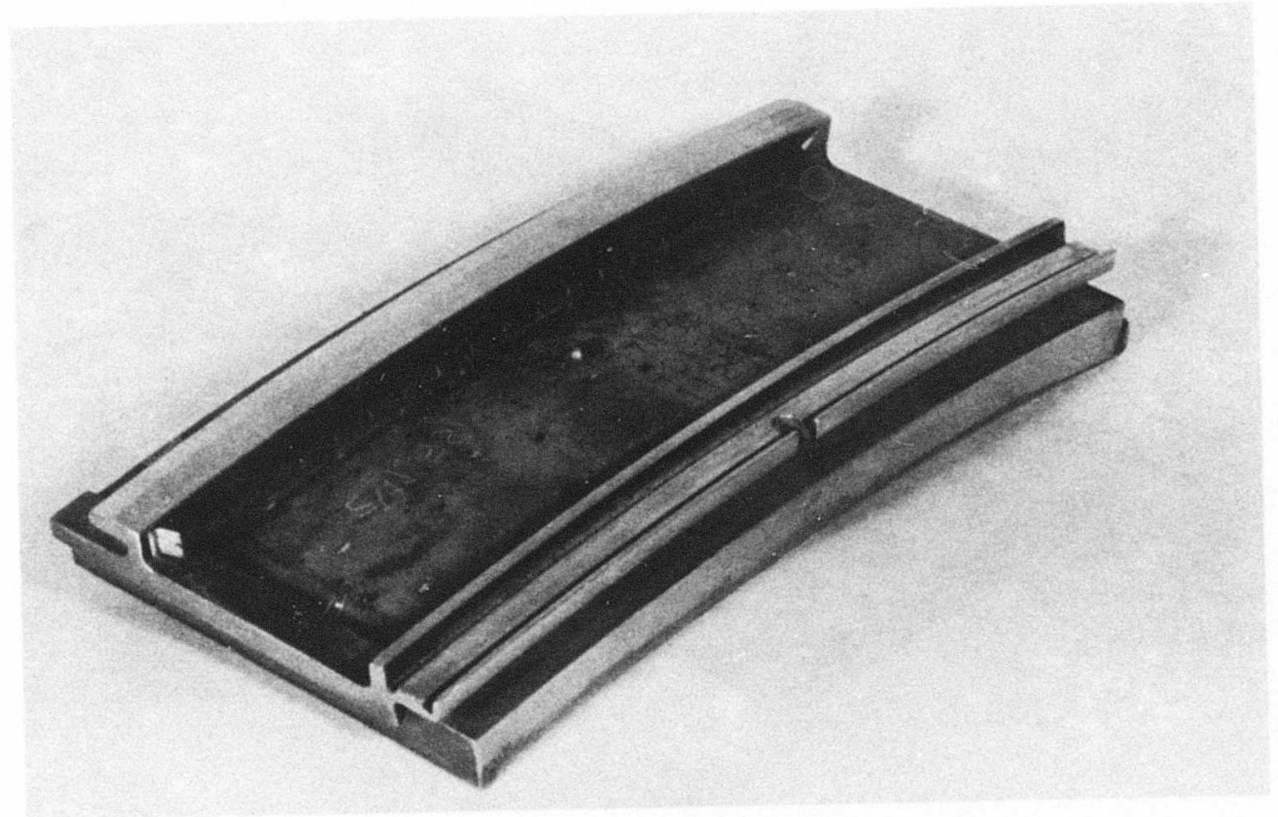

Figure 14. Transpiration-Cooled Shroud Segment, Backside View Featuring the Aft Shroud Hanger. 


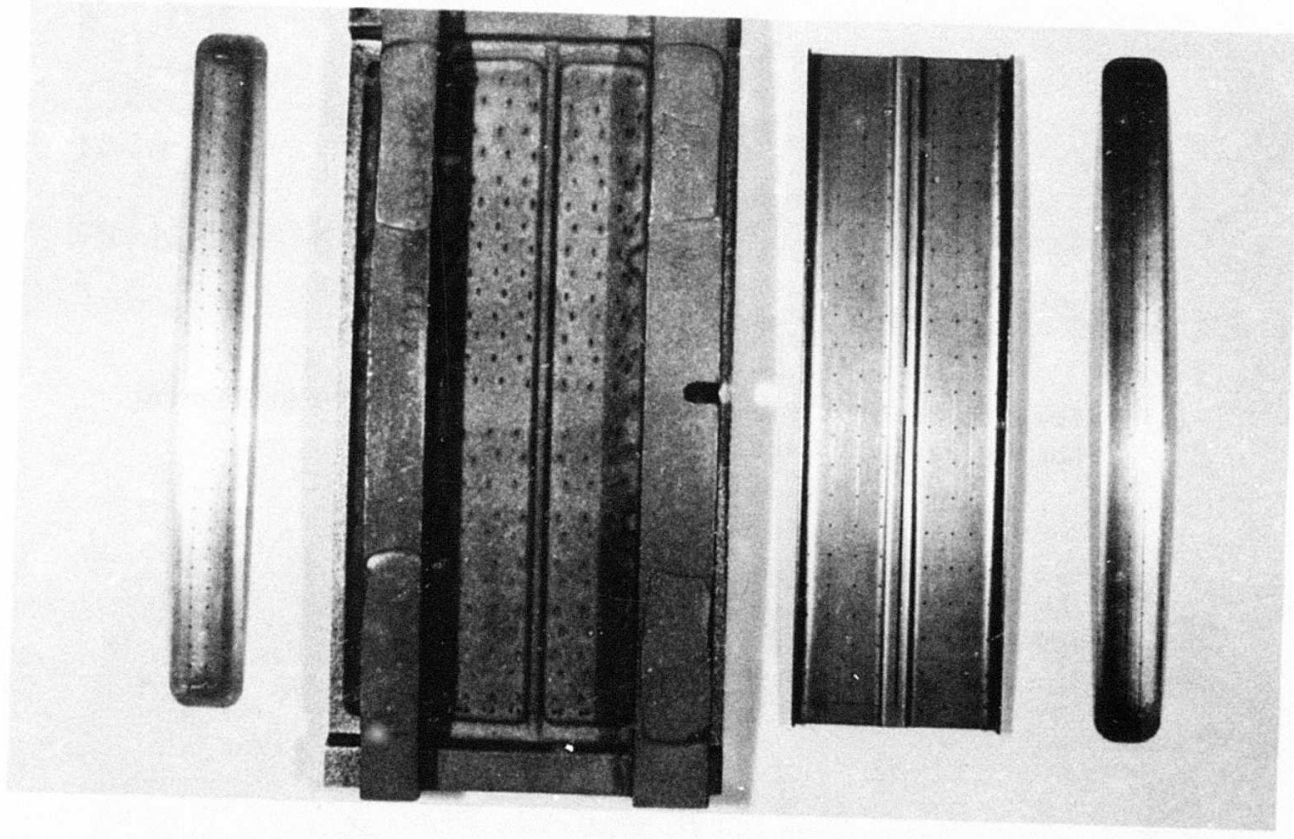
Figure 16. Film-Impingement-Cooled Shroud Segment Components Prior to
Braze, Backside View. 


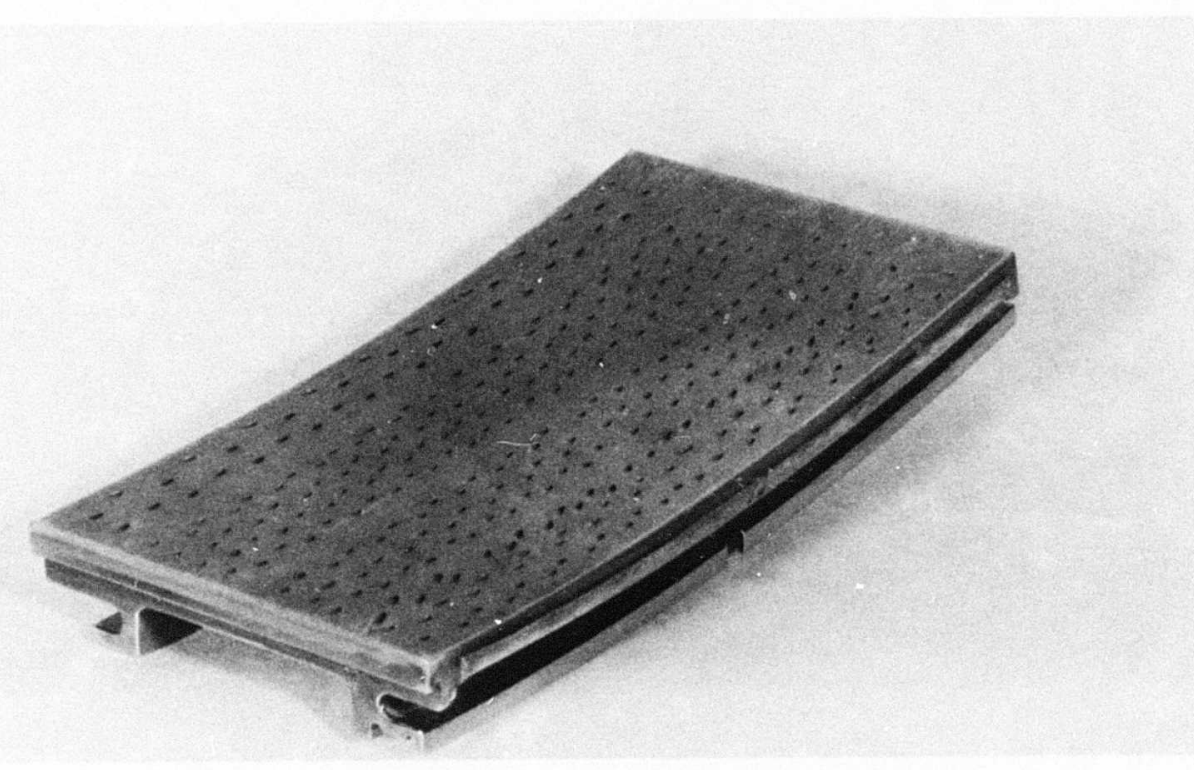

Figure 17. Final Machined Film-Impingement-Cooled Shroud Segment, Flowpath Surface View. 


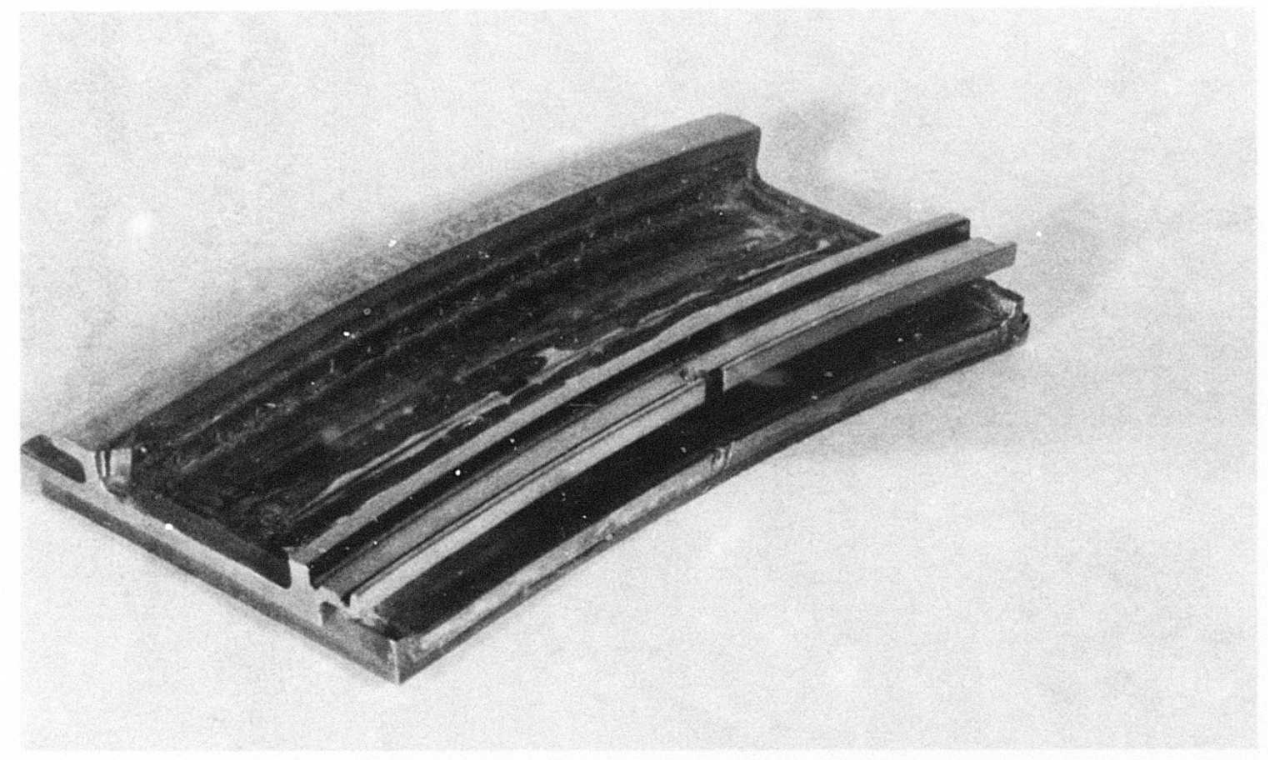

Figure 18. Film-Impingement-Cooled Shroud Segment, Backside View Featuring the Aft Shroud Hanger. 


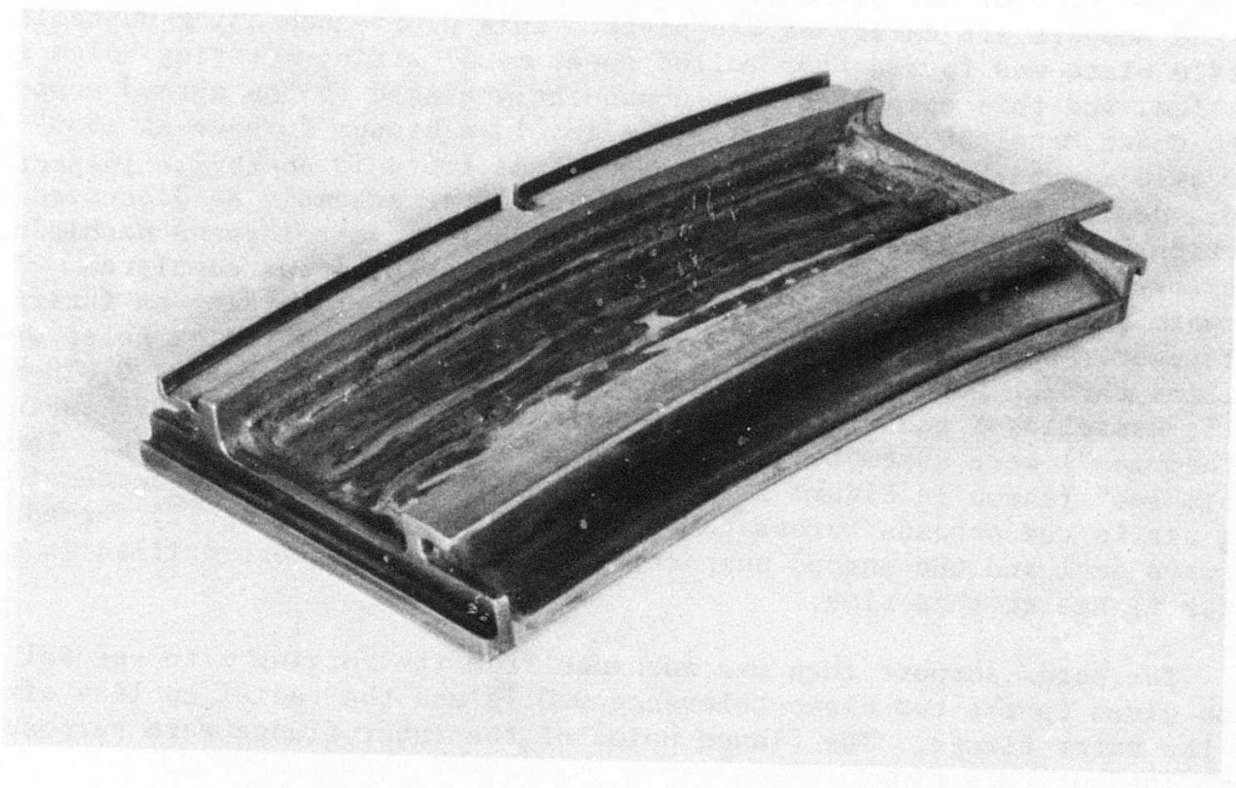

Figure 19. Film-Impingement-Cooled Shroud Segment, Backside View Featuring the Forward Shroud Hanger. 
assembly consisted of a shroud support, a forward seal, and an outer support. Al1 three components are made from René 41 forgings for high temperature strength and stabłlity. The forward seal was machined from a forging with special attention given to the close tolerance of the I.D. and the radial cooling slots in the outer flange. After machining, the forward seal was assembled as a matched piece to the shroud support, as will be discussed 1ater. The shroud support alse was machined from a forging. Rough machining was done first, and was followed by holp driling to provide supply air holes to the shrouds. Finish machining then was done on the other $f$ lange as well as on the O.D. of the aft shroud support to provide locating surfaces for the shroud support aft cavity baffle plate. This 0.025 -inch-thick Hastelloy $X$ baffle plate was formed from rolled sheet metal strip; metering holes were drilled, and this component was subsequently brazed to the shroud support with Coast Metal 50 (Spec AMS 4779) alloy in a vacuum furnace at $1950^{\circ}-2000^{\circ} \mathrm{F}$ (This deviation was to give trouble during found in posthraze inspection. Section 4.5). Follow give trouble during later assembly as discussed in the fortard and fft the forward and aft hanger $0 . D$. and aft seal surfaces was completed. The forward seal then was slipped onto the shroud support forming an interference, air tight, and radial fit between these parts. Matched radial holes were drilled through both parts, and lengths of 0.250 -inch-diameter, 0.020-inchwal1, Hastelloy $X$ and 0.188 -inch-diameter, $0.014-$ inch-wa11 IN 625 tubing ("thimbles") were assembled and flaired at each end of the tubing. These "thimbles" (shown in Figure 1) provided a direct, leak-tight source of cooling air to the shrouds across the forward shroud support cavity formed by the forward seal and the shroud support. No flange holes were drilled in the outer flange at this time.

The outer support then was machined from its forging with special attention given to the two close-tolerance 0.D.'s and the radial cooling air slots at the outer flange. The flange holes of the inner flange were purposely not completed at this time.

With all three components of the support system now complete, except for the flange bolt holes, the components were ready for matched alignment. Concentricity of the outer support with the forward seal/shroud support subassembly was set and flange holes were match-drilled through the three pieces. This setup then was disassembled, and clearance holes with matching radial slots were machined in the inner flange of the outer support using the previously drilled match holes for reference points. Spacer sleeves of 0.3435-0.D., 0.095-1nch-wal1 L605 then were inserted in the oversize holes and the entire three-plece assembly was bolted together. The spacer sleeves prevented tight bolt clamping on the outer support and allowed the inner support to be free to grow radially while providing centering for the shroud assembly.

The completed shroud support assembly is shown in Figures 20, 21, and 22. Note, in particular, the cooling slot details and cooling thimbles shown
in Figure 22. 


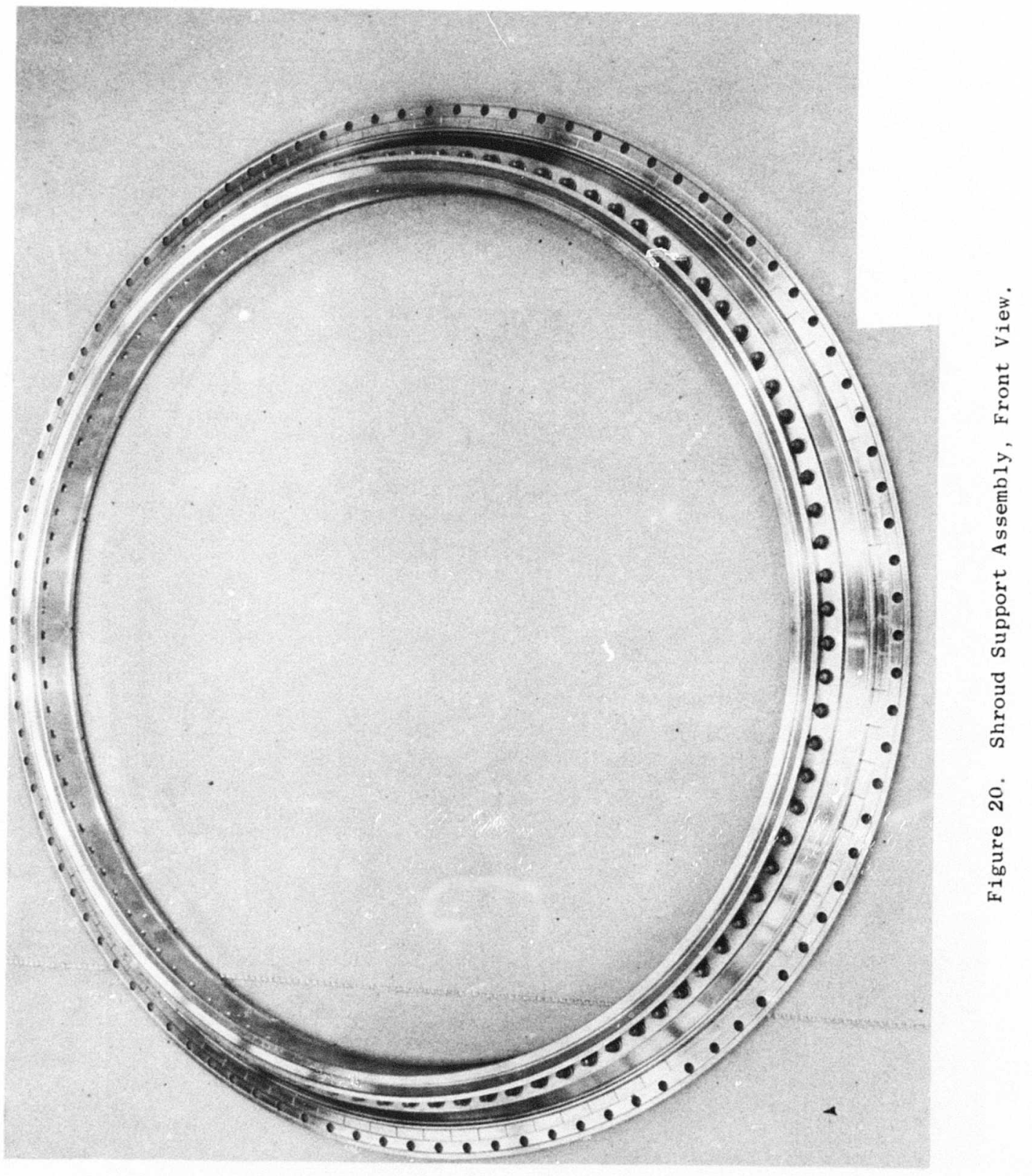




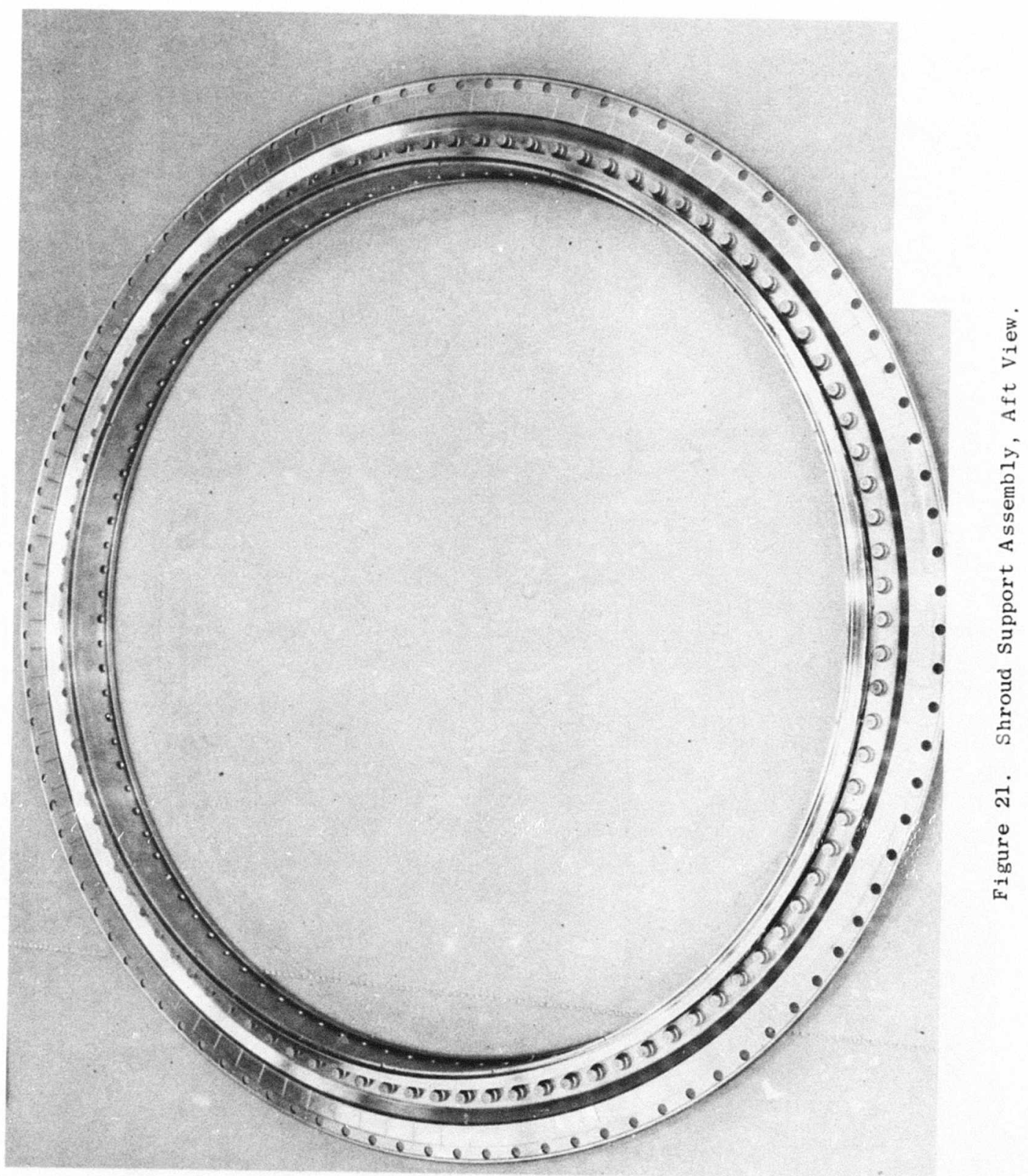




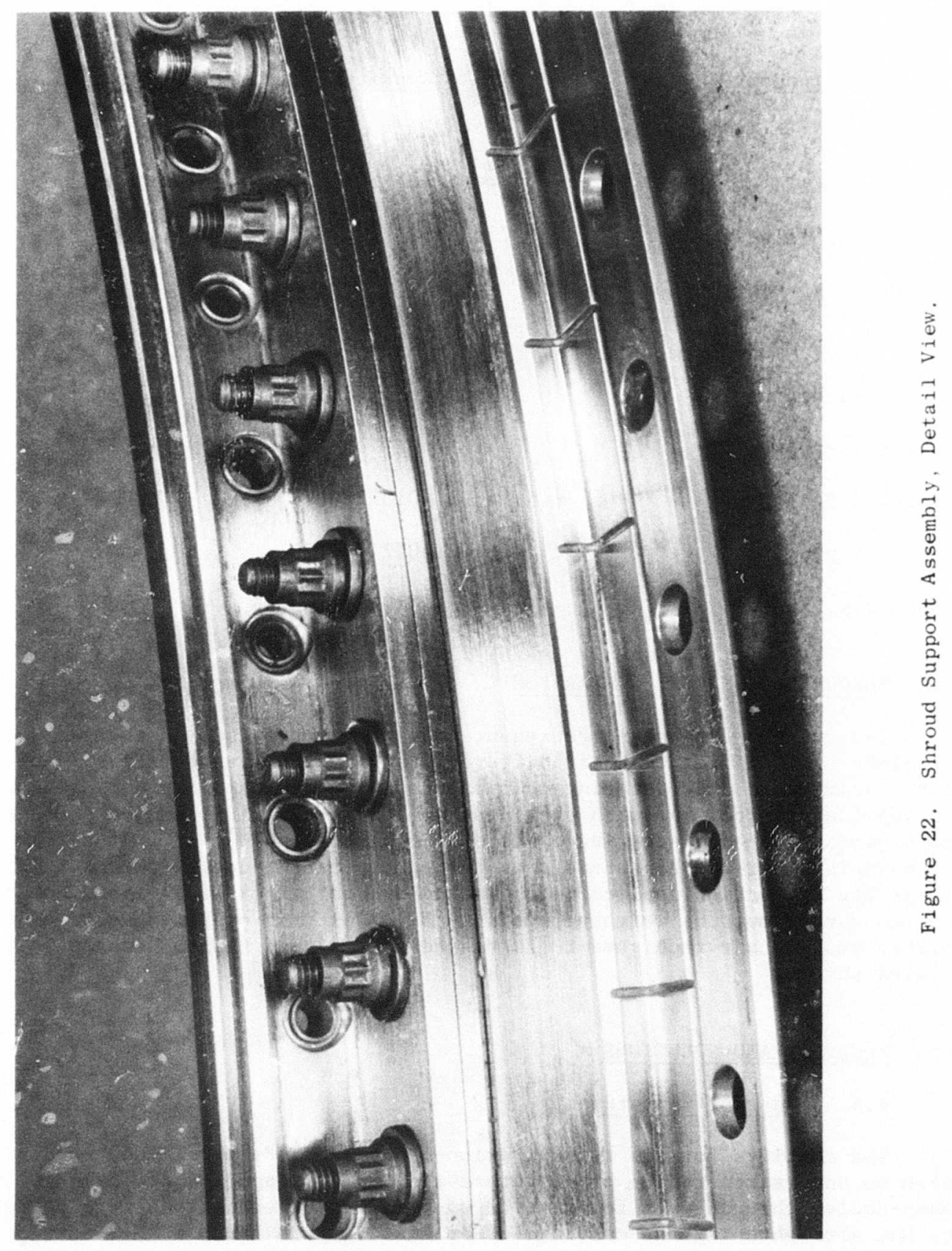


Detall drawings of the components discussed in the previous sections are 1isted below by drawing number and are shown in Figures 23 through 30 :

\section{Component}

Transpiration-Cooled Shroud

- casting

- machining

Film-Impingement-Cooled Shroud

- casting

- machining

Shroud Support

Forward Seal

Outer Support

Assembly, Shroud
Drawing No.

4013178-146

23

4013178-147

24

4013178-153 25

$4013178-154$

$\begin{array}{ll}4013178-174 & 27\end{array}$

$\begin{array}{ll}4013178-175 & 28\end{array}$

$4013178-176$

4013178-178G04 $\quad 30$

\subsection{SHROUD DESIGN COST COMPARISON}

The two shroud designs represent different approaches to the same design problem. In addition to their different technical characteristics (cooling alr requirements and operating temperatures), there are different manufacturing costs associated with each design. For the 11mited number of development parts, the manufacturing costs showed a 2.2 higher cost factor for the f1lm-1mpingement-cooled shroud over the transpiration-cooled shroud. In: $a$ long-11fe production application, the higher cost of the film-impingementcooled shroud must be weighted against the offsetting operating cost of the higher cooling alr requirement (Increased $\mathrm{sfc}$ ) of the cheaper transpirationcooled shroud.

\subsection{PROBLEMS AND SOLUTIONS}

\subsubsection{Cast1ng Curvature}

The castings for the transpiration-cooled shrouds were found to be made with an undersized radius of curvature and the castings for the f $11 \mathrm{~m}-1 \mathrm{mp} 1 \mathrm{nge-}$ ment-cooled shrouds were found to be warped. These conditions were corrected by hot stralghtening the castings after heating them to $1850^{\circ} \mathrm{F}$. Some Initial scrap pleces were cracked during the early straightening at tempts 

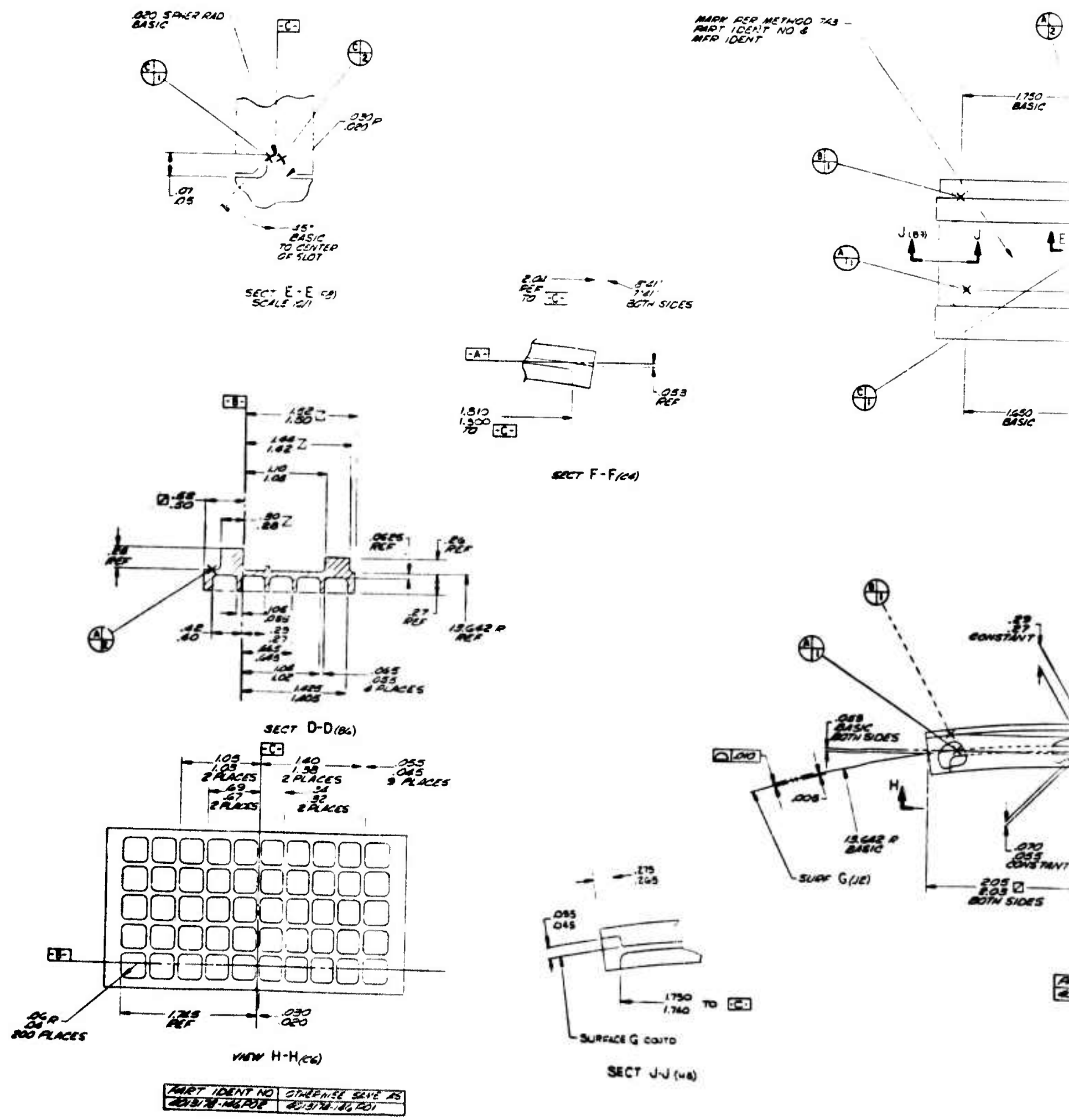

Transpiration-Cooled Shroud Casting Drawing.

Figure 23. 


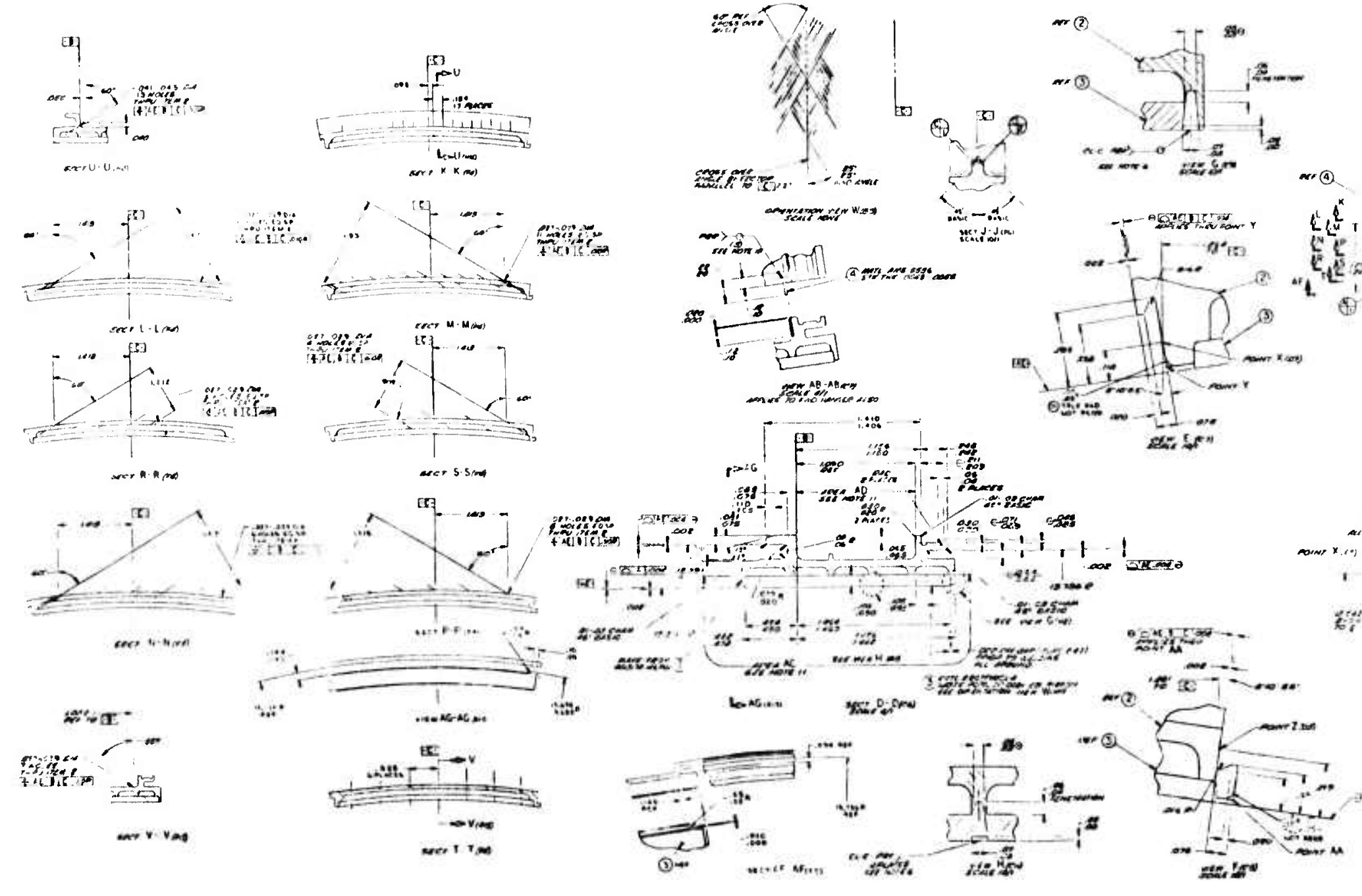

Figure 24. Transpiration-Cooled Shroud Machining Dra 

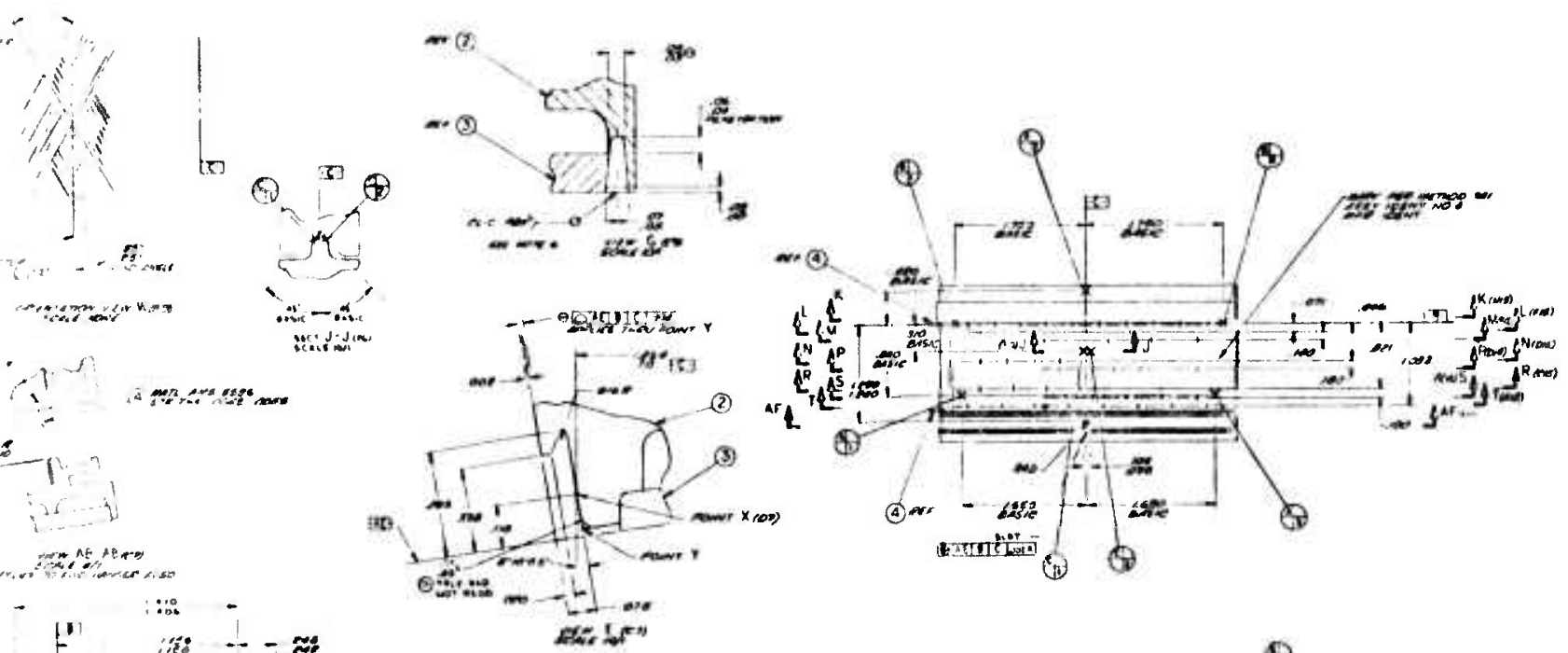

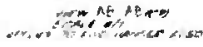

$\therefore$

F... F

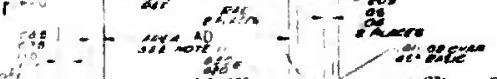

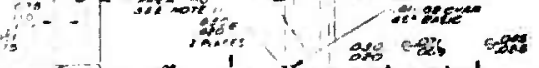

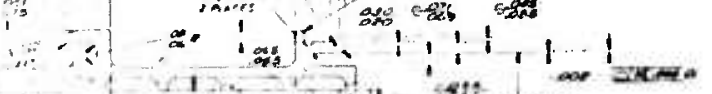

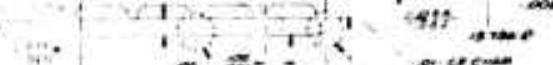

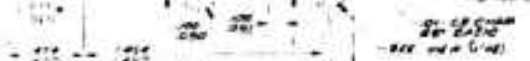

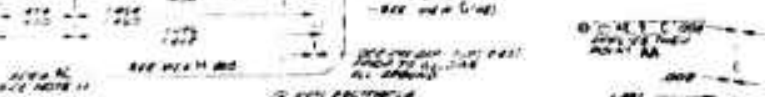

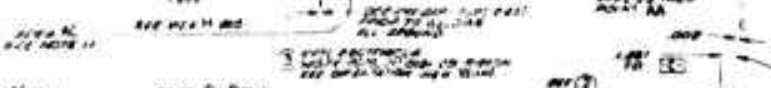

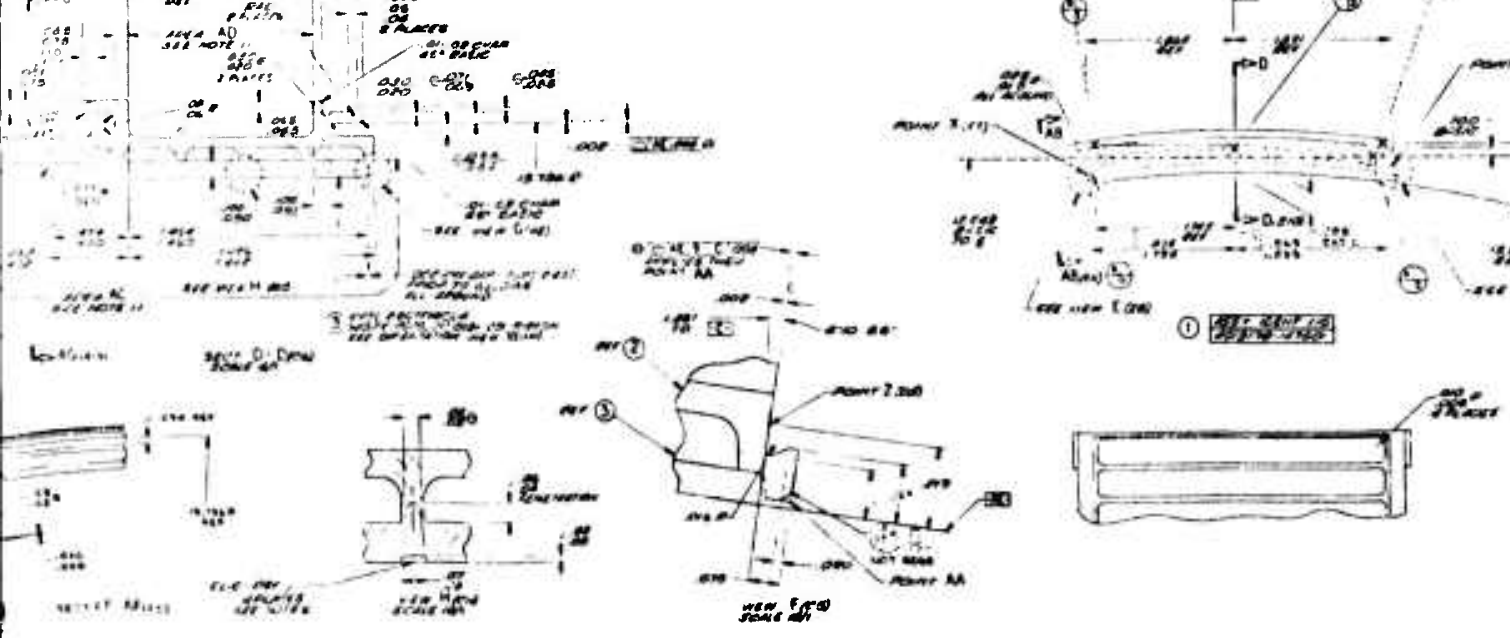

re 24. Transpiration-Cooled Shroud Machining Drawing.
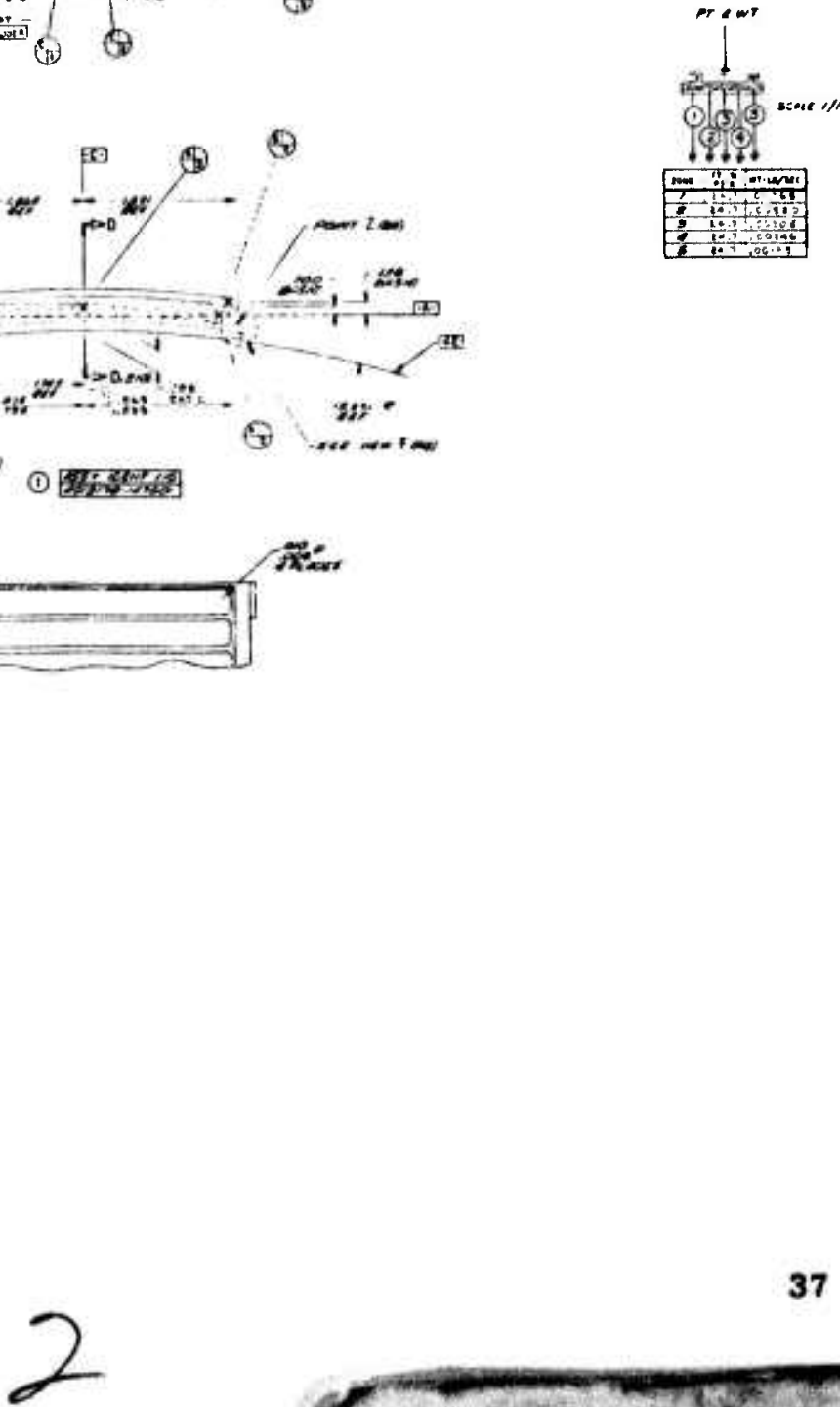


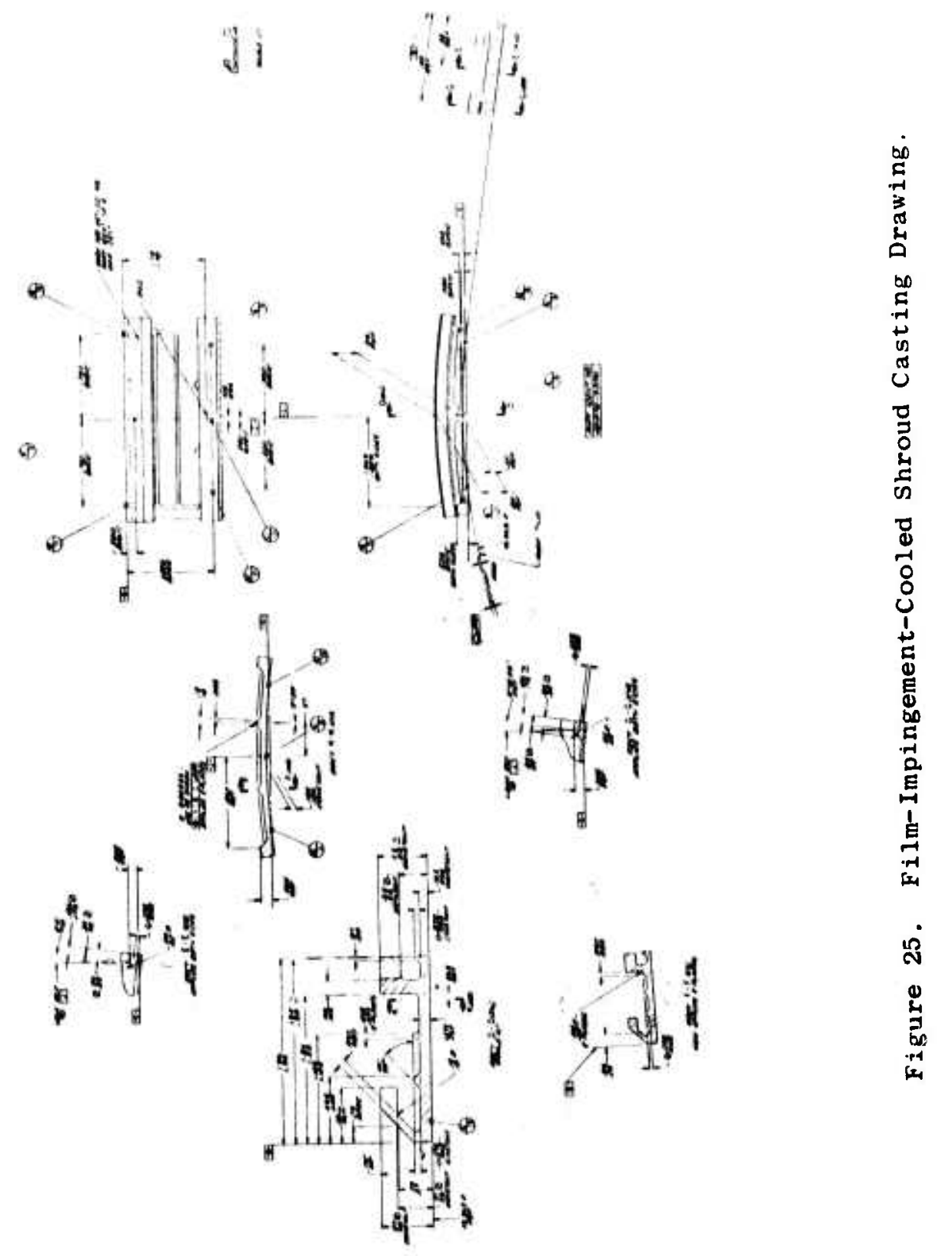



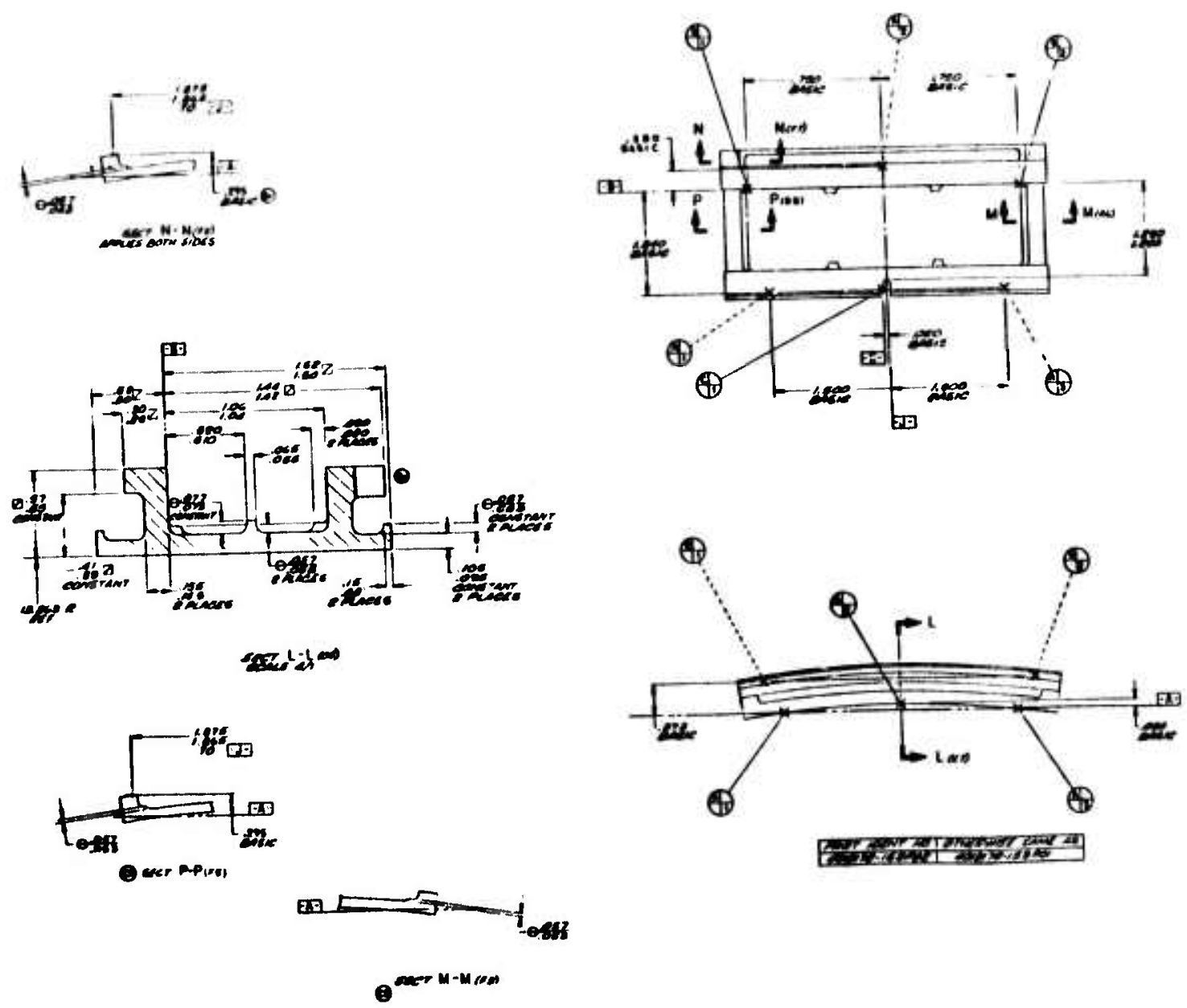

Figure 25. Film-Impingement-Cooled Shroud Casting Drawing (Concluded). 

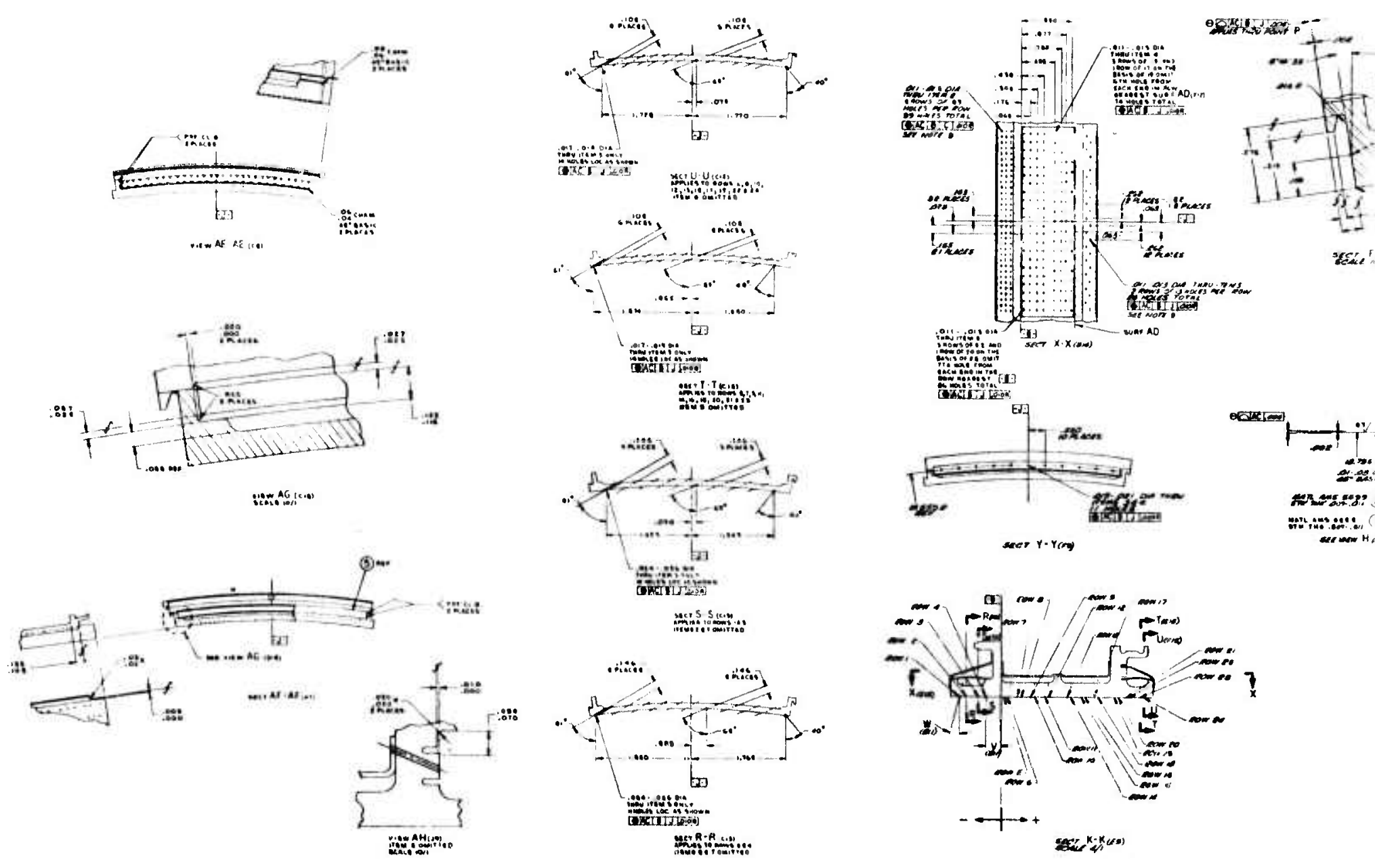

Paure 26.

41

F11m-Impingement-Cooled Shroud Machining Drawing. 


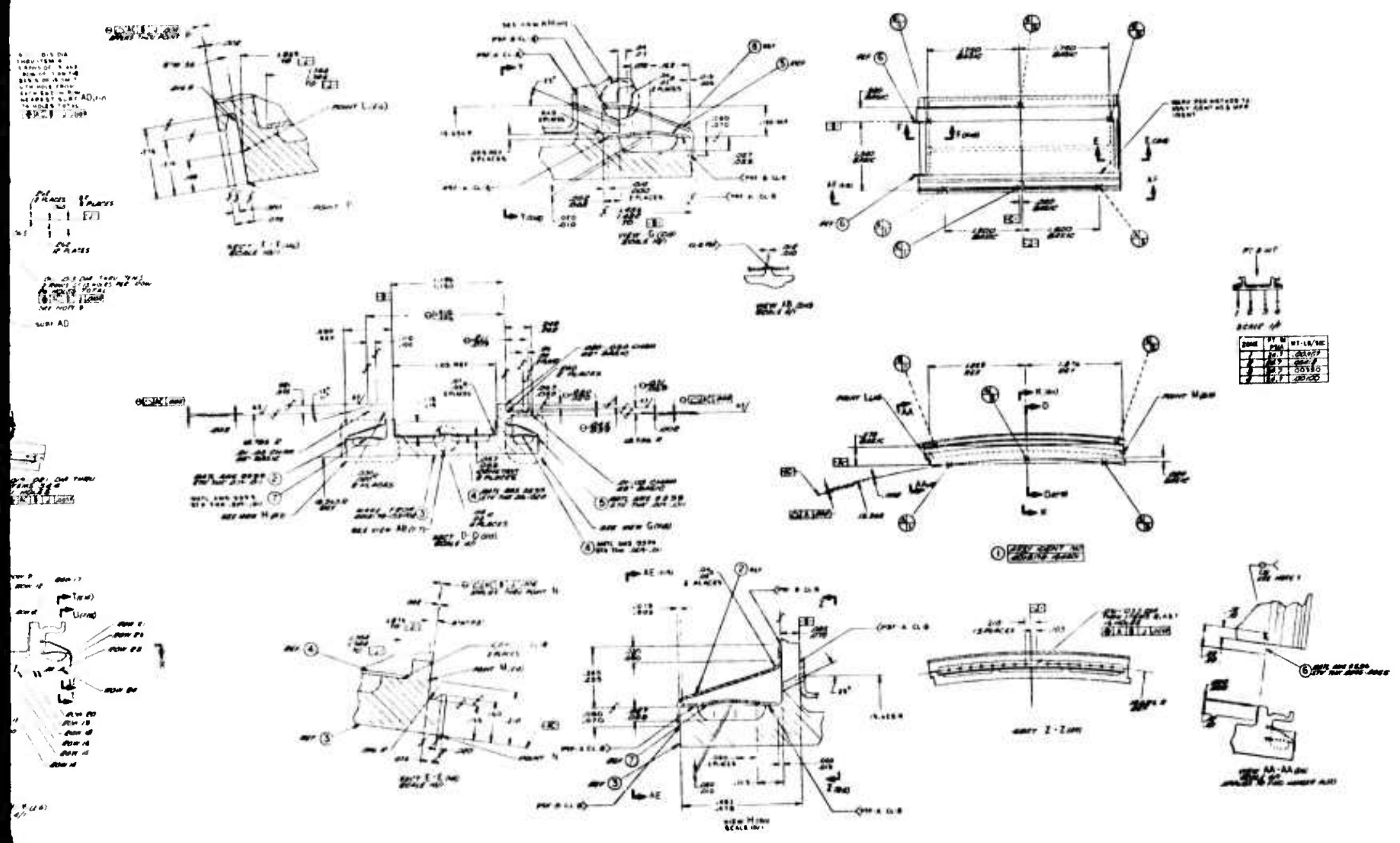




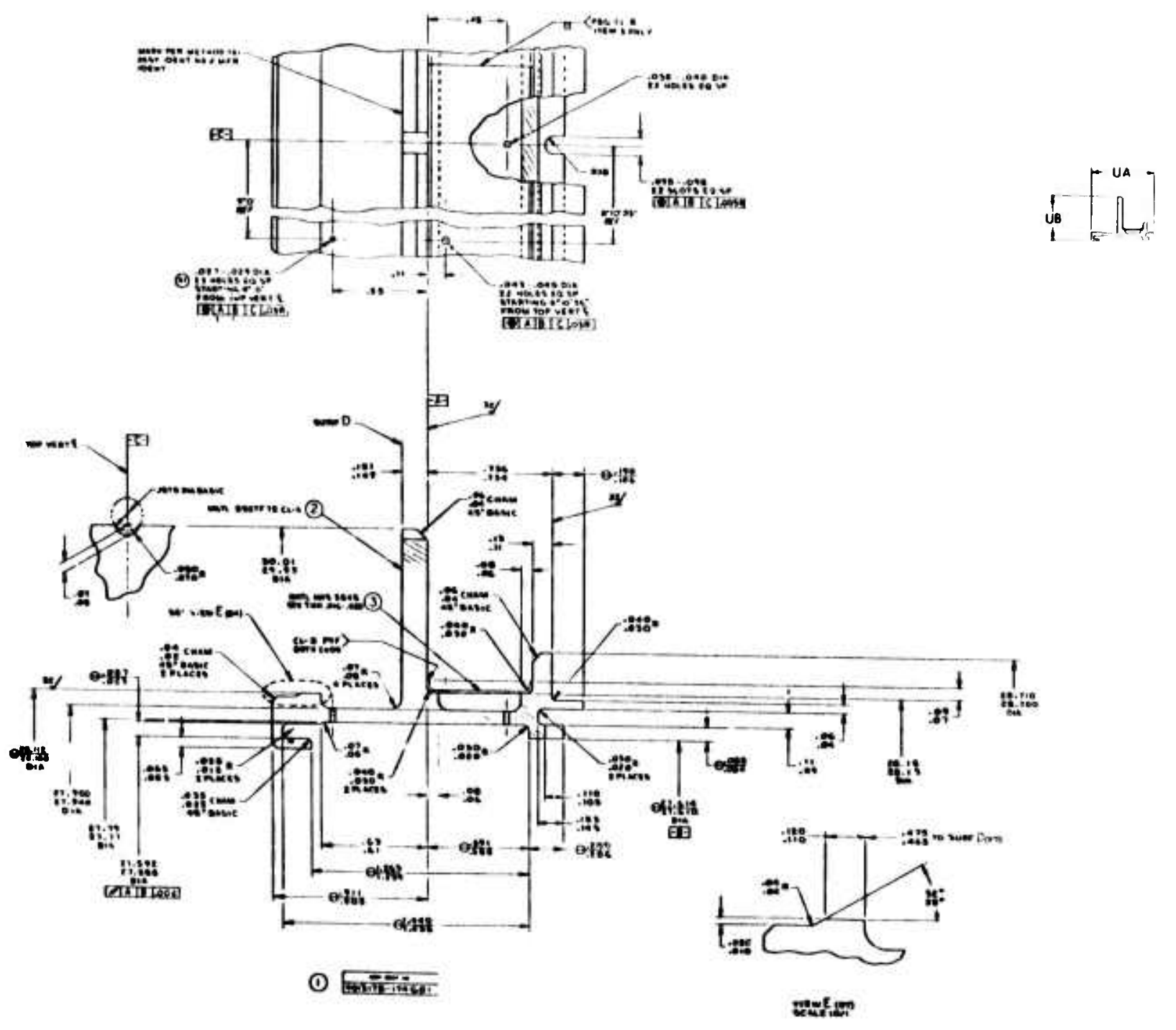

Figure 27. Shroud Support. 

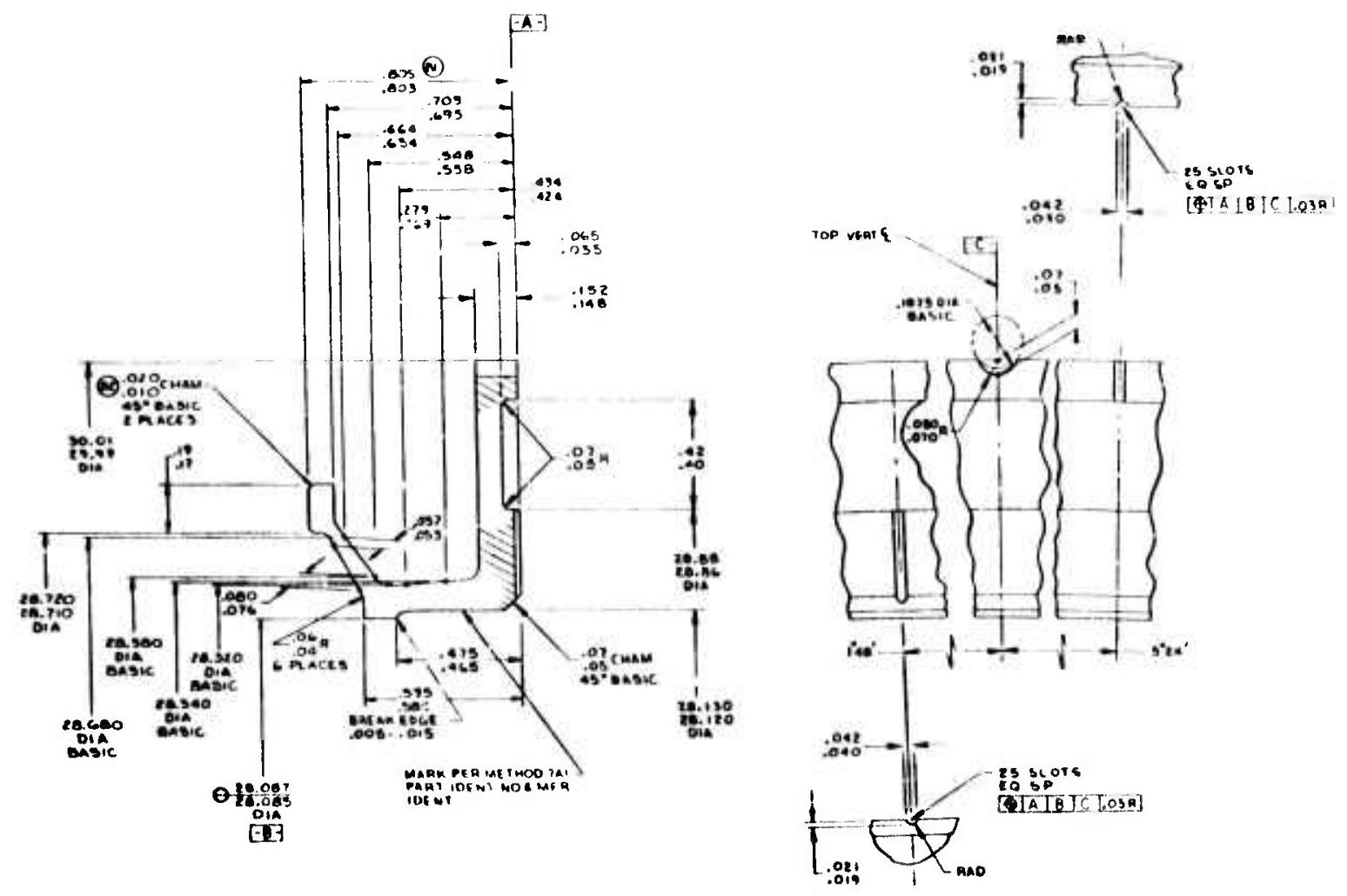

Figure 28. Forward Seal. 


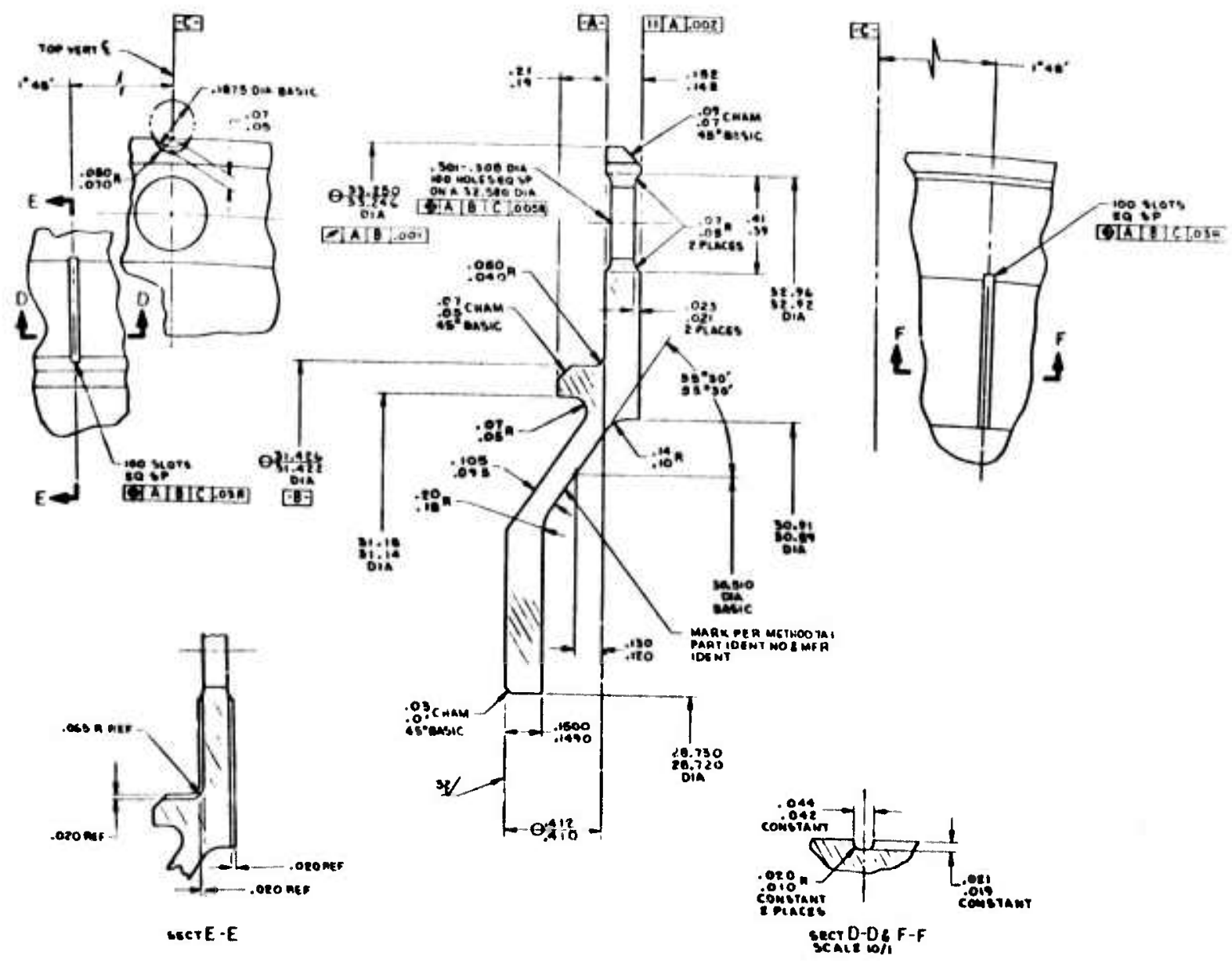

Figure 29. Outer Support. 

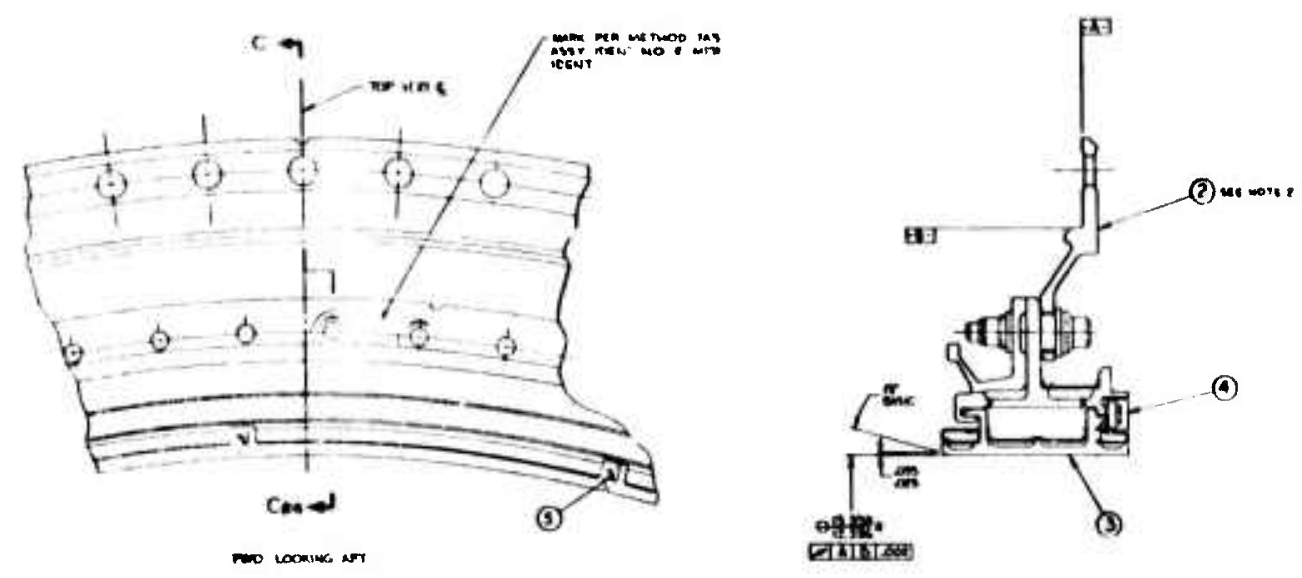

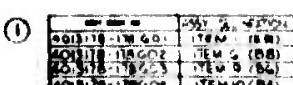

manto ic:

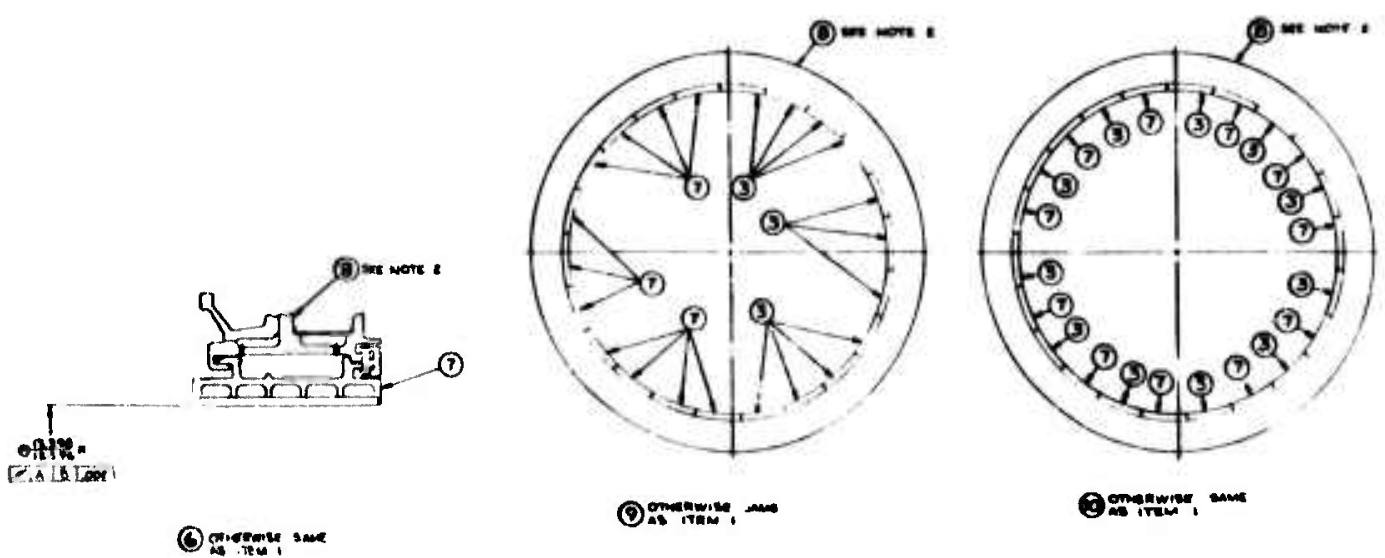

Figure 30. Shroud Assembly. 
when all the curvature was removed in a single operation. However, by golrg. to a two-step straightening operation, all of the shroud castings were satis factorily straightened with no cracks. In large quanticy shroud production, this problem would be solved by correcting the casting dies and no straighten ing would be required.

\subsubsection{Sheet Metal Redesign, Film-Impingement-Cooled Shrouds}

As show: in Figure 3la, the original design of the film-impingementcooled shroud incorporated forward and af mantfolds made up of rectangularshaped sheet metal. Concern was ralsed about this design in several areas: (1) adequate brazing of the lower sheet metal to the casting might allow excess braze fiow that would seal the impingement holes in the impingement plate; (2) the small height of the forward manifold forced the metering holes to be drilled at a difficult angle and risked overdrilling through the impingement plate; and, (3) thermal growth mismatch between the cool 1mpingement plate and the hot casting might fall the connecting braze joint, dumping cooling air and allowing overtemperaturing of the forward shroud.

The solution (Figure 31) was a modified design featuring is two-piece forward and aft manifold and two braze cycles. The new impingeinent plates were bowed to allow thermal flexibility and were brazed first with $B 2 E$ alloy at $2225^{\circ}-2000^{\circ} \mathrm{F}$ for five minutes to allow close visual inspection for any evidence of blocked Implngement holes or lack of an acceptable edge seal. The mid-impingement plate also was brazed during this operation. Then cover plates (a new feature of modified design) were made and brazed in place with GE81 alloy at the lower temperature of $2150^{\circ}-2125^{\circ}$ F for five minutes.

Metering holes were drilled after all brazing was complete.

This redesign worked well; and, in the several cases where braze blockage of the impingement holes was found, the holes were opened up by redriling, thus salvaging the part.

\subsubsection{Leakage Flovi, Film-Impingement-Cooled Shrouds}

off-design flows and pressures were encountered during flow check of the completed f $11 \mathrm{~m}$-impingement-cooled shrouds. The problem was identified as a leakage at the Zone No. 1 and Zone No. 4 metering holes, where incomplete sheet metal fit-up and braze sealing had occurred (see Figure 32). Detailed part-by-part flow and pressure checks were made and compared with design requirements. It was decided that: (1) sealing of the leakage paths would be risky, expensive, and time-consuming; and, (2) that adequate pressure margins could be assured on all parts with only slightly higher cooling air quantities used. Thus, the parts were determined to be adequate for engine use. 


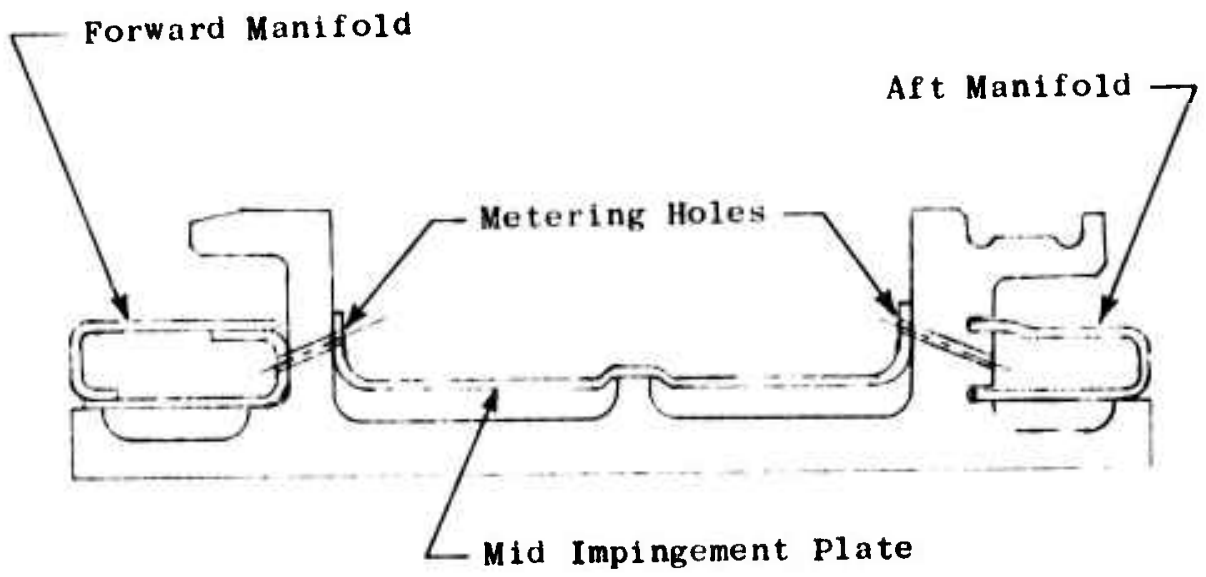

(a) Original Design

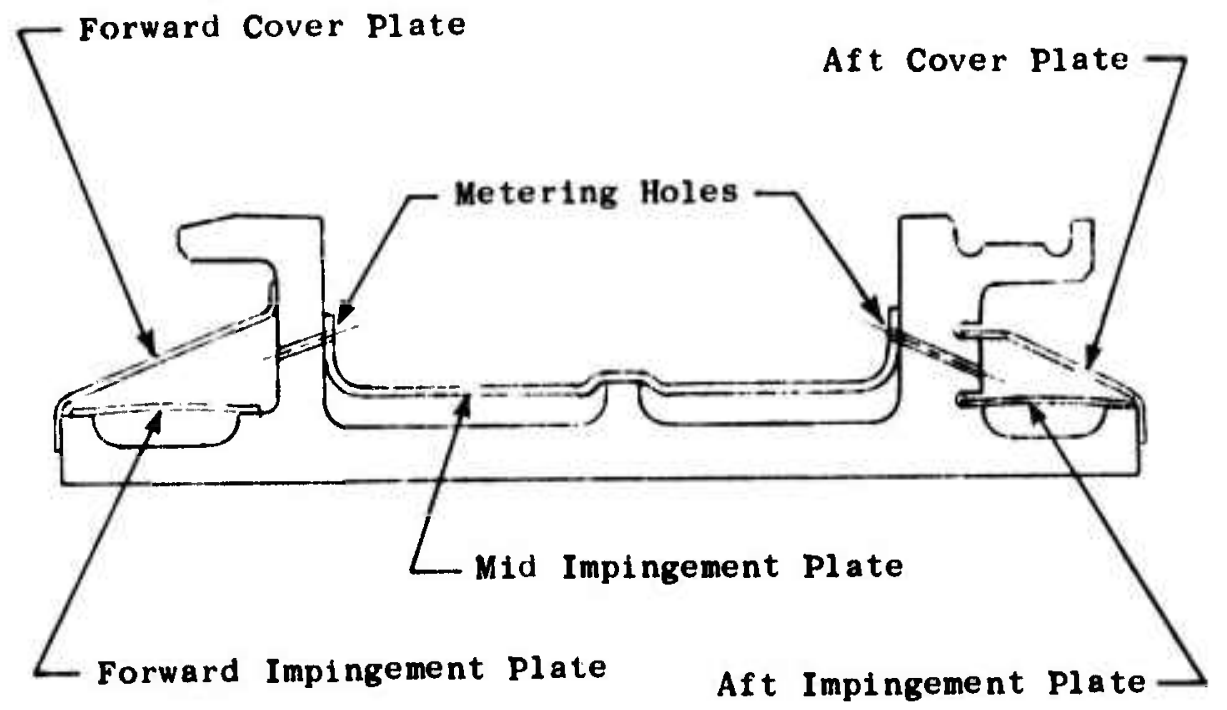

(b) Modified Design

Figure 31. Film-Impingement-Cooled Shroud, Assembly Detail Modifications. 


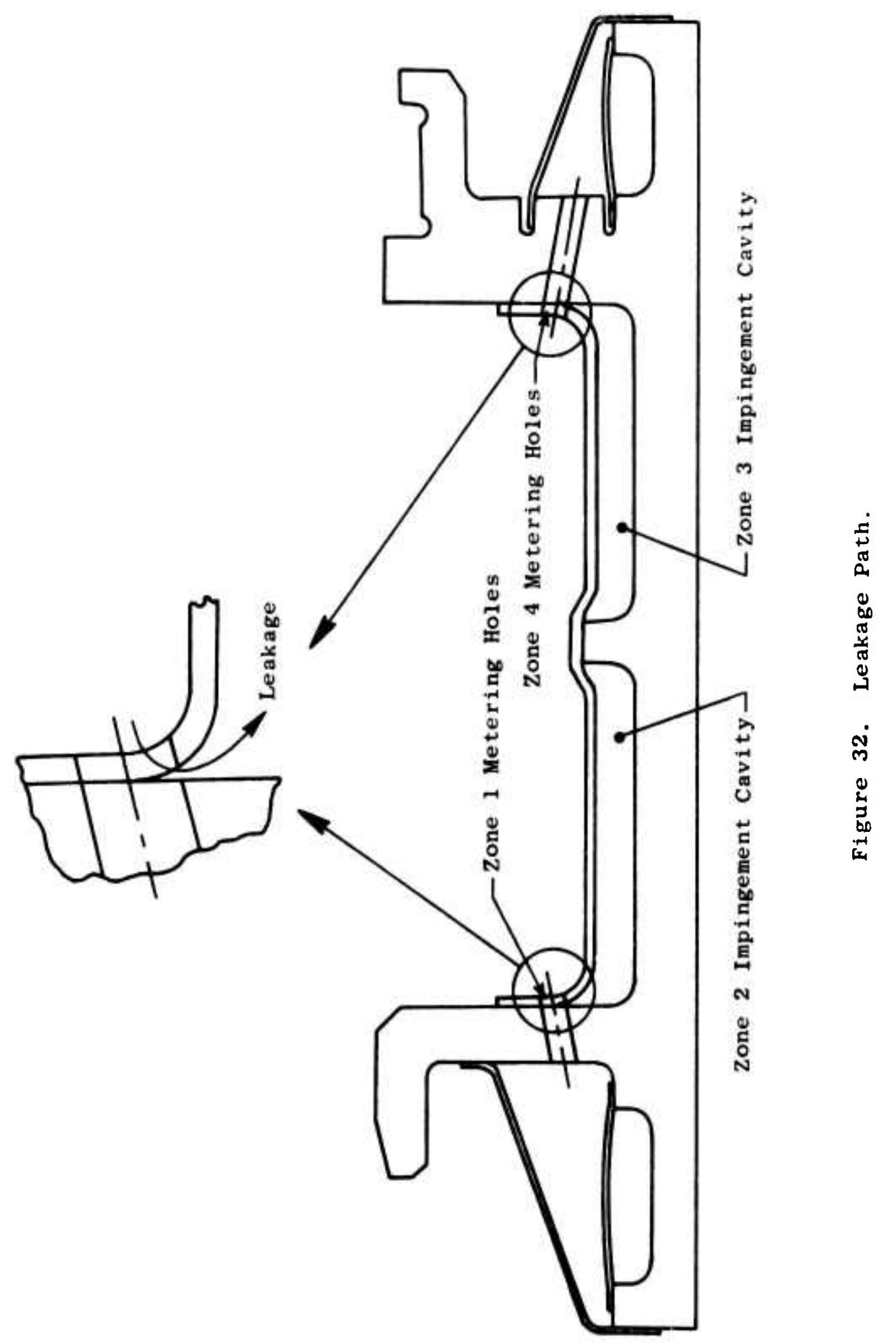




\subsection{ASSEMBLY}

\subsection{SHROUD SYSTEM ASSEMBLY}

Final assembly of the shroud system was made by installing the shrouds into the shroud support system. An overall view of the shroud assembly is shown in Figure 33. Eleven shrouds of each type (11 transpiration-cooled and $11 \mathrm{film-impingement-cooled} \mathrm{for} \mathrm{a} \mathrm{total} \mathrm{of} 22$ shrouds) were assembled in an alternating manner around the circumference. With the support system facedown on an assembly table, each shroud segment was loaded forward into the support in order to engage the forward shroud hook into the forward hanger of the shroud support. Axial shim seals (Hastelloy $X, 0.008$ inch thick) were installed in the gap betweon the shrouds, fitting in the machined seal slots of each shroud. After all the shrouds were loaded in this manner, "C" clips of Rene 41 were pressed axially onto the back, clamping the aft shroud segment hanger and aft shroud support rall and providing a positive radial positioning at the aft end of the shroud. The " $C$ " clips were installed in a staggered pattern such that each clip was centered over the shroud-to-shroud gap retaining the axial shim seal, helping block axial leakage and providing redundant support in the gripping of adjoining shrouds. The " $C$ " clip also incorporated an integral pin, which simultaneously engaged a slot in the shroud and a matching slot in the shroud support and provided a tangential load stop for
each shroud.

A close-up view of the final shroud system assembly is shown in Figure 34, which illustrates the alternating shroud pattern and retaining " $C$ " clips in more detall.

\subsection{SHROUD ECG GRIND}

The radial clearance between the rotor tip and the shrouds is a critical factor in determining turbine performance. To obtain the smallest clearance gap, close control must be obtained on both the rotor tip diameter and on the shroud diameter. This is obtalned by having excess stock on both the blade tip and shroud faces, which then is ground to a close-tolerance diameter prior to engine assembly.

The process chosen to grind the shrouds was ECG (electrochemical grind). This process has been used at General Electric on many prior engines with good success. It involves the use of a grinding wheel in conjunction with a cutting fluid which is charged with an electrical current. This enables material to be slowly and precisely removed by a combination of mechanical grinding and electrochemical deplating. The precision obtained is due primarily to the "stress free" machining with no distortion of the part due to tool pressure or heating. 

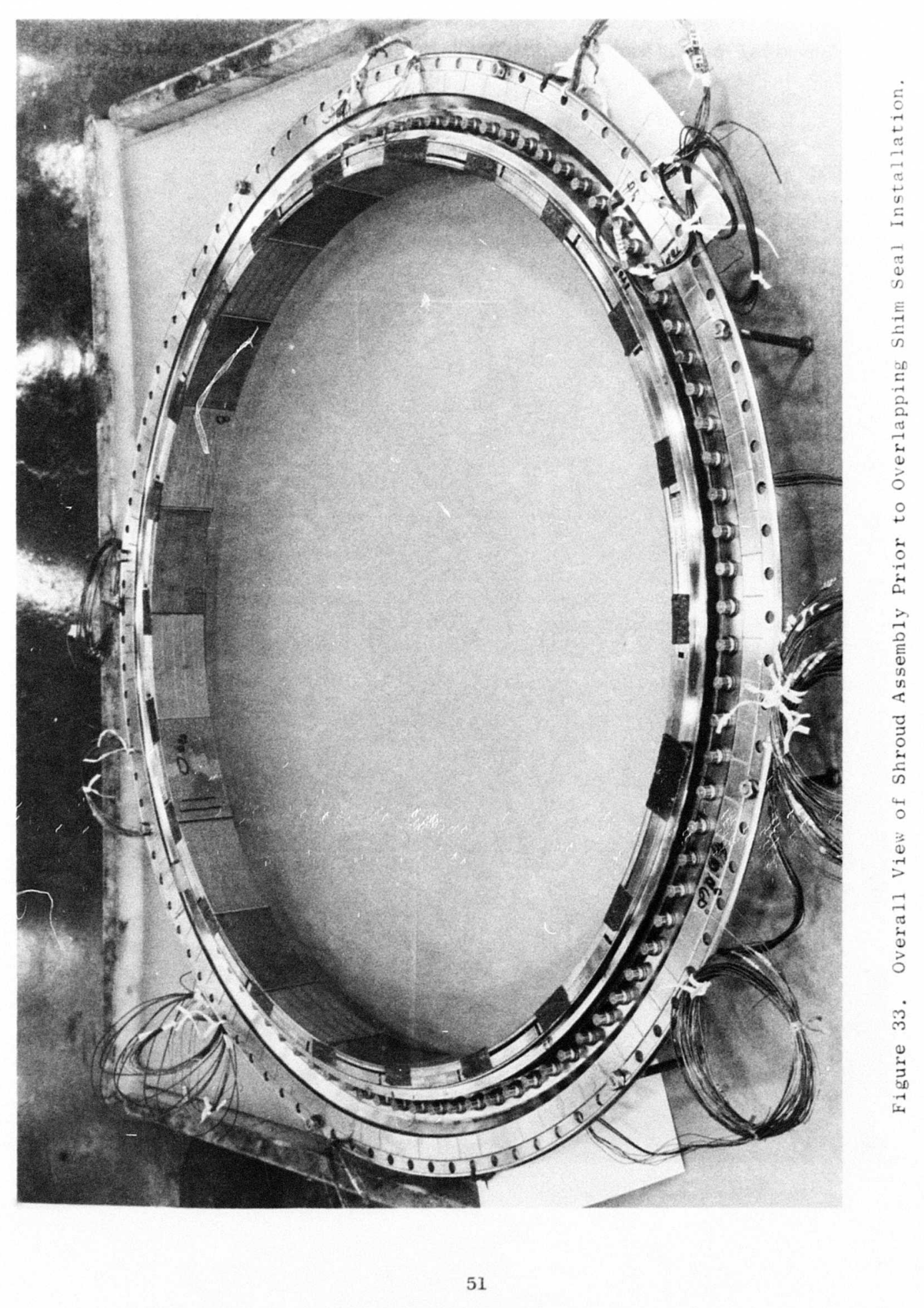

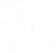




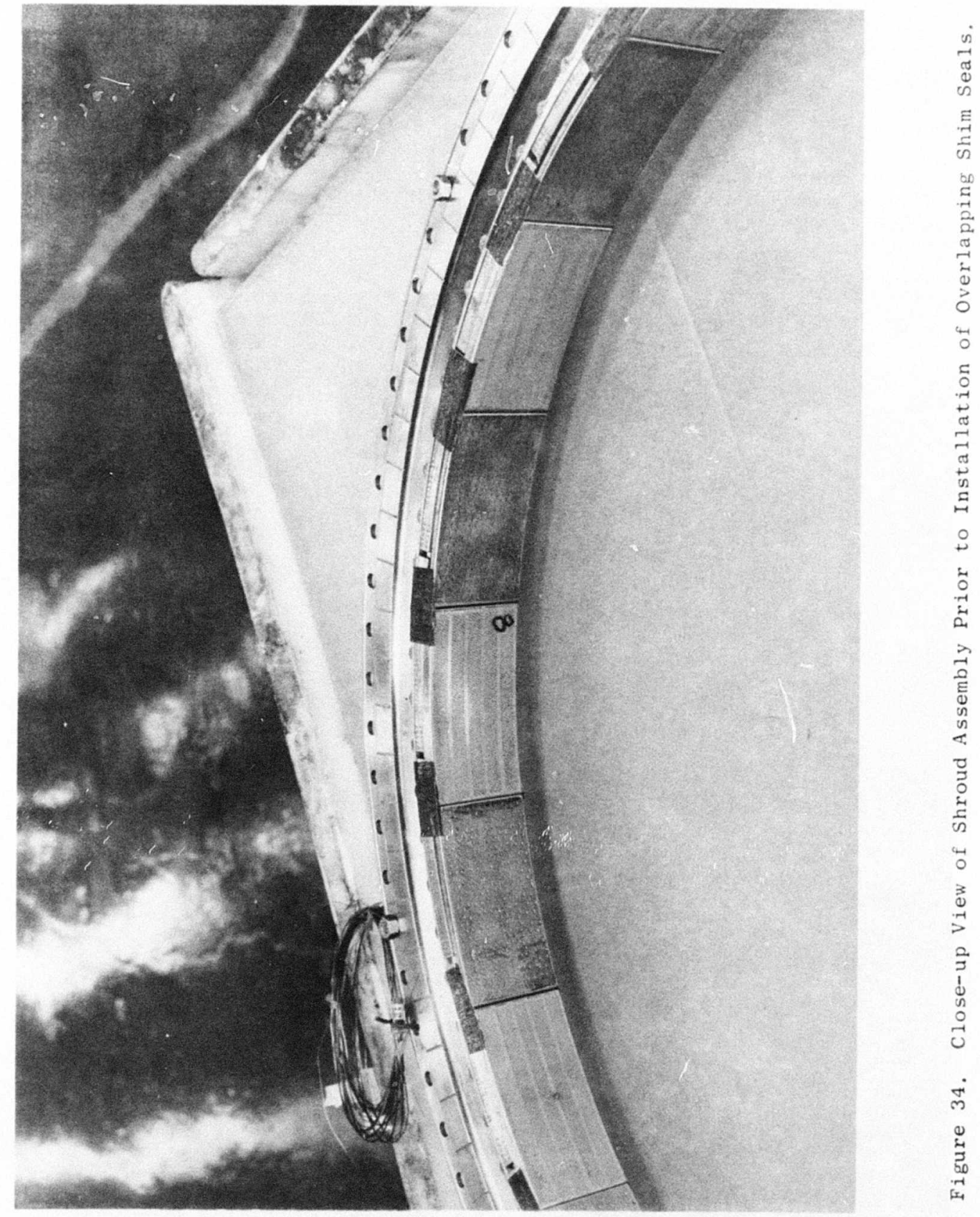


Initial questions about the use of the same grinding parameters to simultancously grind the "open weave" poroloy transpiration-conled shrouds ark the "solid-face" film-impingement-cooled shrouds were answered by a trial machining study. Sample pieces of both shroud types were found to grind in an excellent manner with good dimensional tolerance and no measurable chemical surfacr attack. This study allowed machining parameters (type and composition of grind solution, cutting speed, and feed rate) to be set prior to shroud machining for the engine, alleviating the risk of damaging the cng ine shrouds.

Tlie actual ECG of the engine shrouds was carried out with the outer support fixtured at the 0.D., as it would be in the full engine assembly. The ECG results were excellent. Postgrind inspection showed the shrouds to measure exactly equal to the objective average diameter with variations in diameter 1 imited to \pm 0.0005 versus $0.001-$ inch ohjective. This was better than anv previnus ATEGG assembly grind by almost 0.010 inch.

\subsection{SHROUD SUPPORT SLIP JOINT PROBLEM}

Inspections of the shroud assembly diameter just prior to installation of the assembly into the engine showed that there was an excessive out-of-round condition with the assembly in the unrestrained condition. After much study, it was concluded that the shroud assembly has been restrained to a round condition during line drilling of the flange bolt holes and it then resumed an out-of-round condition in the "free stage" bolted condition. This large support out-of-roundness did not allow the radial flange slip joint feature to function properly, which resulted in the shroud support being restrained by the outer shroud support during the shroud grind operation and effectively masked the condition until the shroud was removed from the grinding fixture.

This out-of-round condition was satisfactorily corrected by a combination of straightening at the oval points and by the repositioning of selected shroud segments to better clearance locations. The shroud support was rounded to within 0.010 inch FIR (full indicator reading) through judicious load application in the Static Load Laboratory. The shroud assembly then was reassembled and, through proper location of the shroud segments and a stress relief operation, yielded acceptable levels of flowpath run out. 


\subsection{INSTRUMENTATION}

\subsection{LOCATLON/PURPOSE}

The ATEST shrouds were instrumented in order to monitor the component operating conditions, thus providing a safety check on allowable temperature levels and data for comparison and correlation with design predictions.

Axial and radial locations of both pressure and temperature sensors are shown in Figures 35 and 36. Casing cavity pressures and temperatures were measured to provide a base reading on cooling air plenum conditions prior to air entry into the shrouds. Temperatures on the support system were measured at six critical points which determined the support's thermal response. Cooling air pressure between the support and the shroud was read to monitor preimpingement conditions.

Surface temperatures on the film-impingement-cooled shroud were measured in five places; one for each of the four zones of cooling, plus one near the shroud segment mid-rib.

Surface pressures and temperatures were measured on the transpirationcooled shrouds as shown in Figure 36. The pressures were measured at the critical leading portion of each of the five cooling zones, with temperatures measured adjacent to the pressure tap. Reference temperatures also were measured on the shroud segment casting and at distributed locations on the Poroloy gas-stream side surface.

Actual installation of the instrumentation elements was made by drilling access holes from the back side of each shroud segment. The lead wiring then was fed into the holes and welded in place at the desired locations. The surface instrumentation then was benched flush with the flowpath surface. Lead wires were tack welded to the back side of the shroud segment using nichrome sheet for holddown, with care being taken to avoid blocking of the air entry holes. Closeup photos of the instrumented shrouds are shown in Figures 37 and 38 .

Three transpiration-cooled shrouds and two film-impingement-cooled shrouds were instrumented as described above. The instrumented shrouds were located in the shroud assembly as shown in Figure 39. The assembly jocations were selected to provide maximum information on circumferential temperature variations within the shroud assembly during demonstrator engine test.

\subsection{CLEARANCE PIN INSTALLATION}

In order to determine actual rotor tip clearances during engine test. clearance pins were installed in eight of the shrouds. These small 0.040inch-diameter platinum pins were welded into radial holes which were drilled in the shrouds as shown in Figure 40. By extending, into the flowpath beyond the 


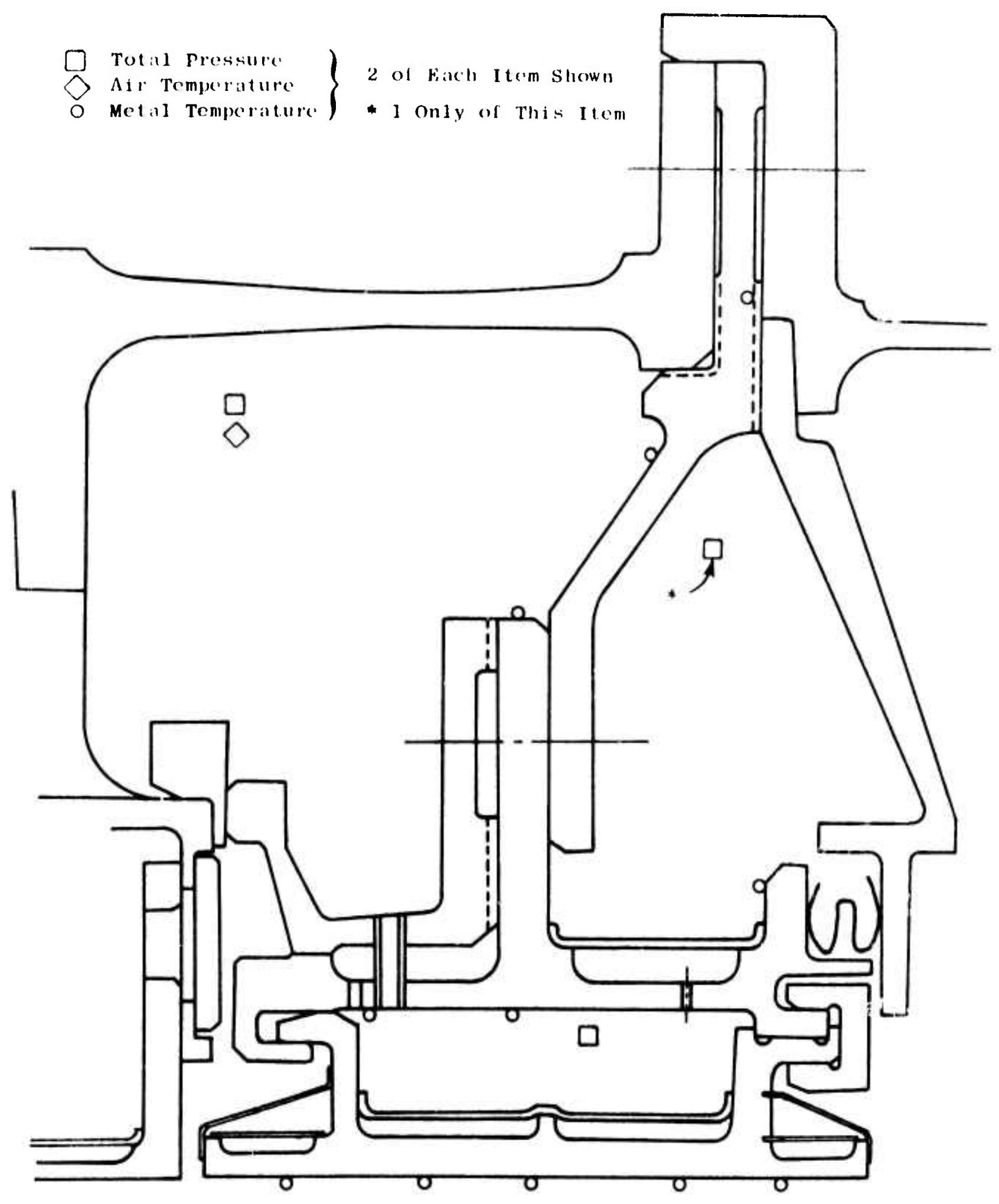

Figure 35 . Shroud Support and Film-Impingement-Cooled Shroud Segment Inst rumentation. 

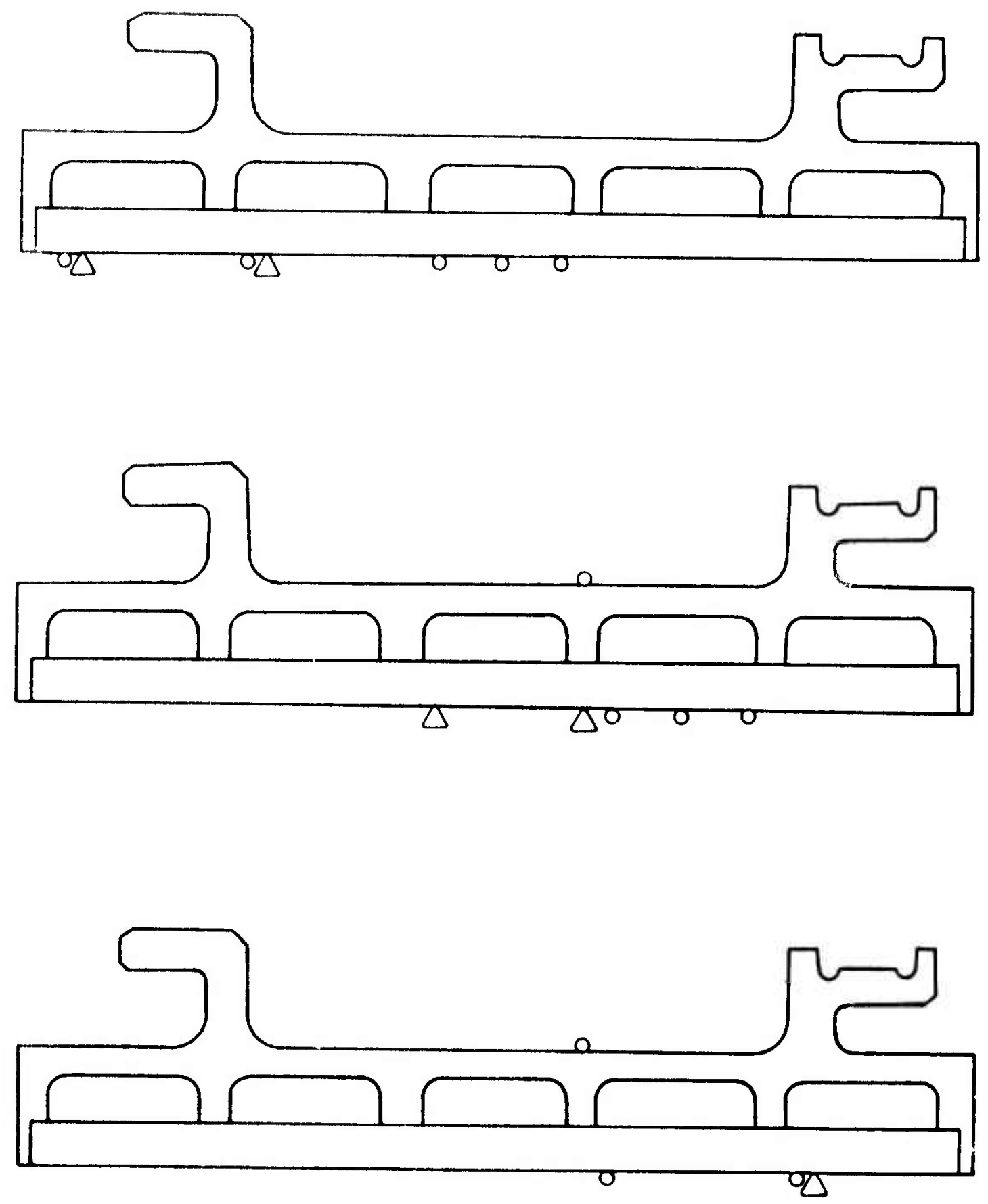

$\left.\begin{array}{l}\text { Metal Temperature } \\ \triangle \text { static pressure }\end{array}\right\} 1$ of Each Item Shown

Figure 36. Transpiration-Cooled Shroud segment Instrumentation. 


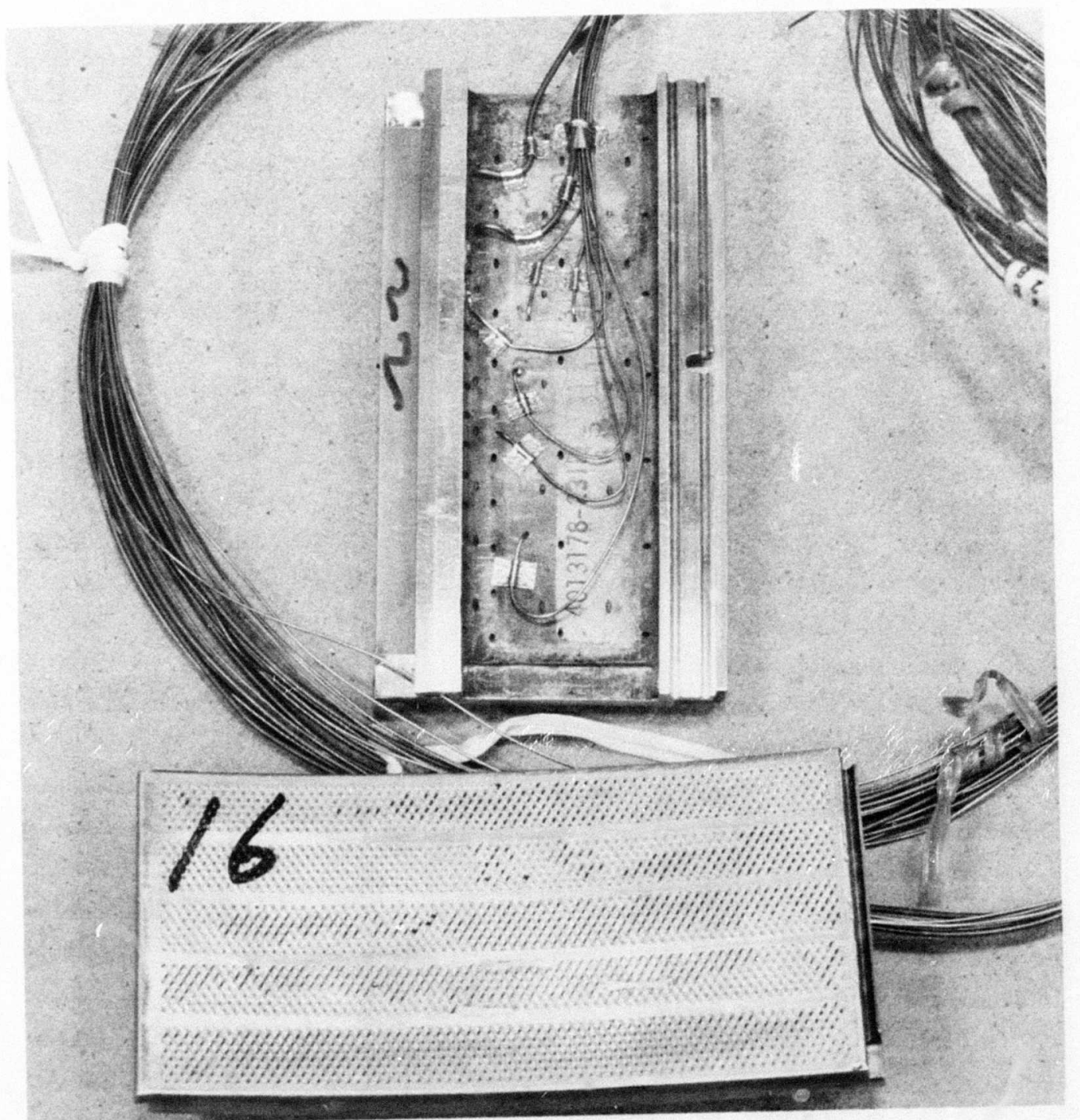

Figure 37. Instrumented Transpiration-Cooled Shroud Segments. 


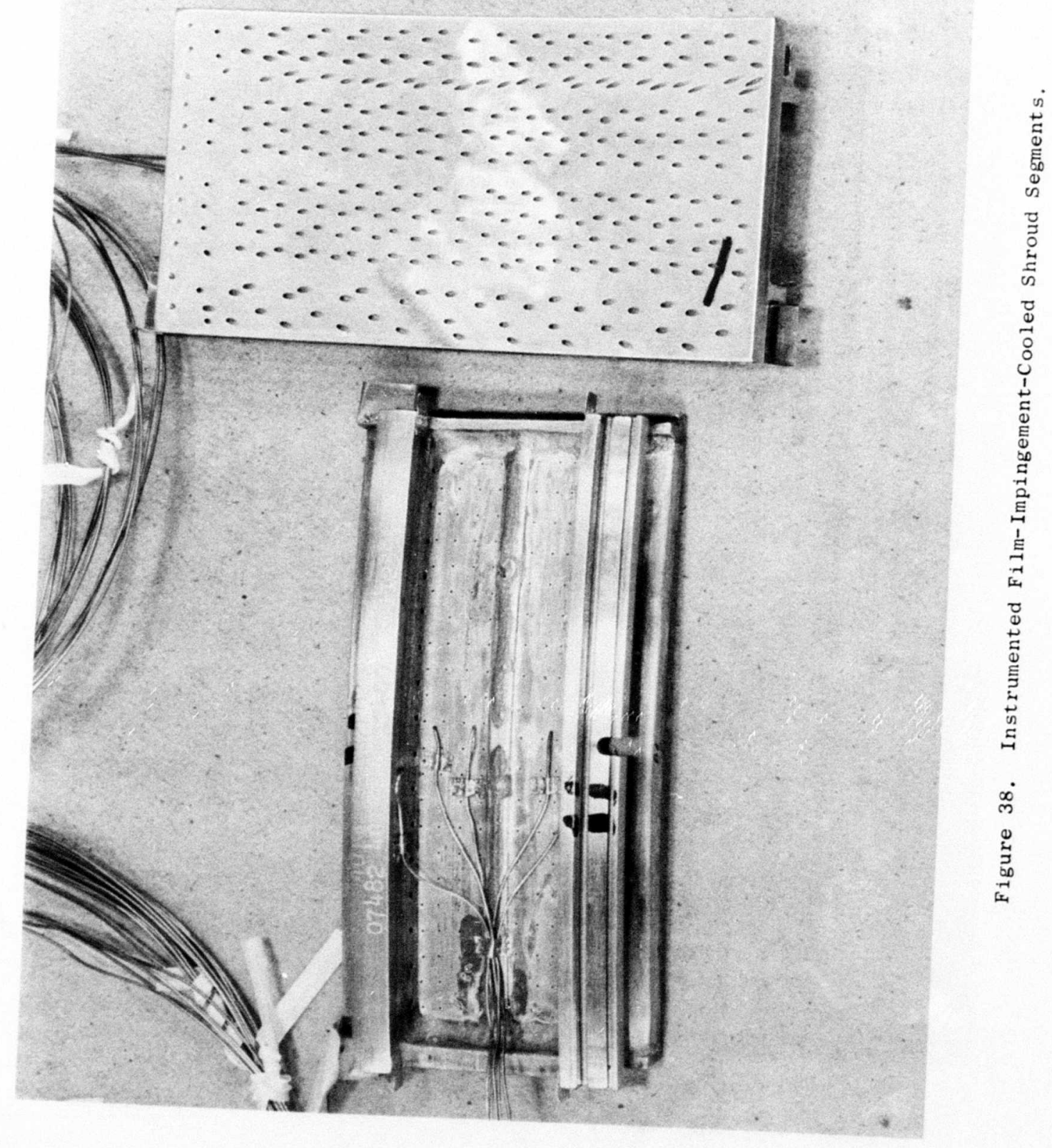



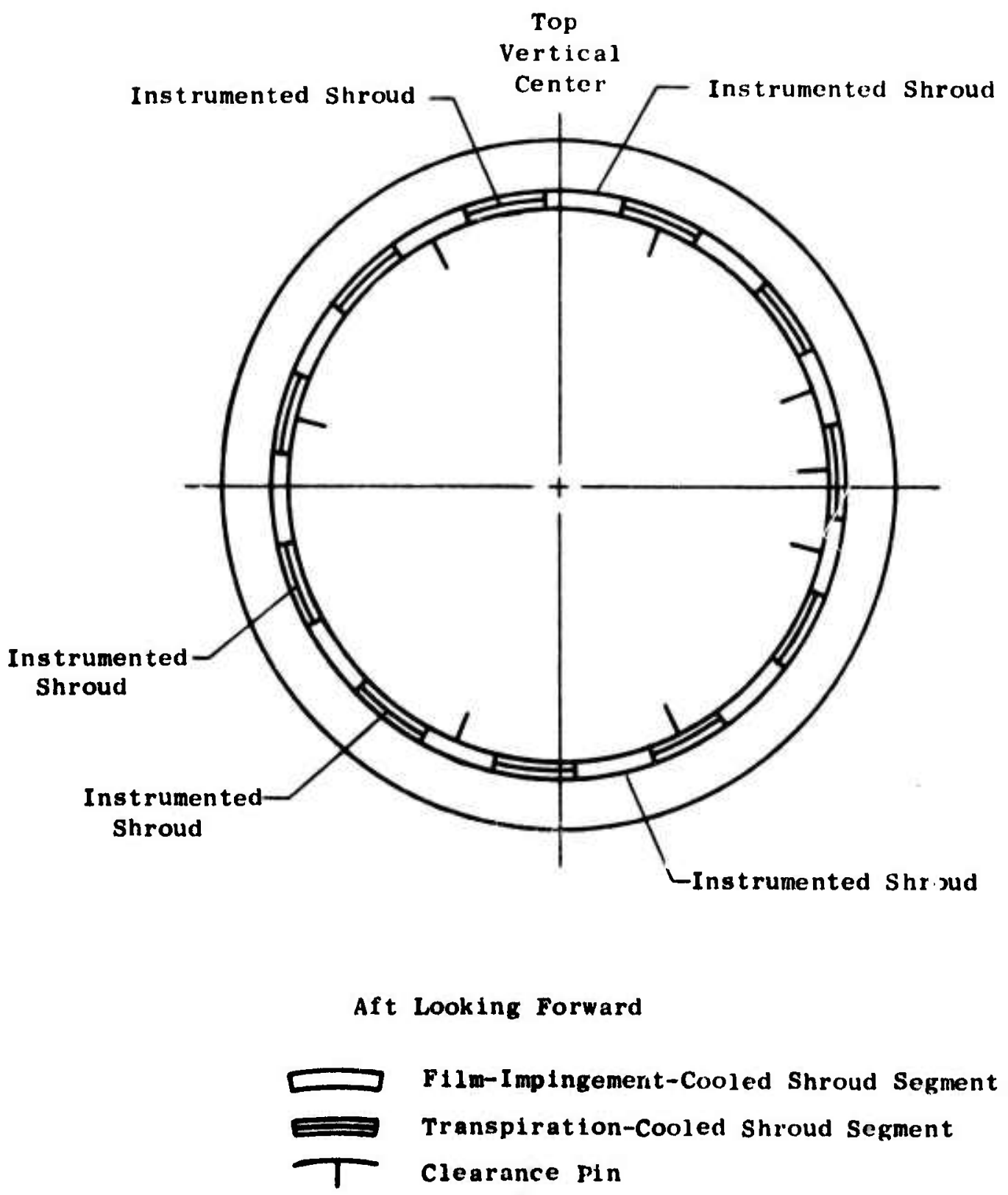

Figure 39. Instrumented Shroud Locations in Shroud Assembly. 

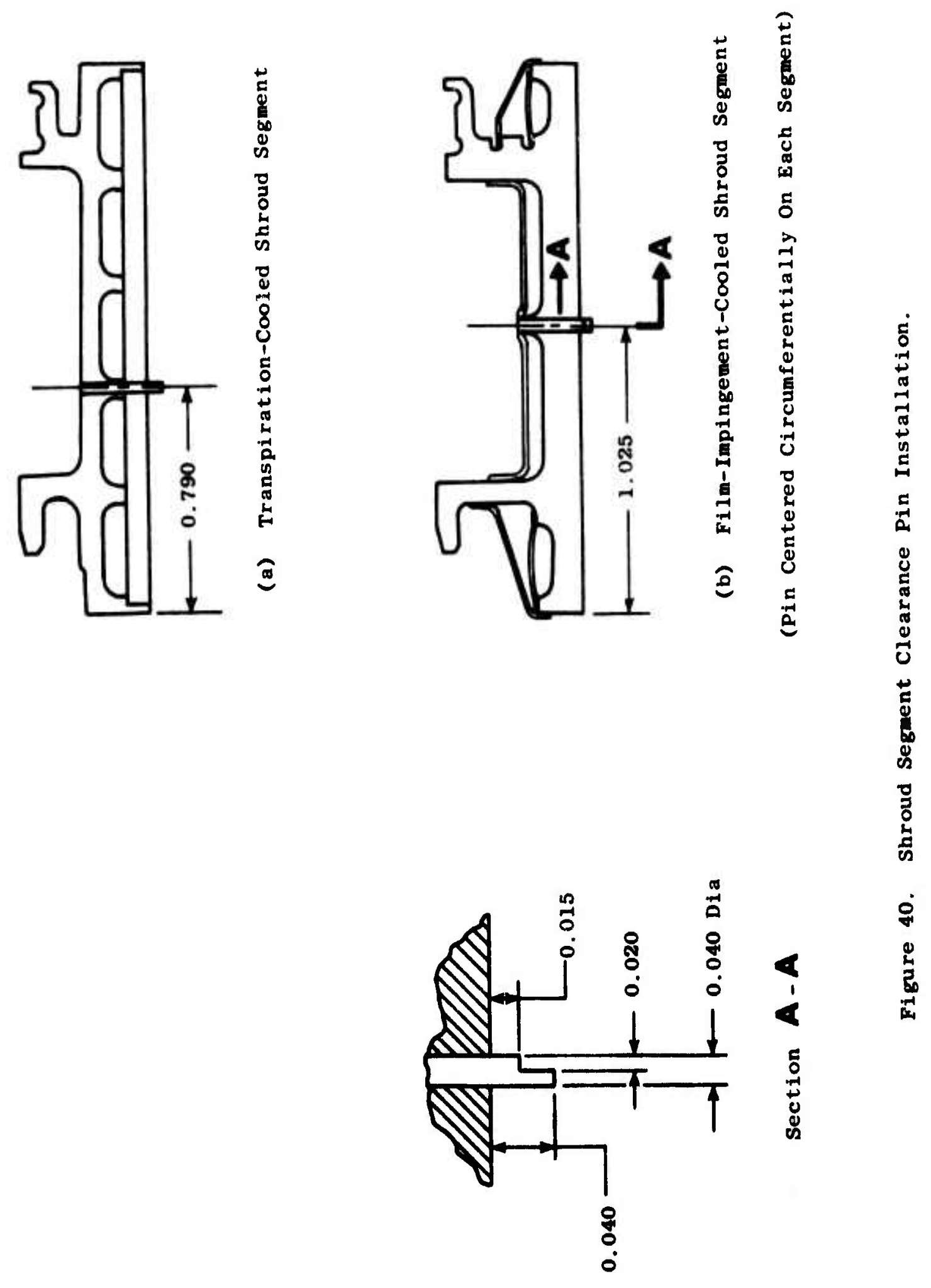
estimated tip clearance gap, these pins would be worn down such that the remaining $p$ in exposure was an actual measure of the $t 1 p$ clearance gap shown in Figure 39.

During welding of the platinum pins into the MAR-M-509 casting, some superficlal surface cracks were encountered. A Materlals Laboratory study was made of the cause of these cracks, and an engineering analysis was conducted study found that the weld, If any, of the cracks on shroud iffe. The laboratory removal of heat following welding were due to poor weld techniques (too rapid excessive heat application with in the film-impingement-cooled shrouds and in the transpiration-cooled shrouds).

Analysis of the effect of the cracks showed the low cycle fatigue life to be adequate. This conclusion was borne out by the lack of crack propagation
during engine tests. 
SECTION 7.0

\section{TEST RESULTS}

As discussed in Section 6.0, three transpiration-cooled and two f $11 \mathrm{~m}$-impingement-cooled shrouds were instrumented and selectively located around the circumference of the turbine shroud assembly. Each of these shrouds was instrumented with a total of 20 surface thermocouples. At the rated $\mathrm{T}_{4}$ demonstration test point, seven surface thermocouples were still operating on the transpiration-cooled shroud gas-stream side surface, seven were operating on the film-impingement-cooled shroud gas-stream side surface, and five additional thermocouples were operational at other shroud locations.

At the rated $\mathrm{T}_{4}$ demonstration point, the film-impringement-cooled shrouds ran at surface temperatures from $1448^{\circ}$ to $1569^{\circ} \mathrm{F}$, while the transpiration-cooled shroud surface temperatures were as much as $200^{\circ} \mathrm{F}$ colder with temperatures ranging from $1219^{\circ}$ to $1473^{\circ} \mathrm{F}$ as shown in Figure 41. At the same time, the shroud support temperatures, as expected, were very close to the $946^{\circ} \mathrm{F}$ cooling air temperature.

Gas-stream pressures were measured on both the transpiration-cooled and film-impingement-cooled shrouds at the five axial locations shown in Figure 42. All of the pressure probes measured accurately except in the aft (downstream) region of the shrouds. Figure 43 shows the typical measured nondimensionalized pressure distribution of the axial pressure decrease across the shrouds.

The cooling system pressures and temperatures measured in the various cavities of the shroud support (Figure 41) show that the cooling air pressure drop between the compressor discharge supply potat $\left(\mathrm{P}_{3}\right)$ and the support is about five psi. The pressure ratlo across the main cooling air supply ports then was measured to be between 1.06 and 1.08 . The pressure in the aft cavity was very low, indicating that there was leakage from this cavity either to the gas stream through the " $W$ " seal or to the rear frame air cooling cavity. The cooling air temperature at the shrouds was $10^{\circ} \mathrm{F}$ less than the compressor discharge cooling air supply temperature $\left(T_{3}\right)$, indicating that a small amount of heat was lost from the cooling air to the engine casing and on into the test cell.

The shroud support metal temperatures were read out continuously during the engine cyclic testing in order to evaluate the shroud system thermal response. Among the cycles that were run was a cycle that consisted of a 15-second decel from $300^{\circ}$ F less than rated $T_{4}$, a two-minute hold at idle, a 10-second accel, and a 2-minute hold at $T_{4}$ rated minus $300^{\circ} \mathrm{F}$. The transient measurements shown in Figure 44 were taken during these cycles and show that the support reached steady state during the two-minute hold period. 

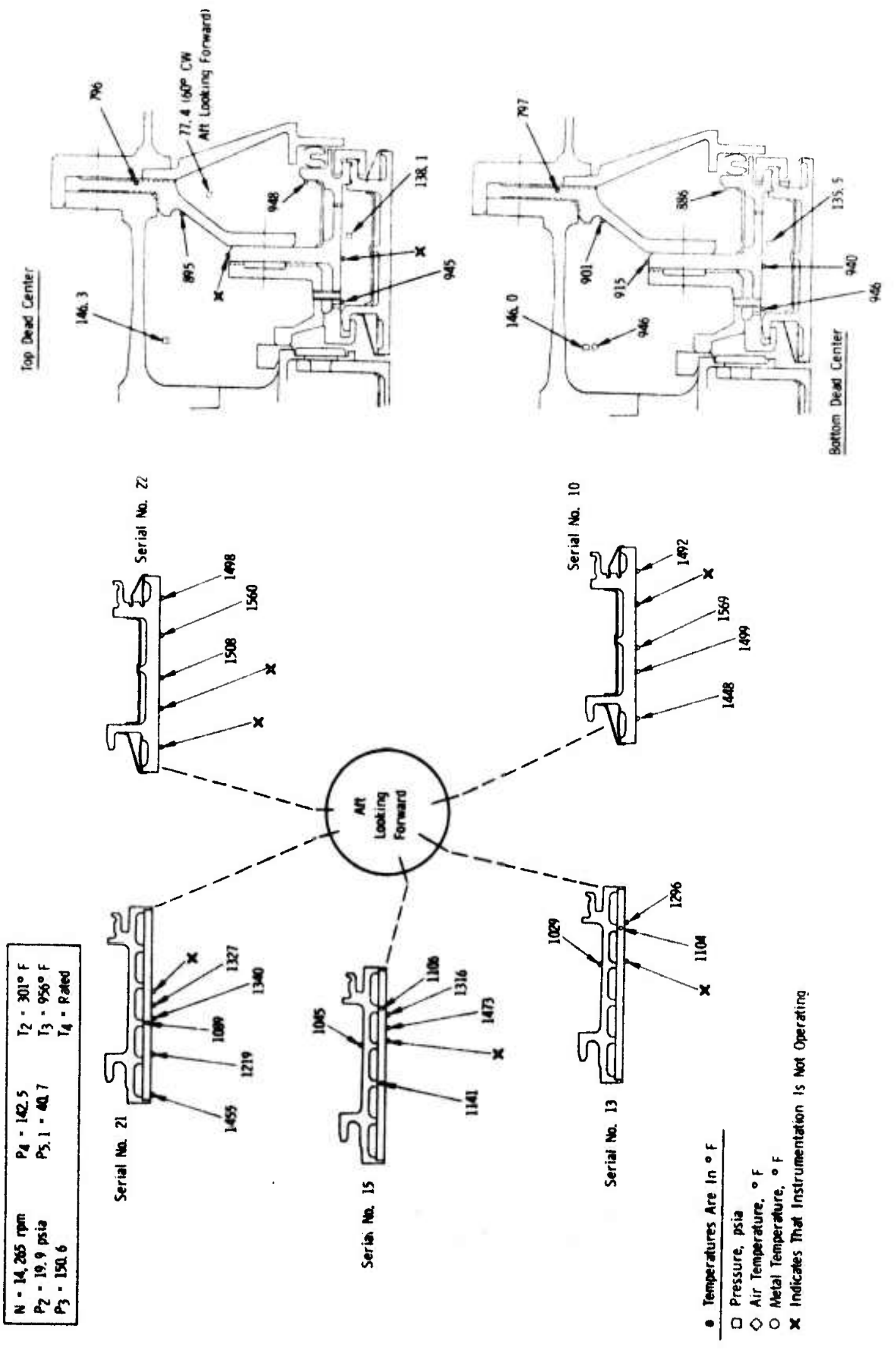

D 


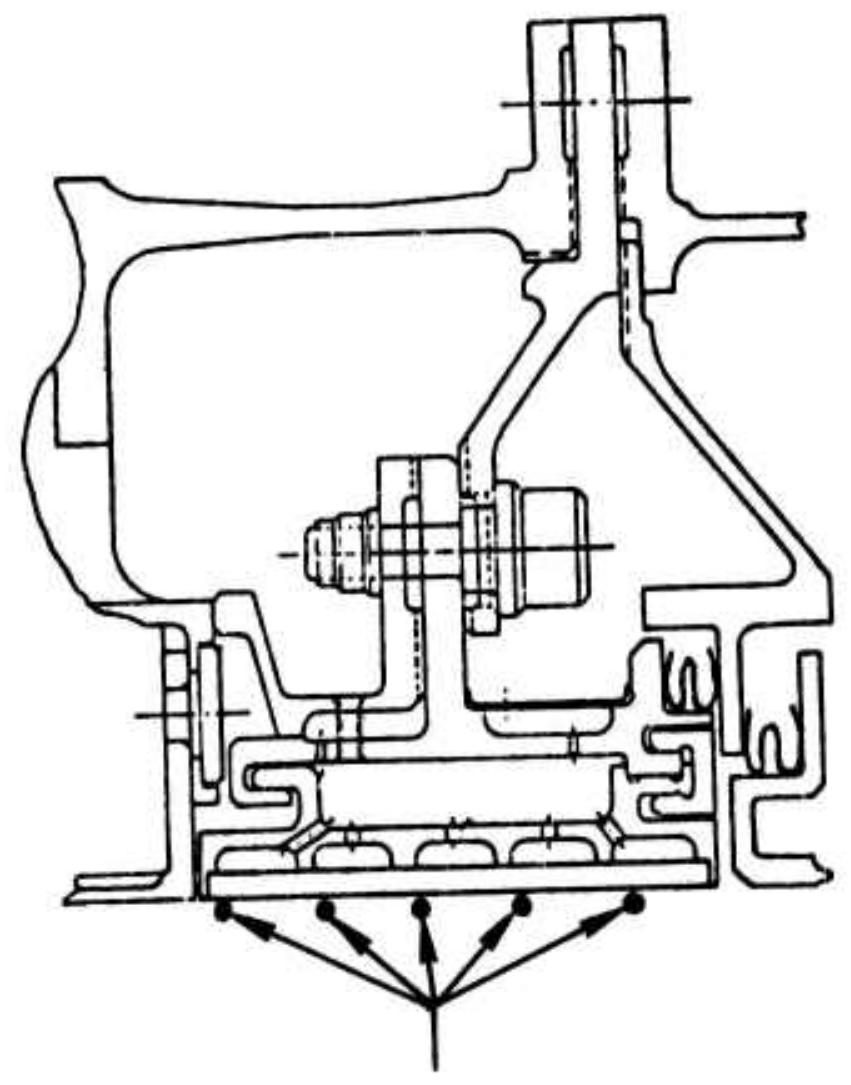

Static Pressure Measurements

F1gure 42. ATEST Shroud Gas Stream Presoure Instrumentation Locations. 


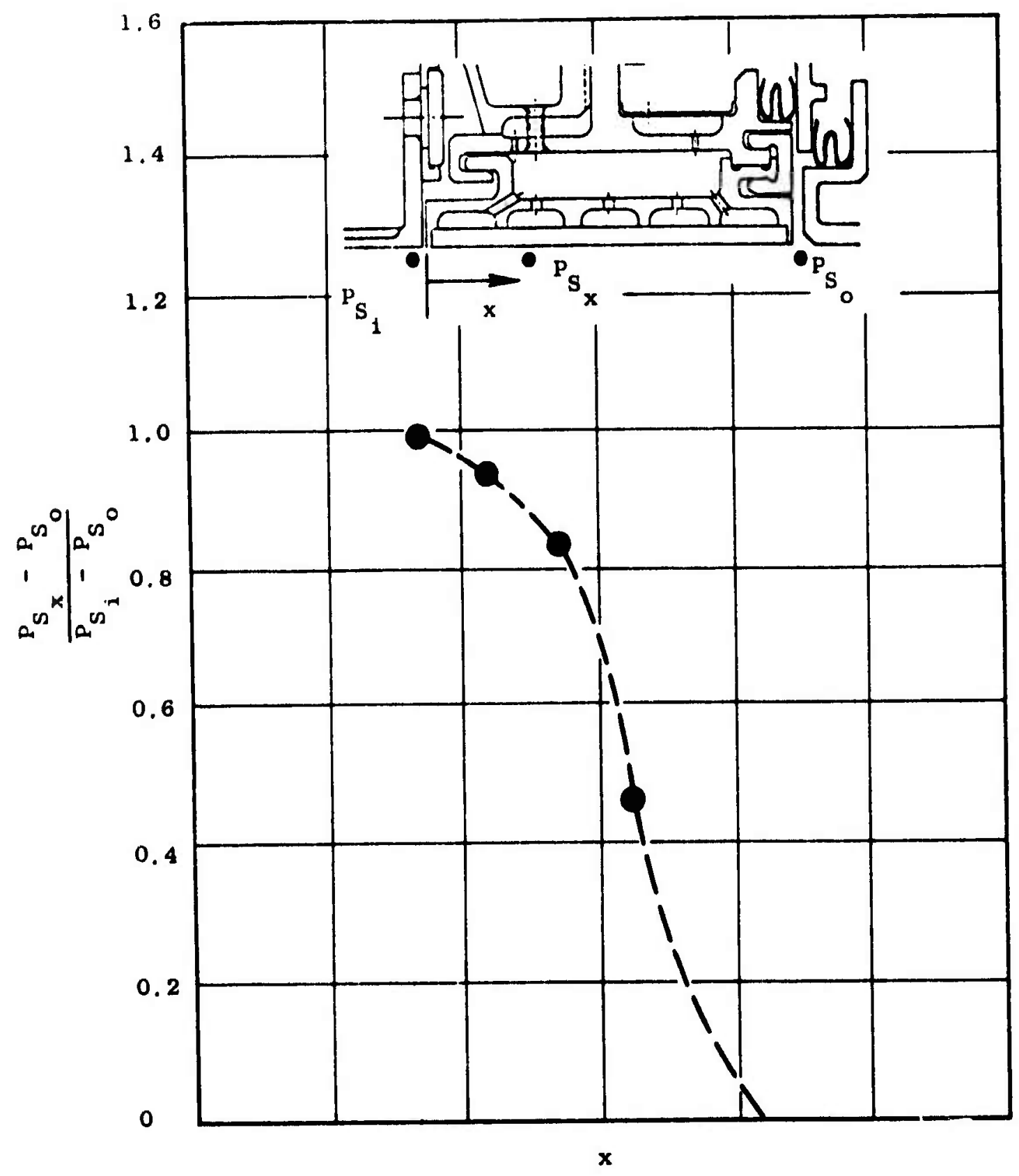

F1gure 43. Measured Shroud stat1c Preseure D1stributions. 


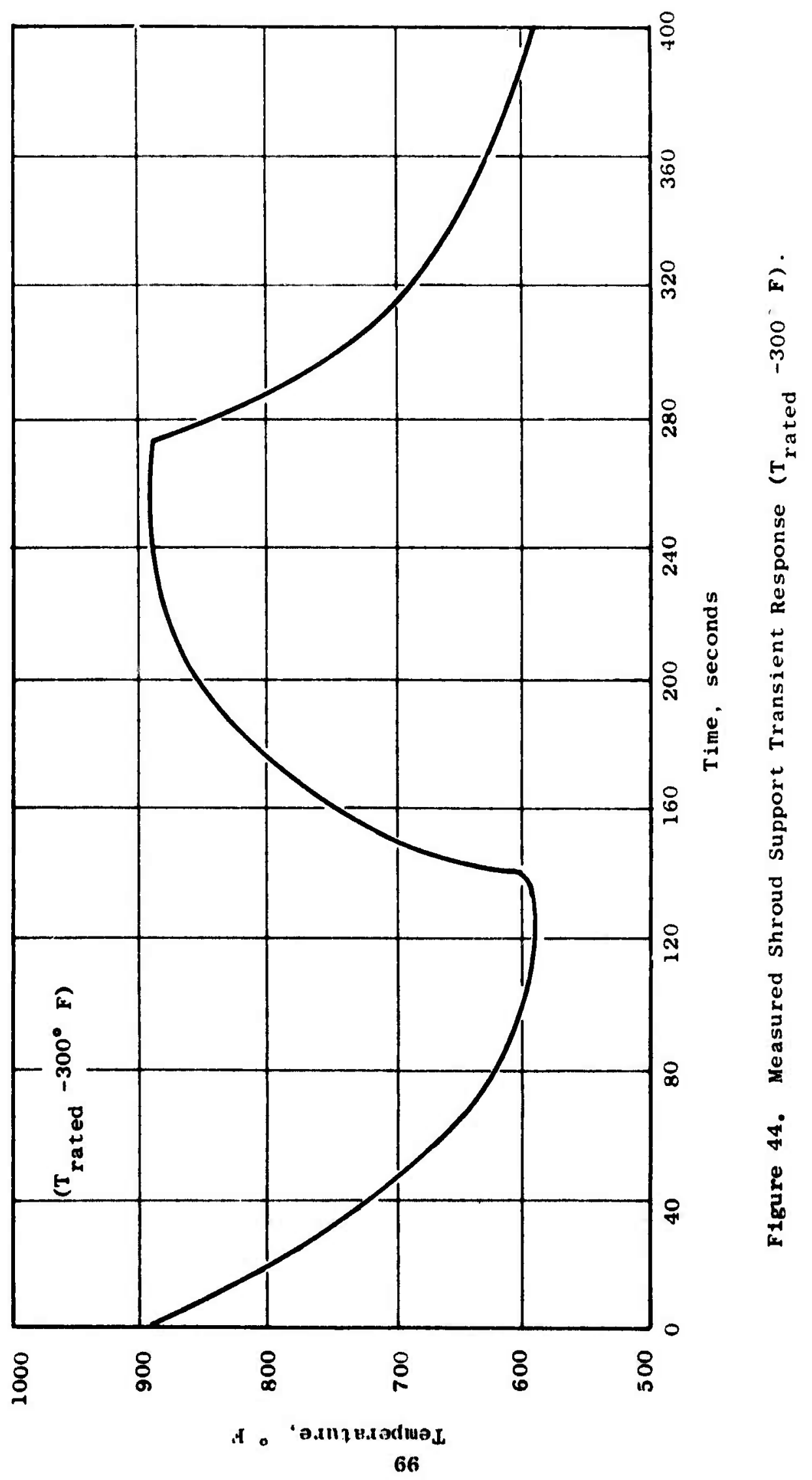


The design point for the shrouds was the steady-state rated $T_{4}$ condition with one atmosphere engine inlet pressure, $300^{\circ} \mathrm{F}$ engine inlet temperature, nominal $\mathrm{A}_{4}$ setting, and $15,286 \mathrm{rpm}$ rotor speed, as shown in Table 2. At this condition, the shrouds were exposed to hot streaks of rated $\mathrm{T}_{4}$ minus $400^{\circ}, \mathrm{F}$. The shrouds were designed to withstand temperatures $120^{\circ} \mathrm{F}$ higher than anticipated hot streak temperatures as a margin to allow for any manufacturing variations or engine deteriorations that might slightly alter the cooling performance or heat levels in the gas stream. The designs were based on a $120^{\circ} \mathrm{F}$ margin added to the local gas hot streak recovery temperature, which decreases as work is extracted from the gas stream passing through the turbine as shown in Figure 45.

The calculation of the design cooling supply system performance indicated that the air temperature would increase by $50^{\circ} \mathrm{F}$ in traveling from the compressor discharge to the turbine shrouds. At the same time, it was calculated that the air pressure woulo decrease by eight psi.

The air turbine tests reported in Reference 1 showed that the gasstream static pressure decreases axially on the shroud surface as shown in Figure 46. The cooling air metering system on the ATEST shrouds was sized to supply enough pressure in each of the axial zones on the shroud, as shown in Figures 47 and 48 , to provide sufficient cooling without backflowing in the shroud leading edge regions.

The design heat loads on the shrouds were calculated for a flat plate in turbulent flow with the trajectory of the gas as shown in Figure 49. The heat loads on the film-1mpingement-cooled shrouds then were adjusted (based on the air turbine tests of the solid uncooled shrouds) to provide a 30 percent increase toward the shroud trailing edge as shown in Figure 50 . The heat loads on the transpiration-cooled shrouds were adfusted (based on the turbine results reported in Reference 1) to provide a 160 percent increase at the shroud leading edge as shown in Figure 51.

The predicted temperature distributions on the transpiration-cooled shrouds at design conditions are shown in Figure 52 with a maximum surface temperature of $1750^{\circ} \mathrm{F}$ on the gas-stream side surface. The predicted temperatures on the film-impingement-cooled shrouds are shown in Figure 53, with a maximum surface temperature of about $1850^{\circ} \mathrm{F}$. These predictions assumed Reference $1 \mathrm{film}$ effectiveness levels and were reduced by 25 percent to account for any unknowns associated with engine operation, such as turbulence levels and blade proximity.

The shroud segments and support system were designed to control blade tip clearance so that a rub would not occur during a transient and, at the same time, to maintain the steady-state clearance close enough for good turbine efficiencies. The predicted shroud support cyclic temperature response during repeated cycling with a $15-$ second decel from rated $T_{4}$ to idle, a 2-minute hold at idle, a 10-second accel to rated $\mathrm{T}_{4}$, and a 2-minute hold at rated $\mathrm{T}_{4}$ is shown in Figure 54. Under these conditions, the turbine runs with a predicted steady-state clearance of 0.024 inch and is line-to-line during a portion of the cyclic transient operation. 
Table 2. Shroud Design Cycle Conditions.

\begin{tabular}{|c|c|}
\hline P2 ${ }_{c}$, Pressuro at Core Engine Inlet, psia & 14.7 \\
\hline $\mathrm{T} 2_{\mathrm{c}}$, Temperature at Core Englne Inlet, ${ }^{\circ} \mathrm{F}$ & 300 \\
\hline W2, Airflow at Core Englne Inlet, $1 \mathrm{bs} / \mathrm{sec}$ & 44.1 \\
\hline$P_{3}$, Pressure at Compressor Discharge, psia & 132 \\
\hline $\mathrm{T}_{3}$, Temperature at Compressor Discharge, ${ }^{\circ} \mathrm{F}$ & 1080 \\
\hline $\mathrm{P}_{4}$, Pressure at Turbine Rotor Inlet, psta & 124 \\
\hline $\mathrm{T}_{4}$, Temperature at Turbine Rotor Inlet & Rated \\
\hline$W_{4}$, Gas Flow into Turbine Rotor, $1 \mathrm{bs} / \mathrm{sec}$ & 34.0 \\
\hline$P_{4}$, Static on Shroud, psia & 58 \\
\hline $\mathrm{P}_{5.1}$, Static on Shroud, psia & 29 \\
\hline $\mathrm{T}_{4}$, on Shroud, ${ }^{\circ} \mathrm{F}$ & Rated -400 \\
\hline$T_{\text {cool }}$, at Shroud, ${ }^{\circ} \mathrm{F}$ & 1130 \\
\hline$P_{\text {cool }}$, at Shroud, psia & 124 \\
\hline $\mathrm{N}$, Turbine Speed, $\mathrm{r}$ pm & 15,286 \\
\hline
\end{tabular}




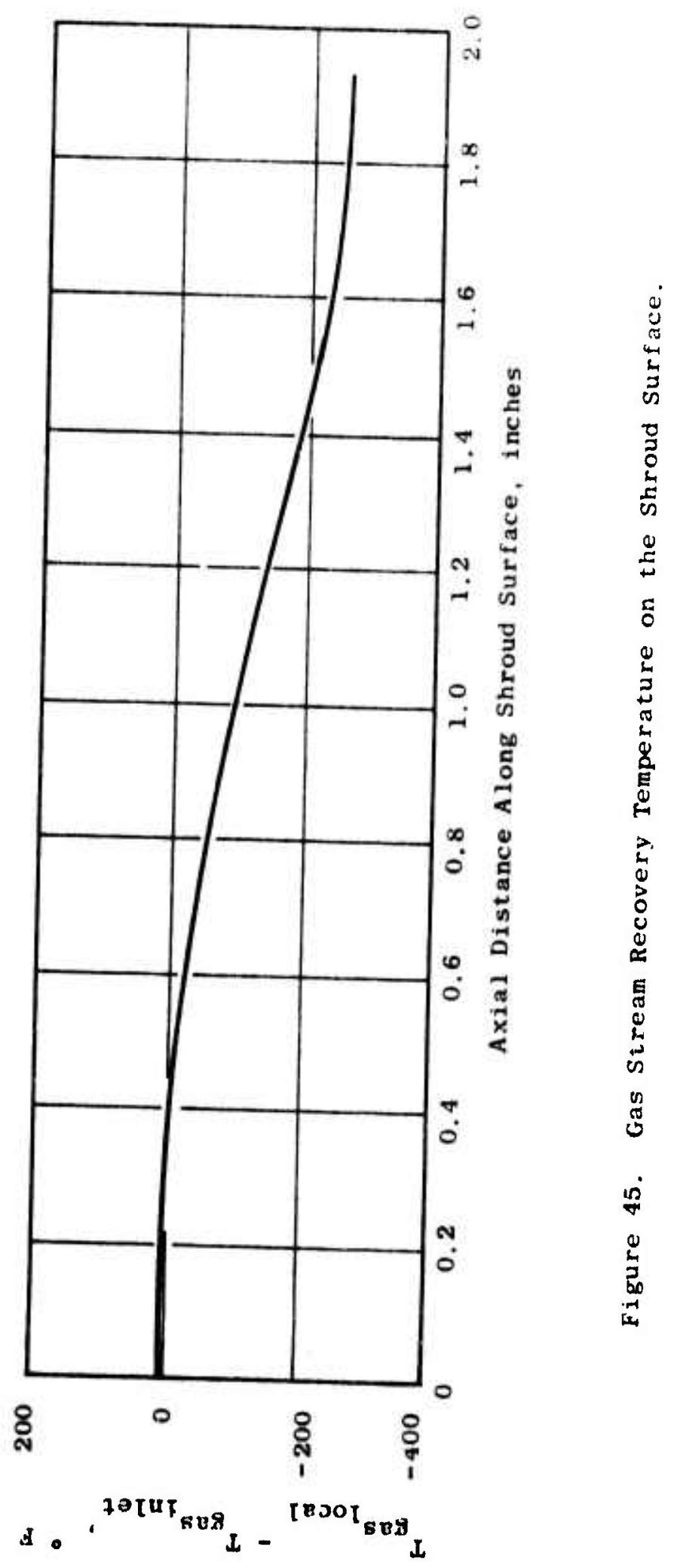




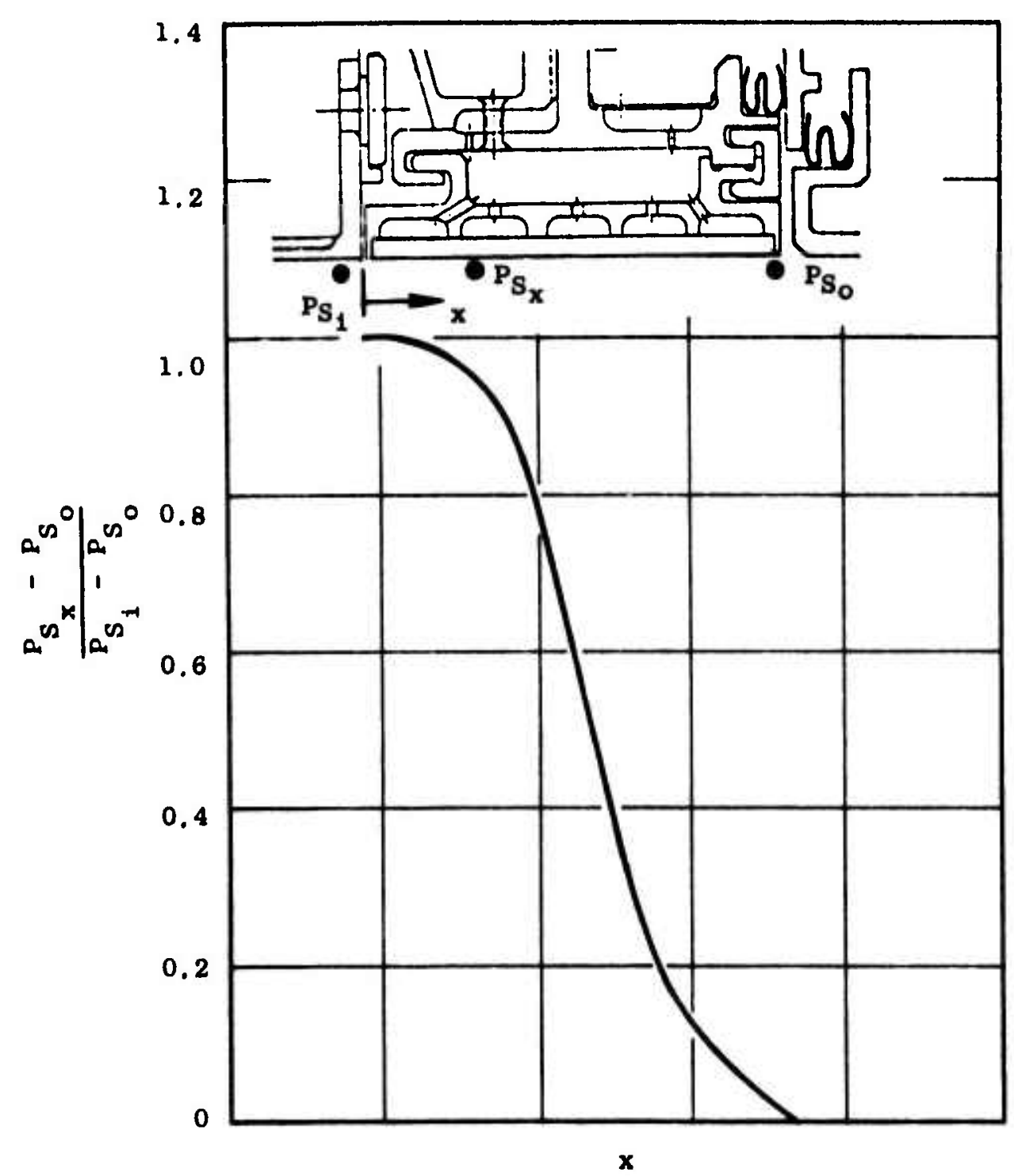

Figure 46. Shroud Design Static Pressure Distribution. 


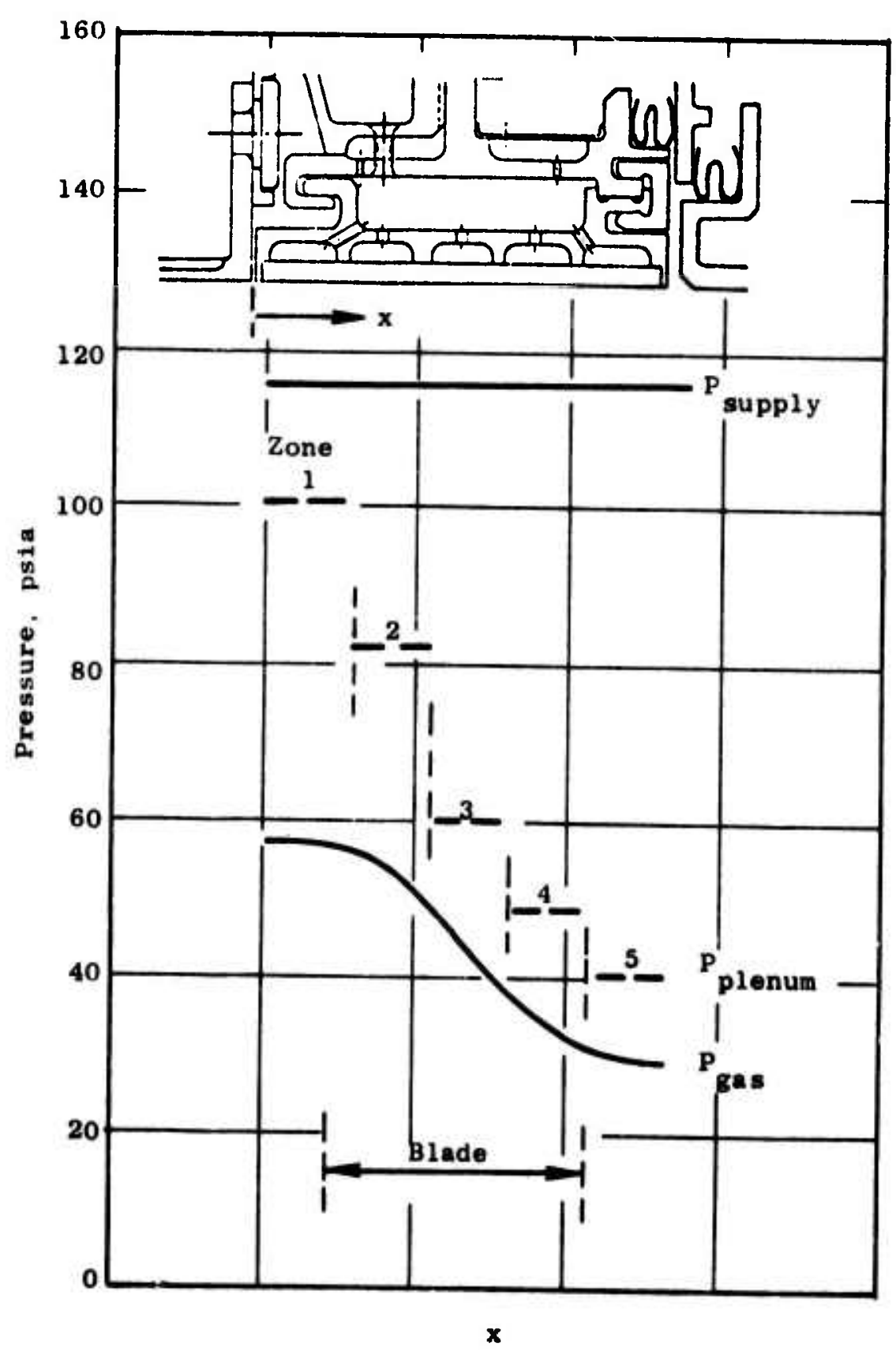

Figure 47. Design Point Cooling Air Pressure Drop Across Transpiration-Cooled Shroud. 


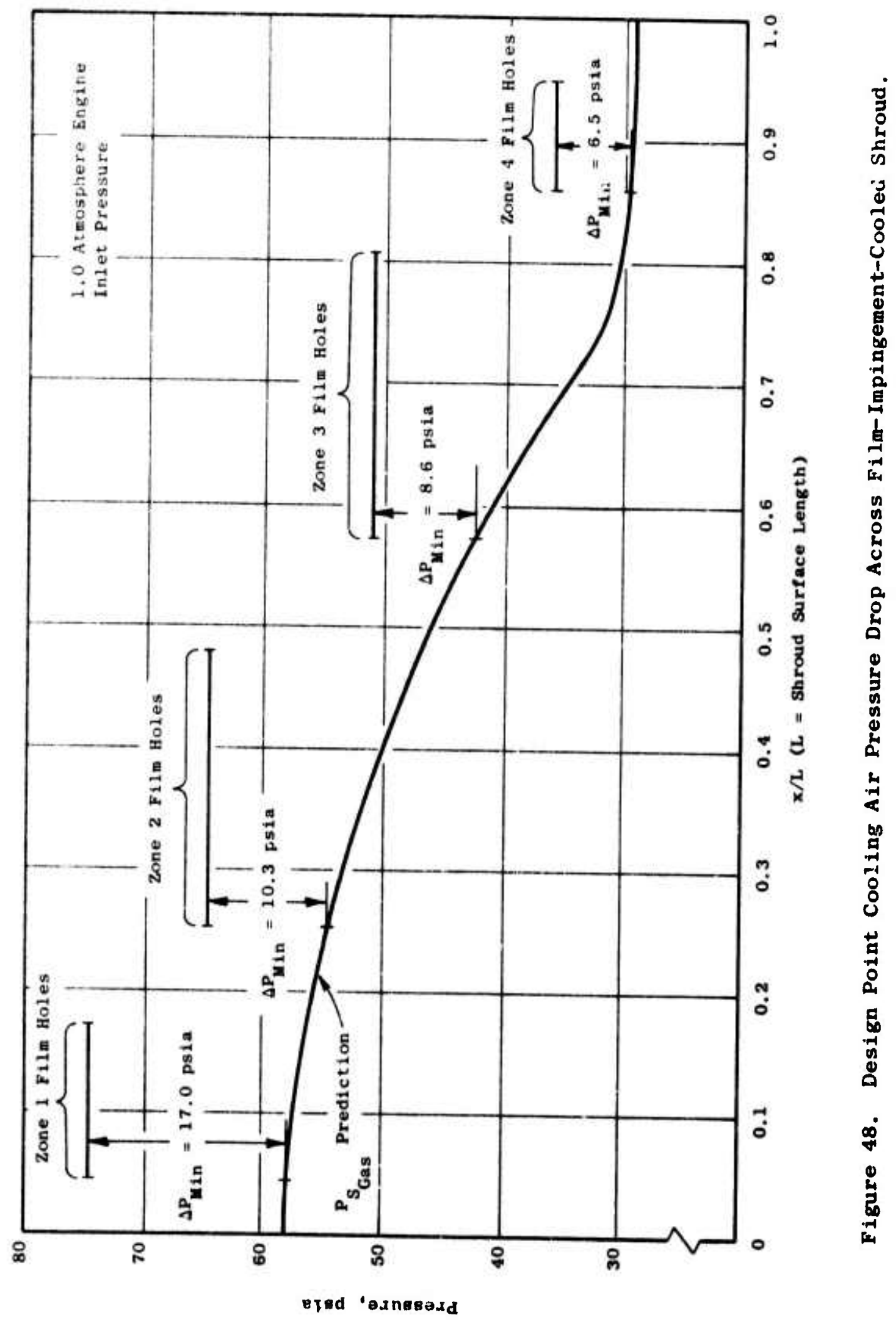




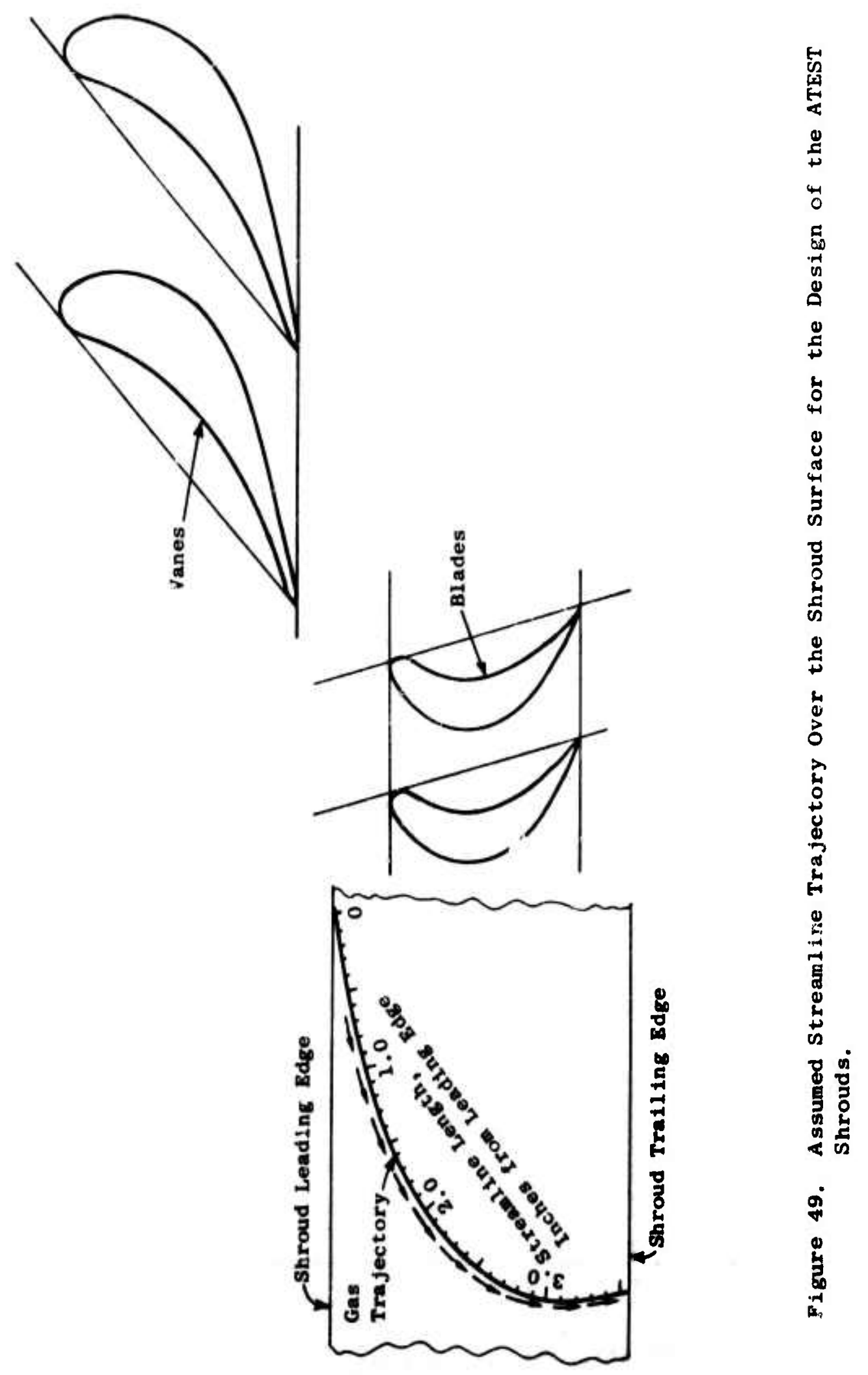




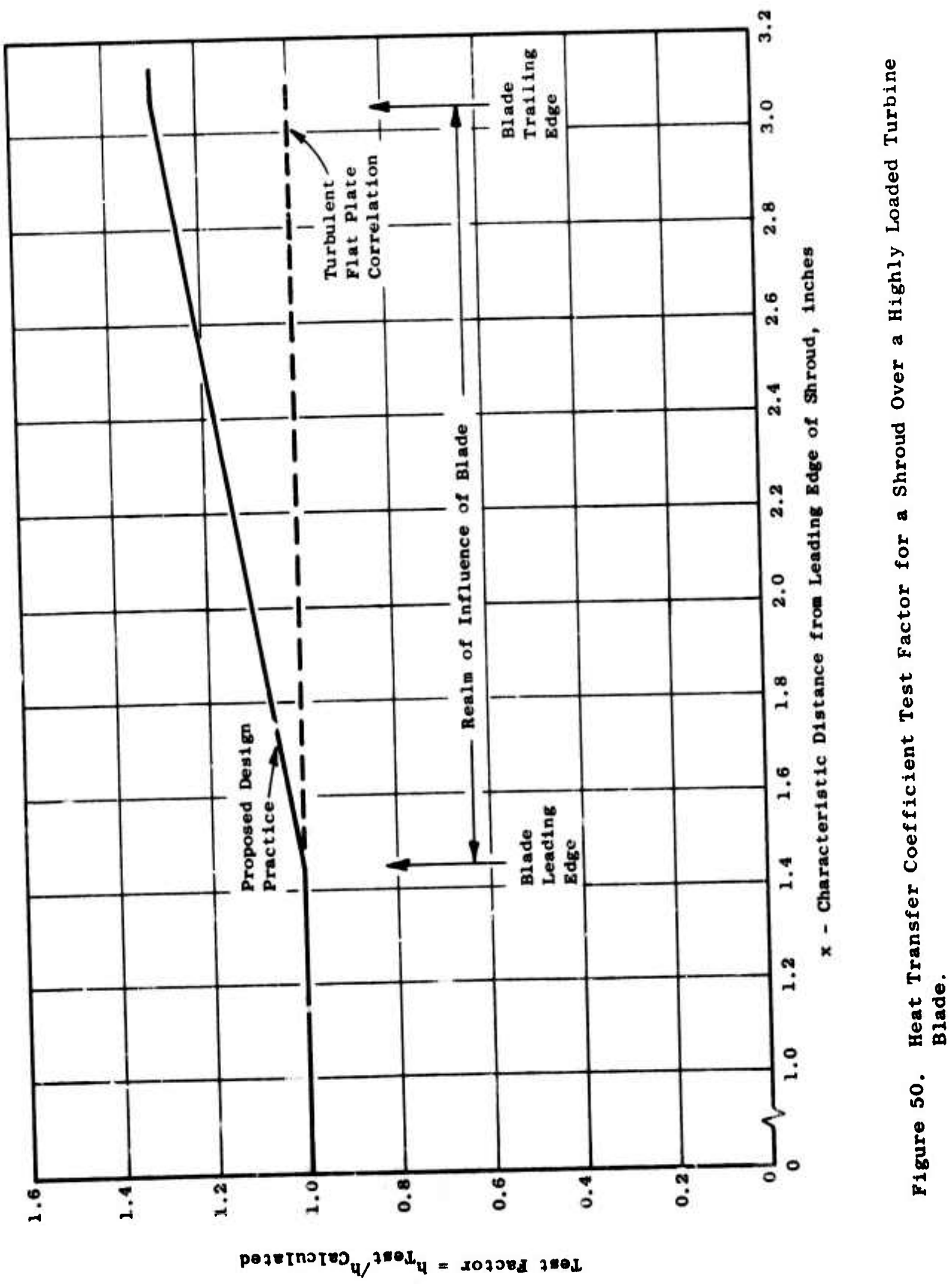




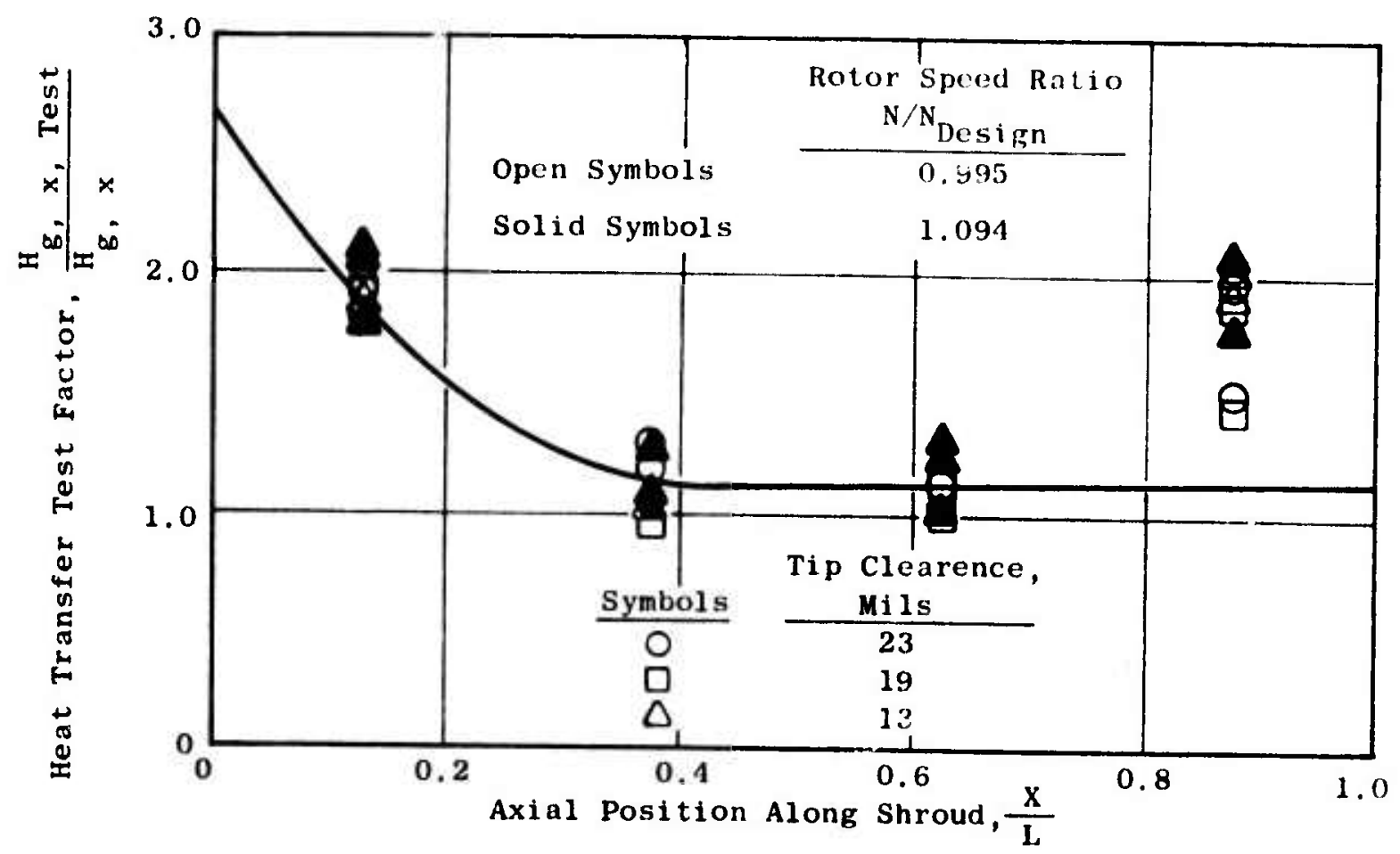

Figure 51. Heat Transfer Test Factor Versus Axial Position Along the Shroud. 


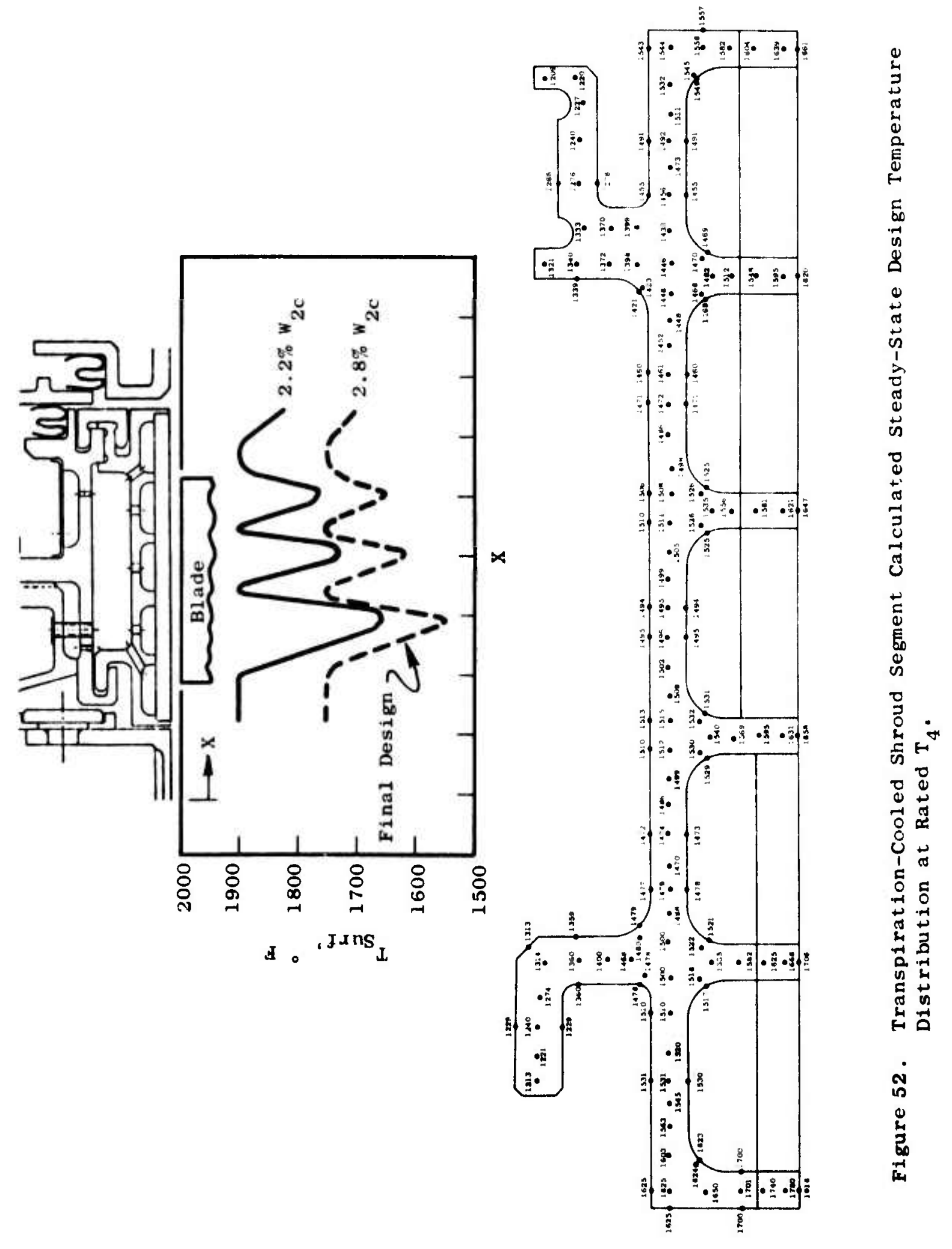




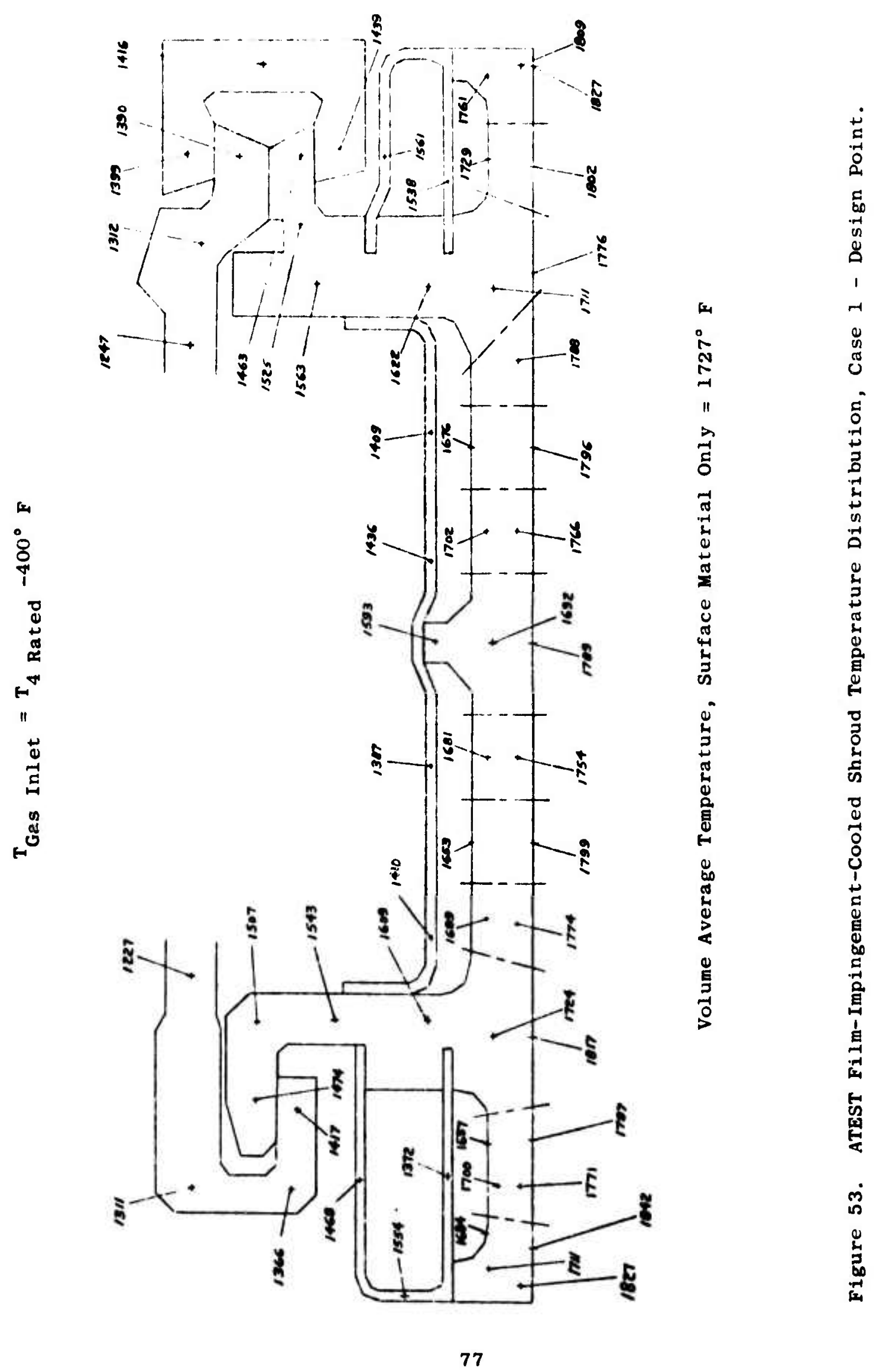




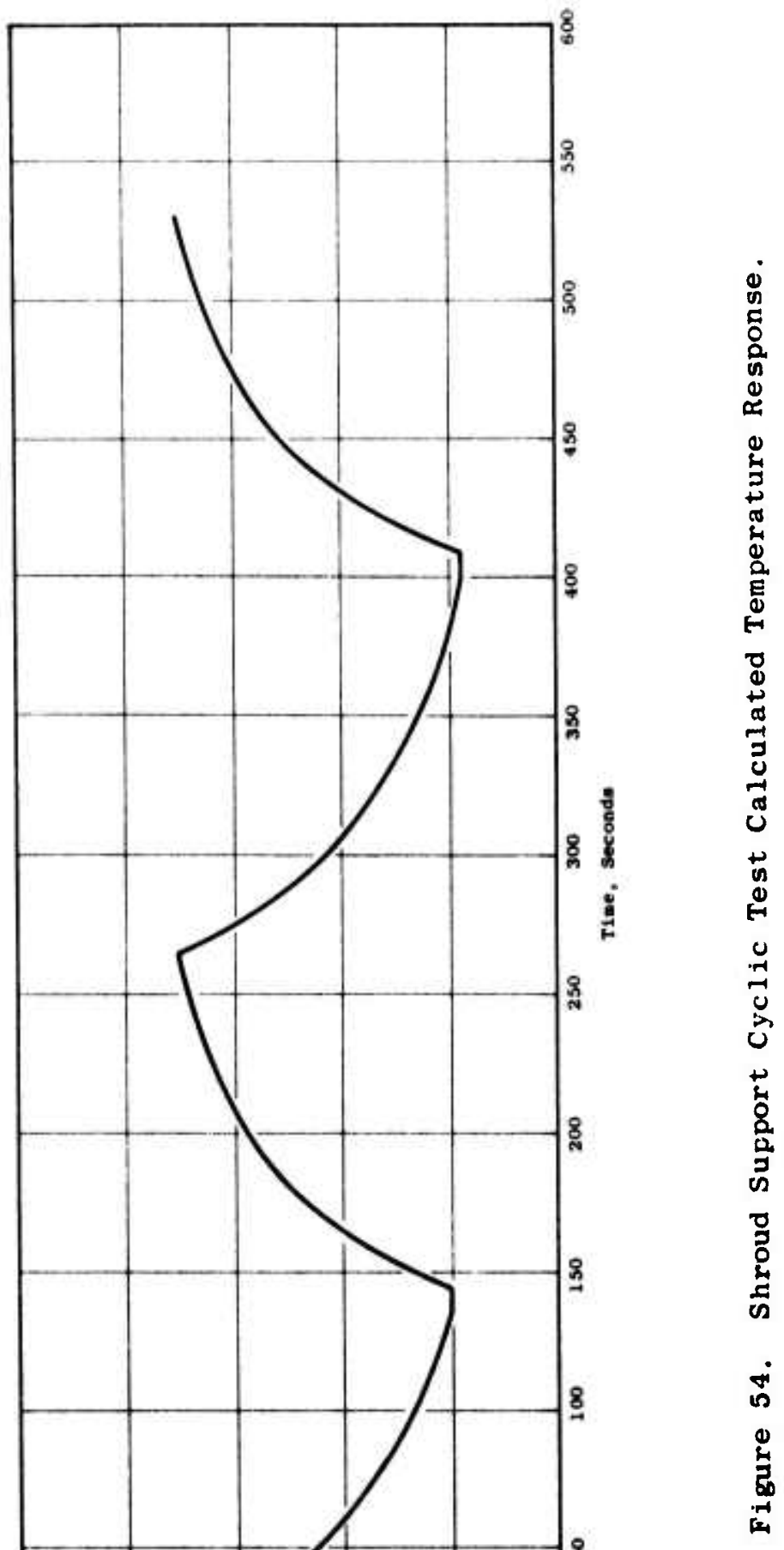


The GE14/J1B3 demonstrator engine was tested at cycle conditions somewhat different from the design cycle. The shrouds were not all exposed to the same gas stream temperature, since hot and cold streaks are present in the engine. The amount of cooling air to various zones of the shrouds was not always at the design values due to manufacturing tolerances, flow coefficient variations, and gas stream pressure distribution shifts. Therefore, in order to judge the cooling performance of the shrouds so as to evaluate the design technique, it is necessary to: (1) adjust the predicted pressures and temperatures to reflect actual hardware configuration and engine operation; and, (2) to compare these adjusted predictions with measurements.

The rated $\mathrm{T}_{4}$ demonstration point for the engine was actually achieved at a lower-than-design engine speed of $14,265 \mathrm{rpm}$, with a 1.36 atmosphere engine inlet as shown in Table 3. The lower-than-design speed resulted in a lower-than-design compressor discharge temperature. Combining this with the heat loss to the engine casing results in a $184^{\circ} \mathrm{F}$ lower shroud cooling air temperature. This lower cooling air temperature reduced the shroud segment temperatures by about $115^{\circ} \mathrm{F}$ f :om design.

The GE14/J1B3 demonstrator, like other gas turbine engines, does not provide uniform gas temperatures into the turbine; 1.e., there are hot and cold streaks present in the gas stream. Since the location of these streaks is not well defined, it is necessary to design all the shroud segments to be adequately cooled in case they are exposed to one of the hot streaks. This means that shroud areas that are not in the hot streak will be oven cooled. Shroud areas that are in streaks which are $200^{\circ} \mathrm{F}$ cooler than the hot streaks will run approximately $60^{\circ} \mathrm{F}$ cooler than the design predicted temperatures.

Figures 55 and 56 show that, due to manufacturing tolerances and flow coefficien: variances from design, the instrumented shroud flows varied from design to 47 percent above design in individual shroud segment zones. The supply pressure drop to the shrouds was only about five psi instead of the predicted eight psi. Thus, more supply pressure was available at the shrouds, which increased the cooling flow. In addition, the gas stream pressure distribution was shifted aft as shown in Figure 57, which altered the cooling flow distribution within the shrouds. These higher-than-design flows lowered the design predicted temperatures of the shrouds by $65^{\circ}$ to $180^{\circ} \mathrm{F}$.

The combined effects discussed above lead to expected temperatures that are $240^{\circ}$ to $355^{\circ} \mathrm{F}$ less than the design predictions. In order to evaluate the validity of the design procedure developed in Reference 1 and applied in Reference 2, the shroud design temperatures were reevaluated based on the Reference 1 design theory but using actual engine hardware configurations, test operating conditions, and allowing for a band of predictions to account for the unknown hot and cold streaks. It is seen in Figure 58, then, that the film-impingement-cooled shrouds performed within the band of revised predictions, indicating that the design theory is valid. The transpiration-cooled shrouds likewise performed as would be predicted, except in the forward two zones as shown in Figure 59. The forward zone temperature 
Table 3. Shroud Test Rated $\mathrm{T}_{4}$ Demonstration Conditions.

\begin{tabular}{|c|c|c|}
\hline & $\begin{array}{l}\text { Rated } \mathrm{T}_{4} \text { Test } \\
\text { Conditions }\end{array}$ & $\begin{array}{l}\text { Design } \\
\text { Conditions }\end{array}$ \\
\hline P2, Pressure at Core Engine Inlet, psia & 19.9 & 14.7 \\
\hline T2 ${ }_{c}$, Temperature at Core Engine Inlet, ${ }^{\circ} \mathbf{F}$ & 301 & 300 \\
\hline W2, Air Flow at Core Engine Inlet, lhs/sec & 53.3 & 44.1 \\
\hline $\mathrm{P}_{3}$, Pressure at Compressor Discharge, psia & 150.6 & 132.0 \\
\hline $\mathrm{T}_{3}$, Temperature at Compressor Di scharge, ${ }^{\circ} \mathrm{F}$ & 956 & 1080 \\
\hline$P_{4}$, Pressure at Turbine Rotor Inlet, psia & 142.5 & 124.0 \\
\hline $\mathrm{T}_{4}$, Temperature at Turbine Rotor Inlet & Rated & Rated \\
\hline$w_{4}$, Gas Flow into Turbine Rotor, $1 \mathrm{bs} / \mathrm{sec}$ & 41.1 & 34.0 \\
\hline$P_{4}$, Stat & 72.5 & 58.0 \\
\hline$P_{5.1}$, Static on Shroud, psia & 39.1 & 29.0 \\
\hline $\mathrm{T}_{4}$, on Shroud, ${ }^{\circ} \mathrm{F}$ & Rated - 400 to 600 & Rated -400 \\
\hline$T_{\text {cool }}$, at Shroud, ${ }^{\circ} \mathrm{F}$ & 946 & 1130 \\
\hline $\mathrm{P}_{\text {cool }}$, at Shroud, psia & 146 & 124 \\
\hline$N$, Turbine speed, rpm & 14265 & 15286 \\
\hline
\end{tabular}



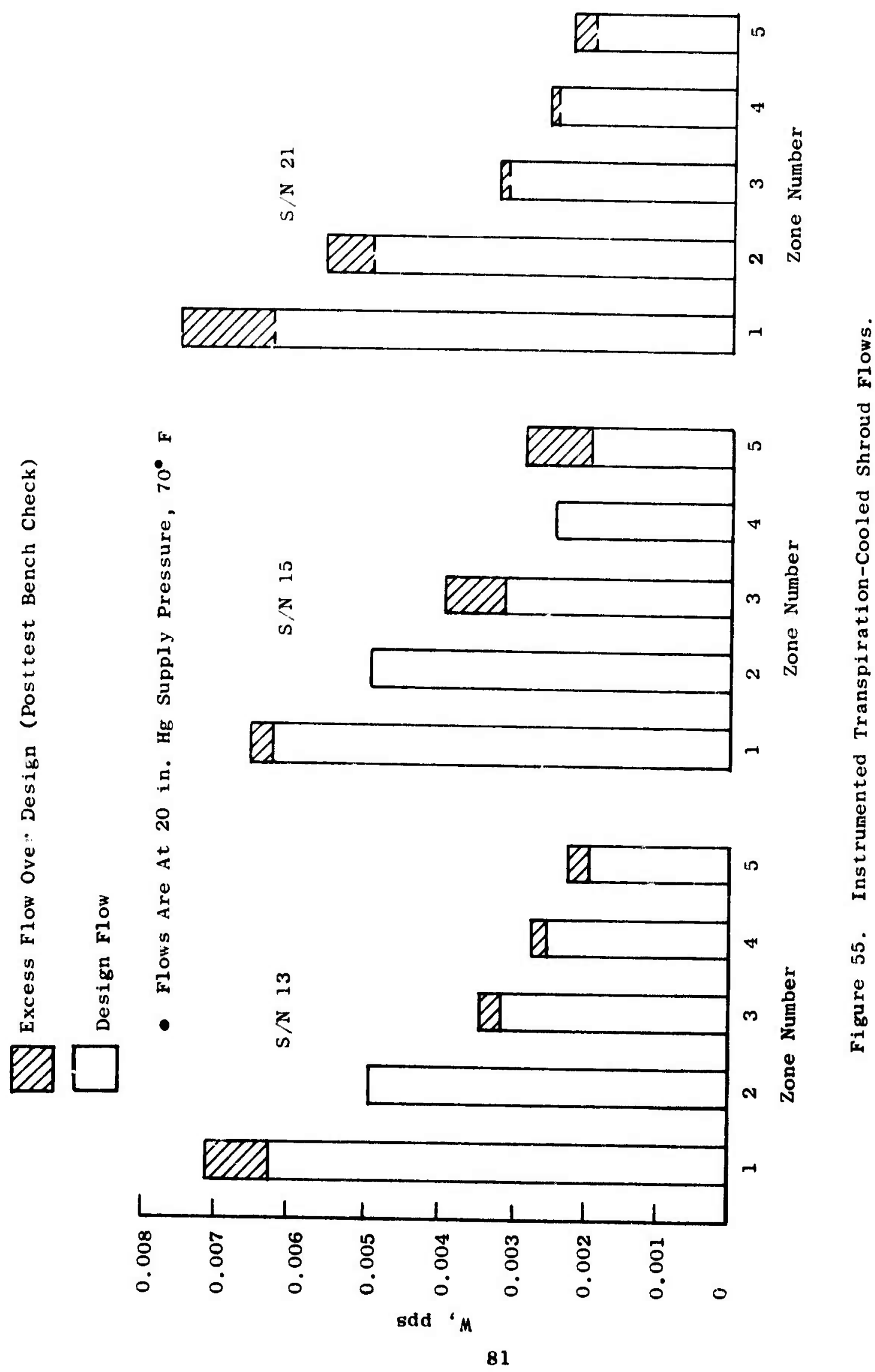


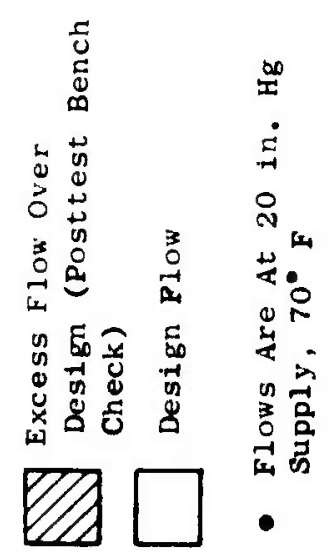

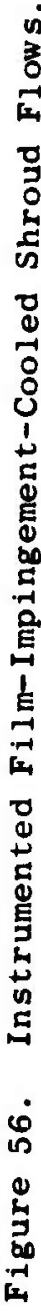

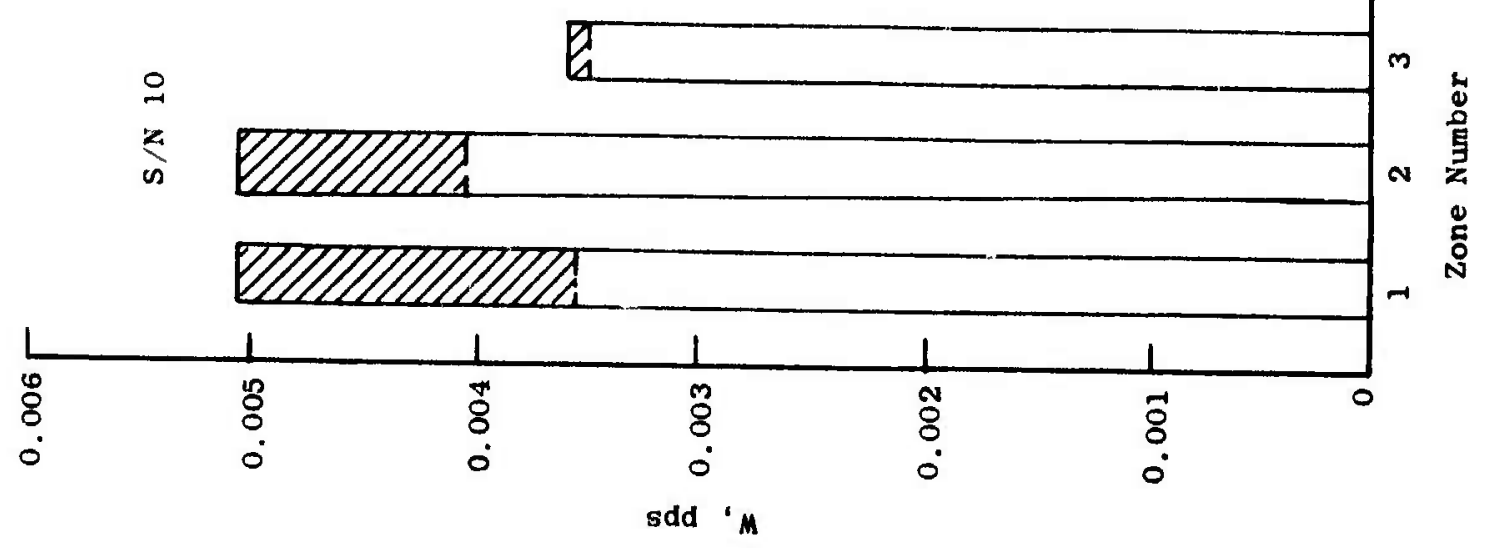




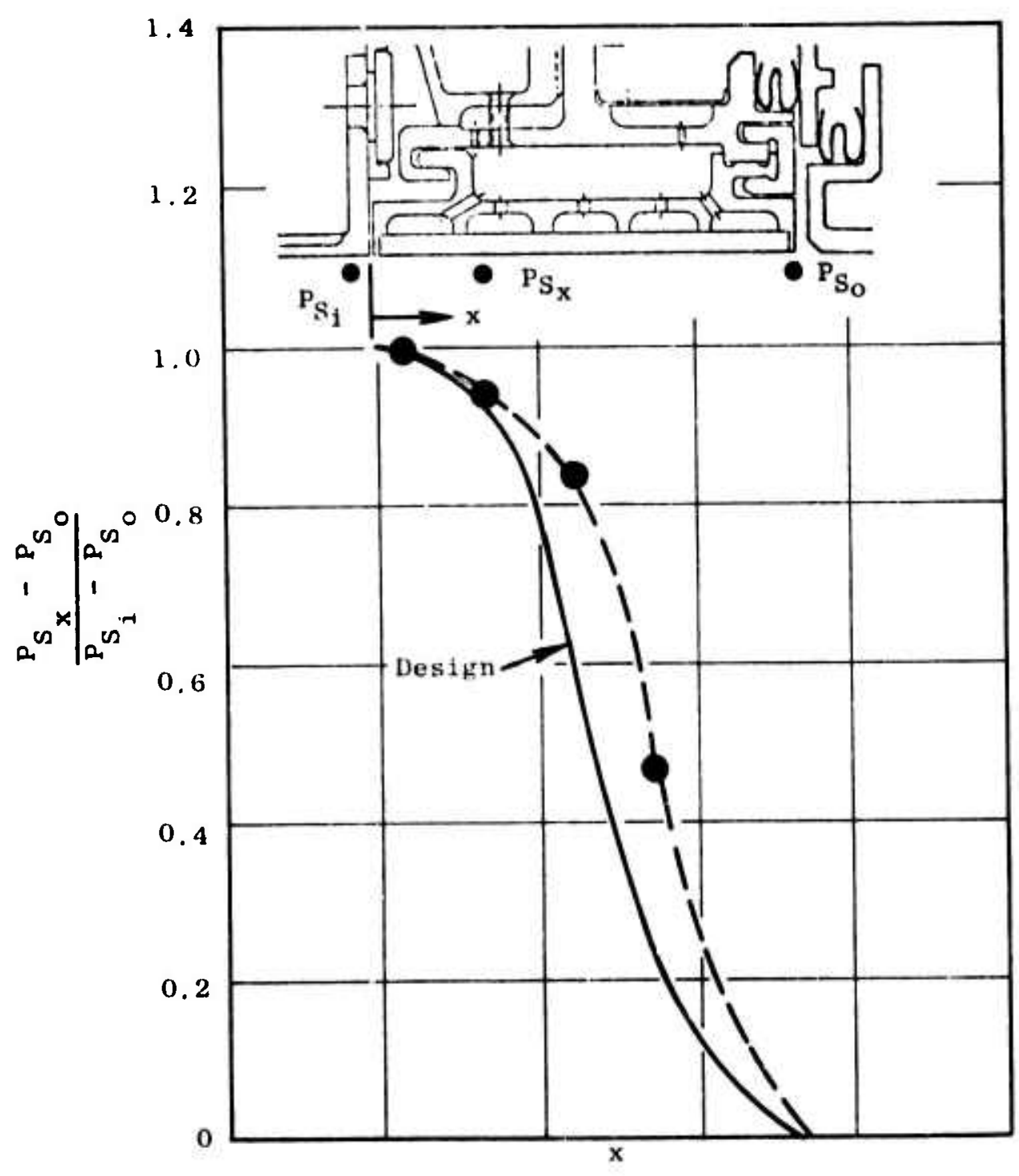

Figure 57. Comparison Of Shroud Design and Measured Static Pressure Distribution. 


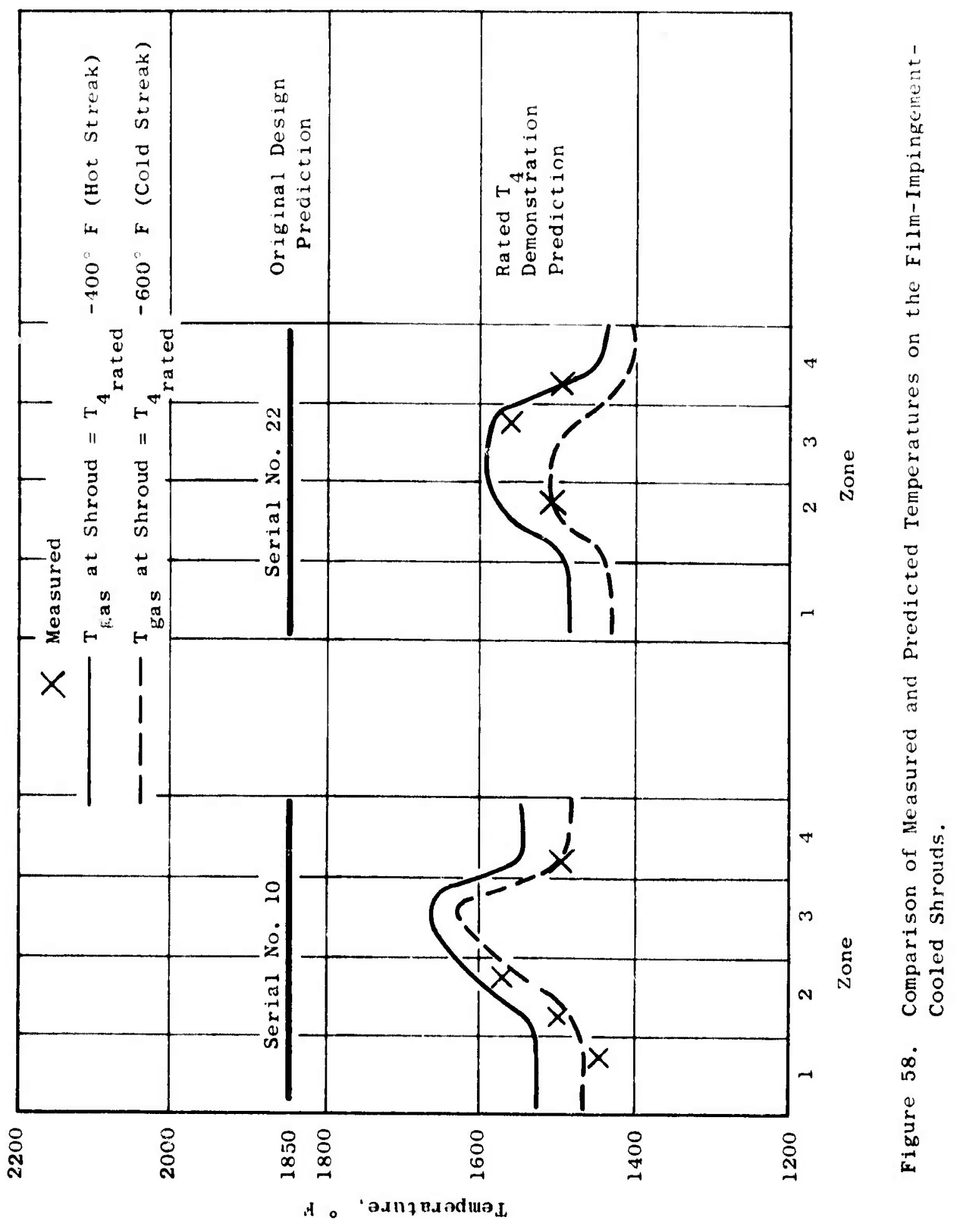




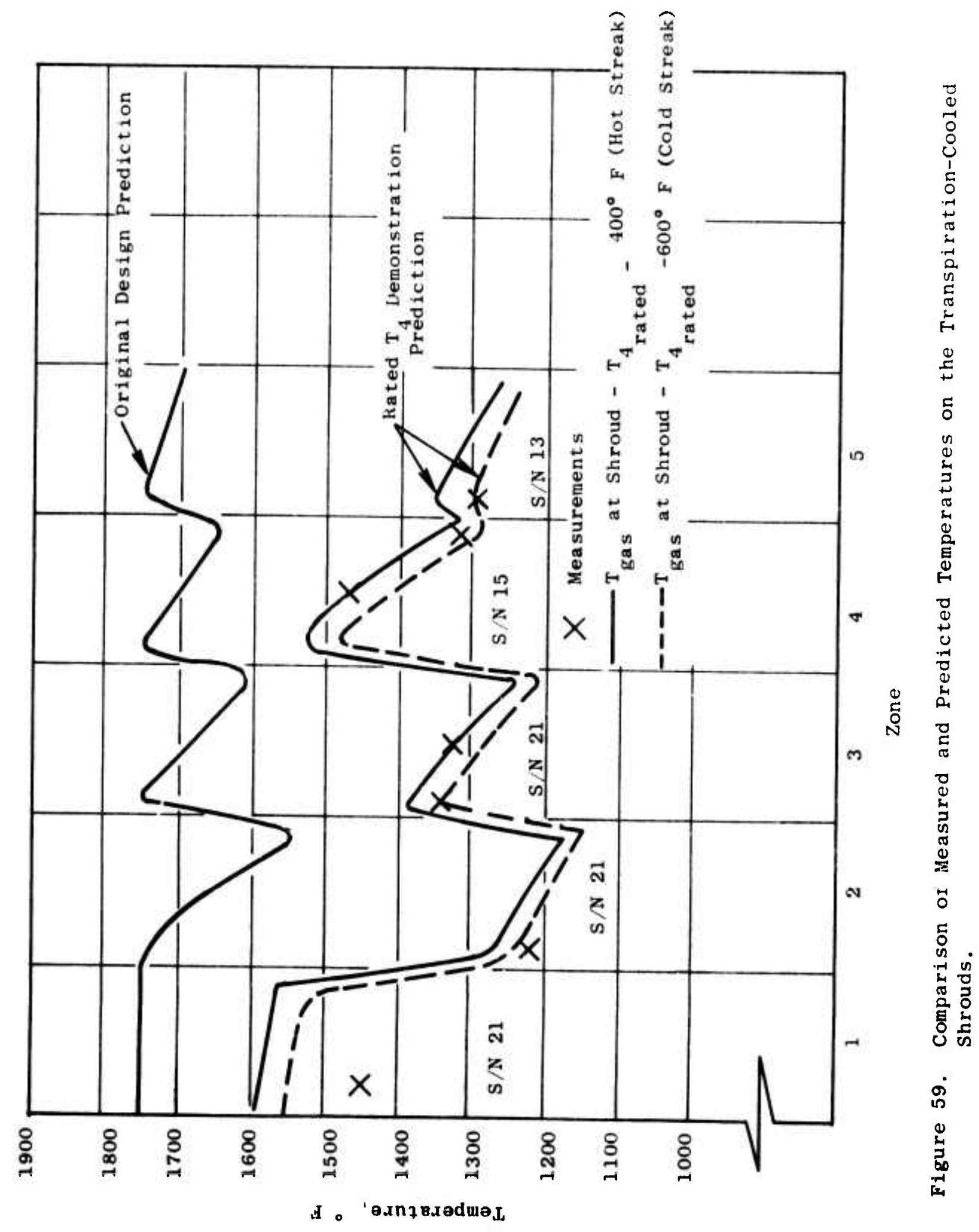


was about $140^{\circ} \mathrm{F}$ lower than predictions, indicating a better-than-design cooling performance. The measured temperatures in the forward zones would about 23 percent from design.

The steady-state cooling effectiveness of the shroud support was about as predicted for the rated $\mathrm{T}_{4}$ demonstration point shown in Figure 60 . as shown in Figure 6l. however, is slightly faster than was predicted 
- Temperatures At Rated $\mathrm{T}_{4}$ Demonstration Conditions

- Temperatures Are In ${ }^{\circ} \mathrm{F}$

$\mathrm{XxX}=$ Measured

$(X X X)=$ Predicted

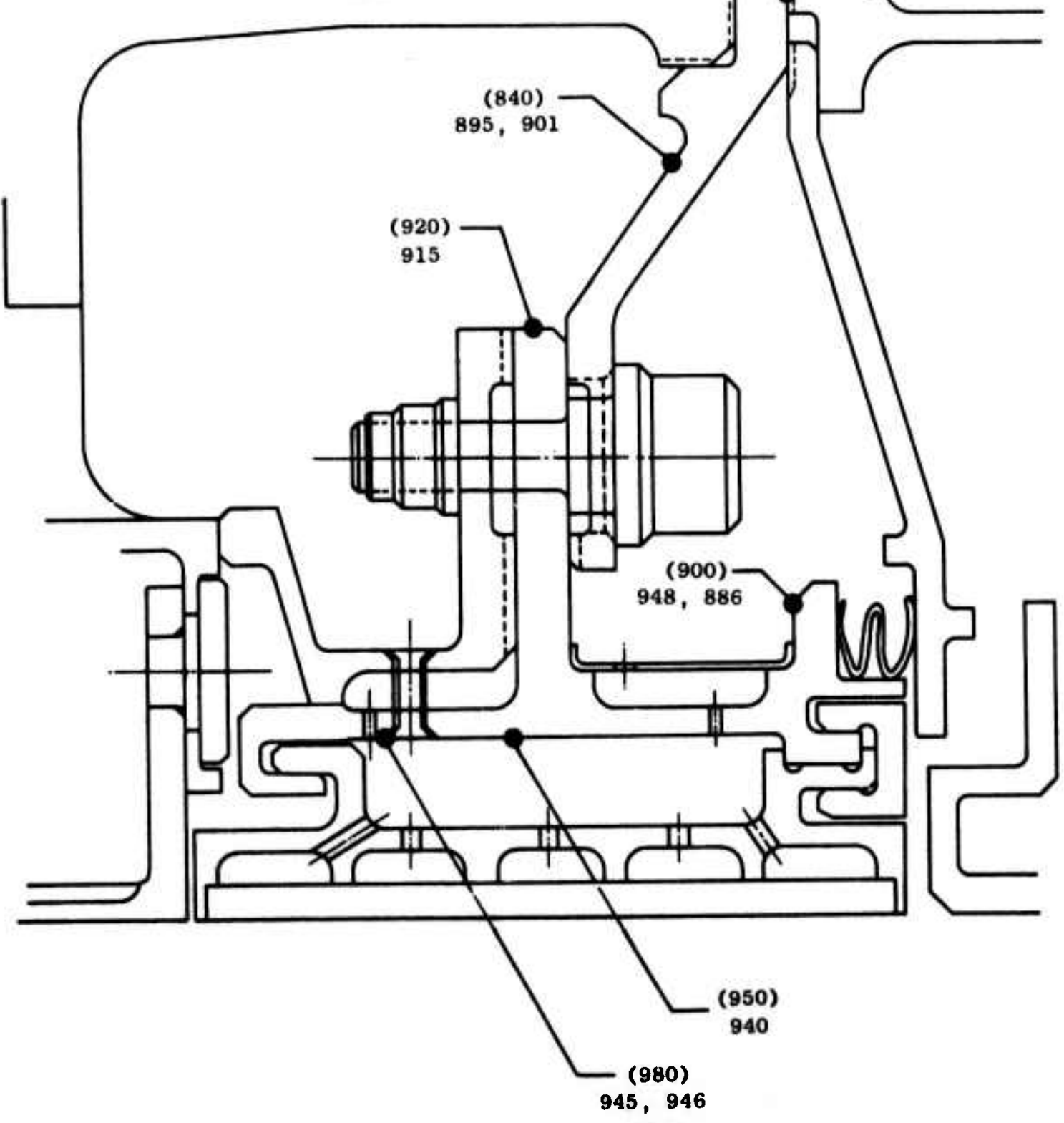

Figure 60. Comparison of Predicted and Measured Shroud Support Temperatures. 


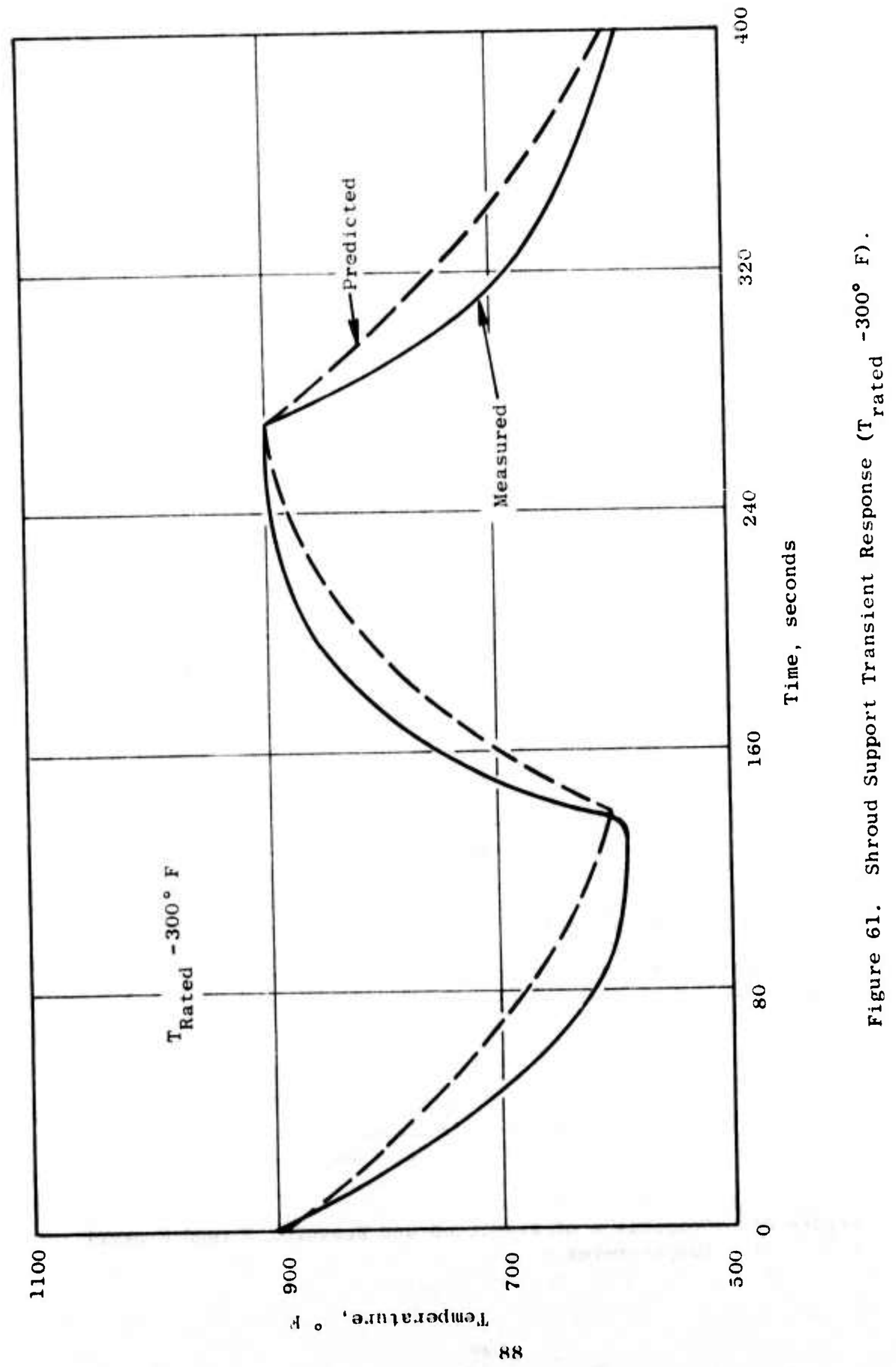


Both the transpiration-cooled and the film-impingement-cooled shroud segments were in excellent condition following the 121 hours of demonstrator engine testing. A sector of the shroud assembly after testing is shown in Figure 62. Figures 63 and 64 show typical shroud segments of each type upon removal from the engine. A light oxide deposit was noted on the segments, but not severe enough to cause hole plugging. The oxidation seemed to be most prevalent in the axial location corresponding to blade squealer tip erosion on the transpiration-cooled shrouds. The major discrepancy observed at teardown was the loss of the axial and circumferential seals between segments (Figure 65). Several of the seals were found and examined. It appeared that the seals vibrated between segments (due to blade passing impulses) as worn edges were seen. With the seals being worn down, the vibrations eventually caused the seals to fall down between the segments.

The segments were Zyglo inspected to determine if cracking had occurred. The only indications found were on the transpiration-cooled segments which had rub pins welded in place. The cracks were located on the back surface of the segments, and a typical crack is shown in Figure 66. However, these cracks were observed at the time the pins were welded in place, and were not caused during engine operation. Propagation of the cracks was minimal during testing.

Evidence of a blade tip rub was seen on five film-impingement-cooled shroud segments which were located at the $2: 00,5: 00,8: 30$, and $10: 30$ o'clock positions. Although the rub was light, material scabbing and smearing was evident. No hole plugging was observed due to this smearing.

The eight rub pins installed in the segments for tip clearance indication were measured at teardown on a rotating table with a dial indicator. The four pins installed in the film-impingement-cooled shroud segments were rubbed flush to the surface. The remaining four pins (installed in the transpiration-cooled shroud segments) were measured with a height gage at $0.12,0.007,0.006$, and 0.005 inch, respectively. (The locations of the eight pins are shown in Figure 67).

The wear pin data correlate well with calculated tip clearance values based on engine test data as presented in Table 4. The individual pins, as measured however, do not describe the precise circular path of the blade tip. These variations may be due in part to a number of factors which are difficult to quantitatively evaluate with precision, such as, measurement accuracy (estimated at $\pm 0.004^{\prime \prime}$, axial location differences between wear pins on the transpiration and film-impingement-cooled shrouds, and local pin damage due to the loss of shroud segment end seals. 


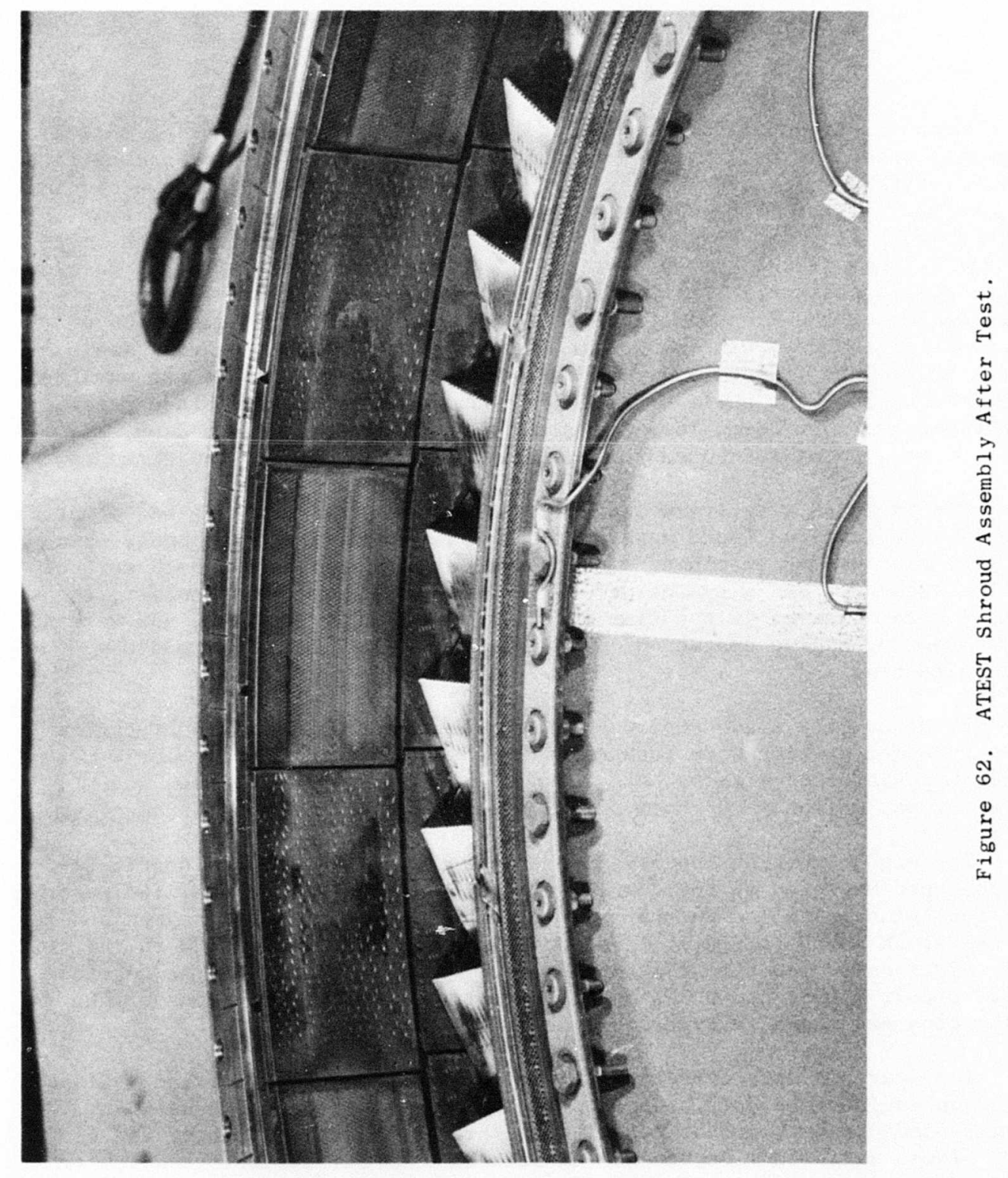




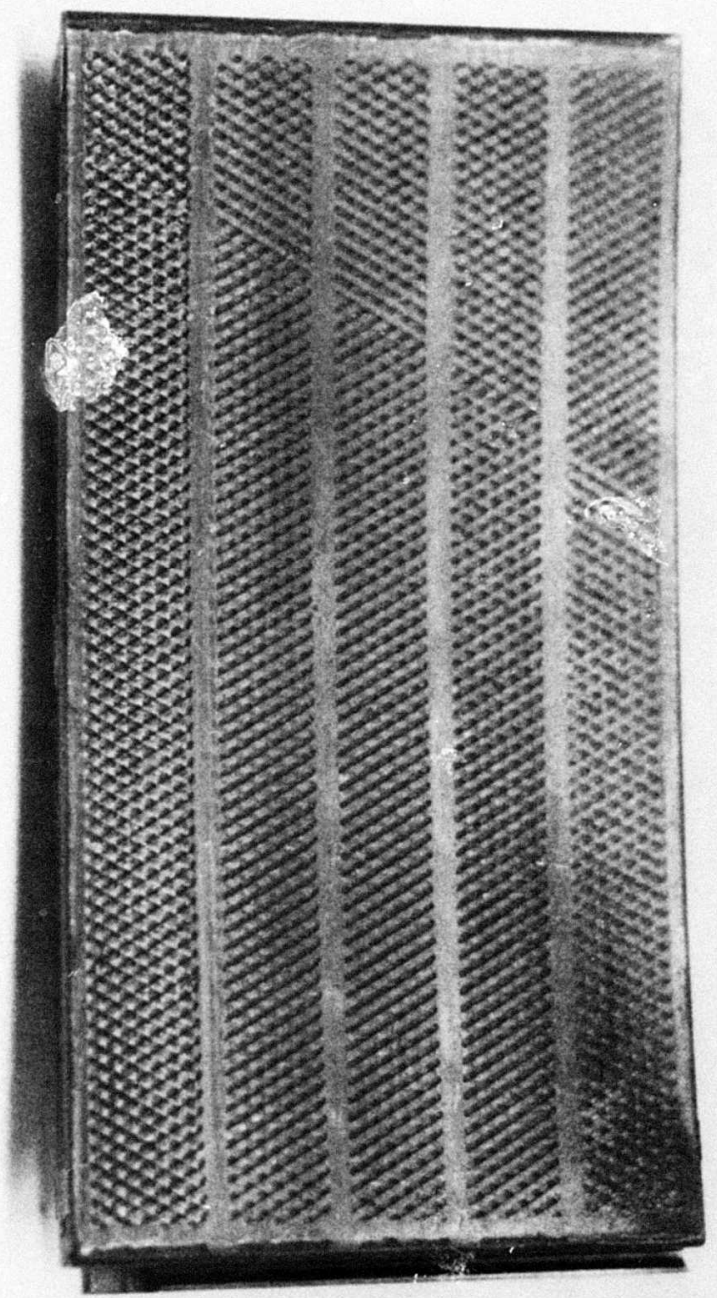

Figure 63. Transpiration-Cooled Shroud Segment After Test. 


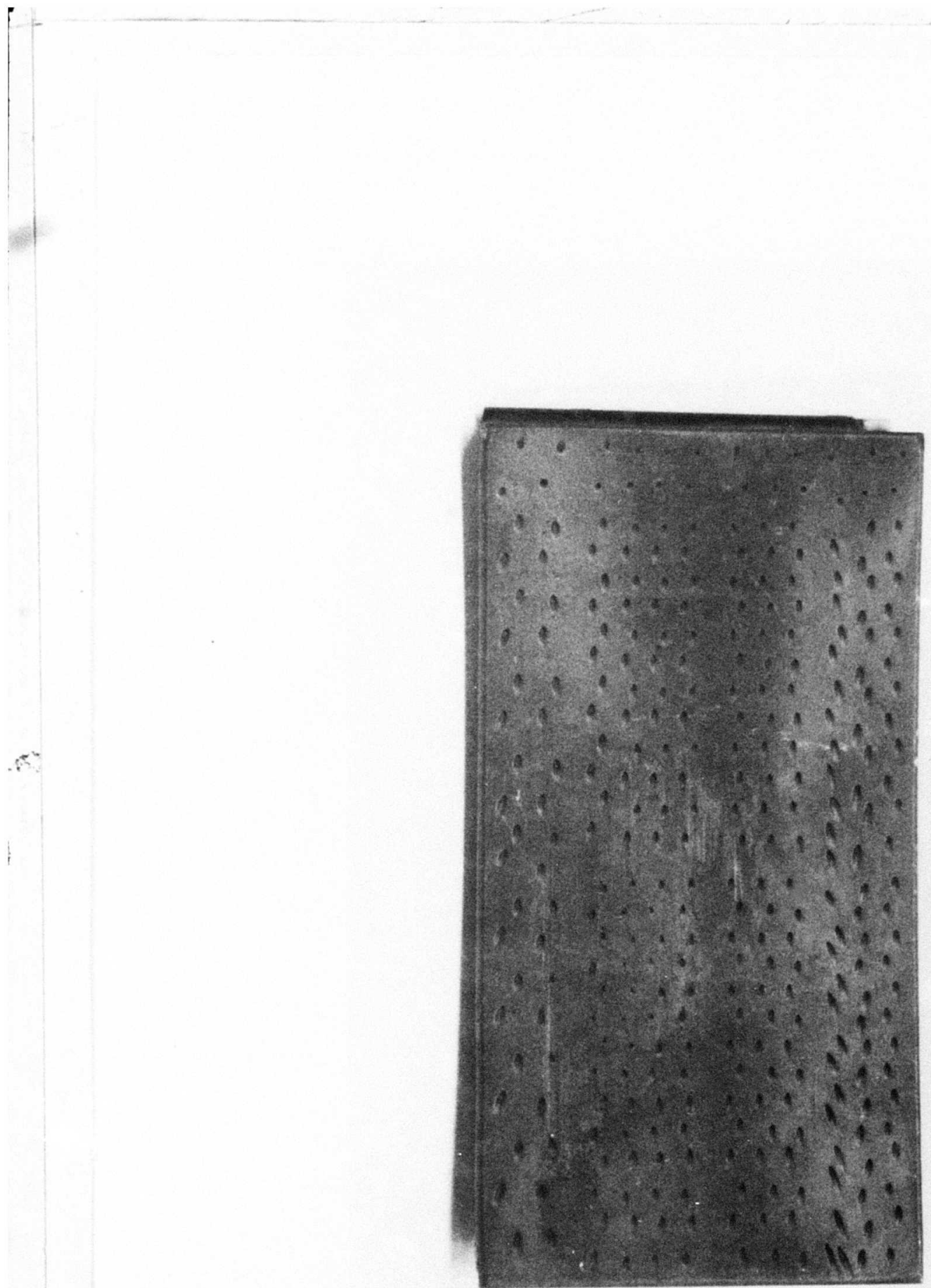

Figure 64. Film-Impingement-Cooled Shroud Segment After Test. 


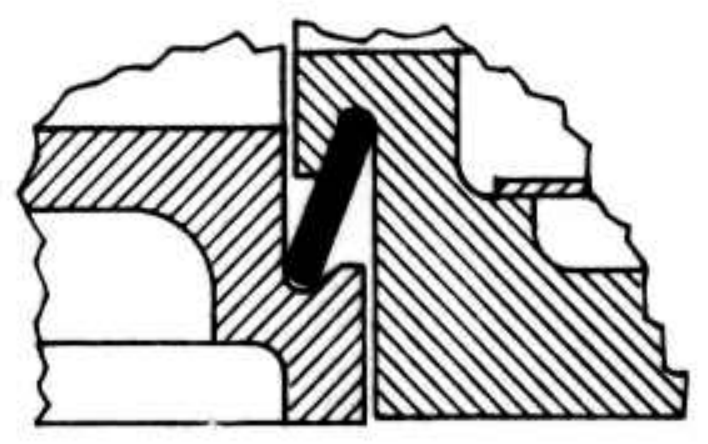

Axtal Seal, 1/2 Missing

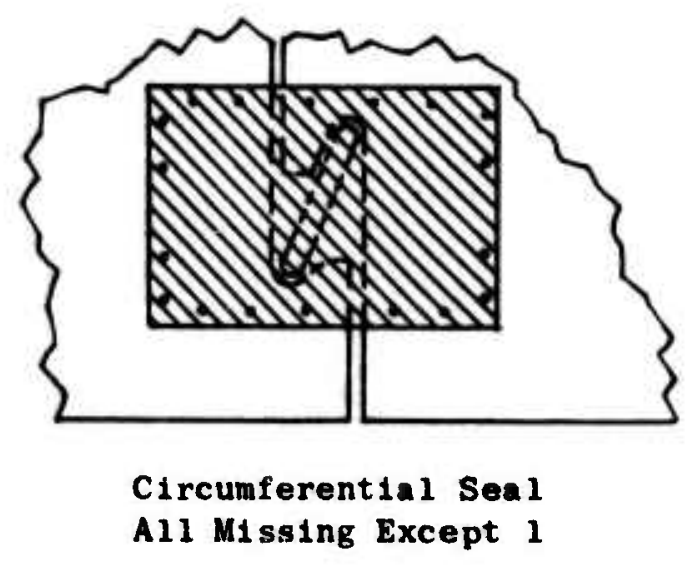

Figure 65. ATEST Shroud Seals Teardown Observations. 


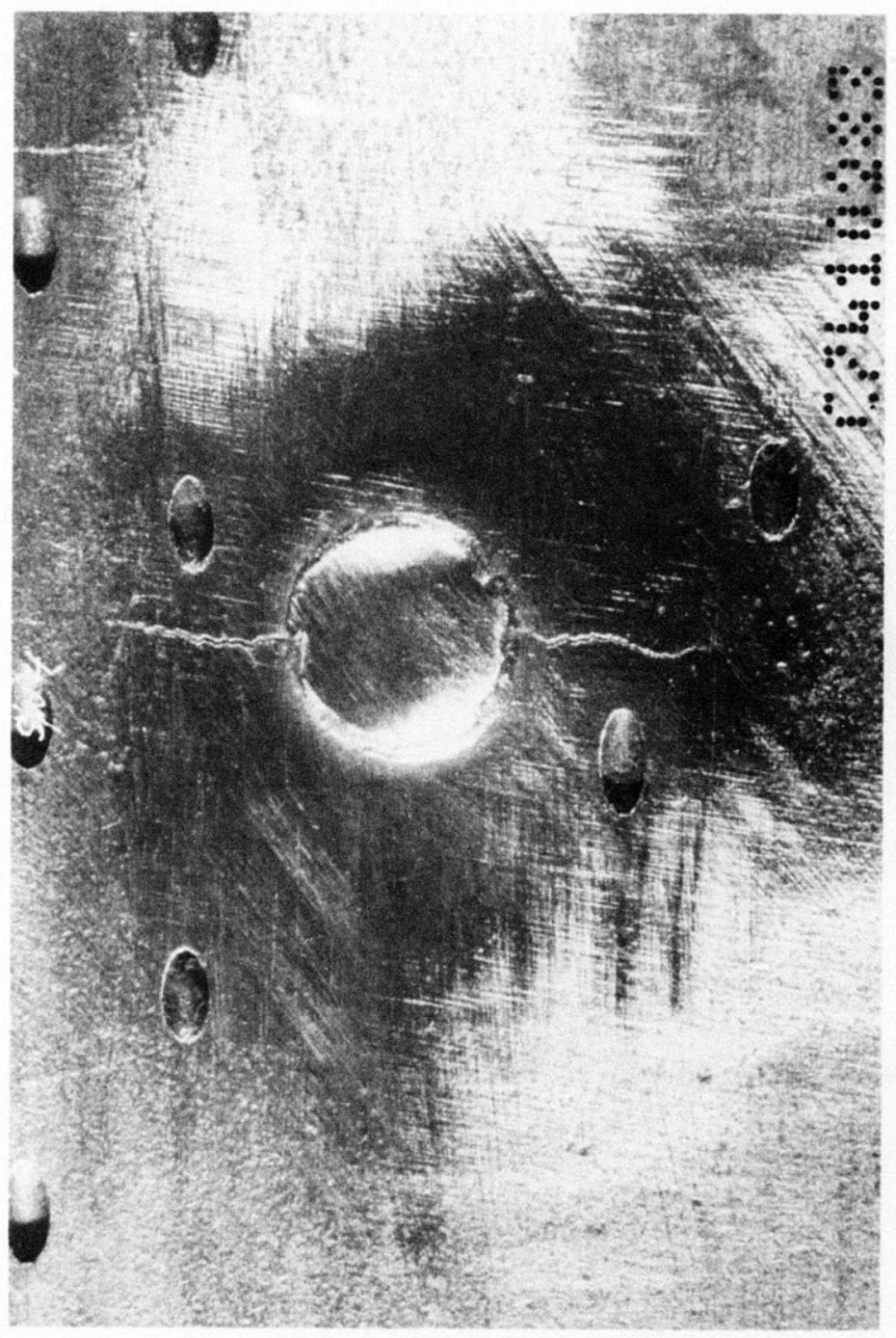

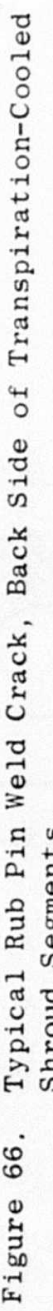




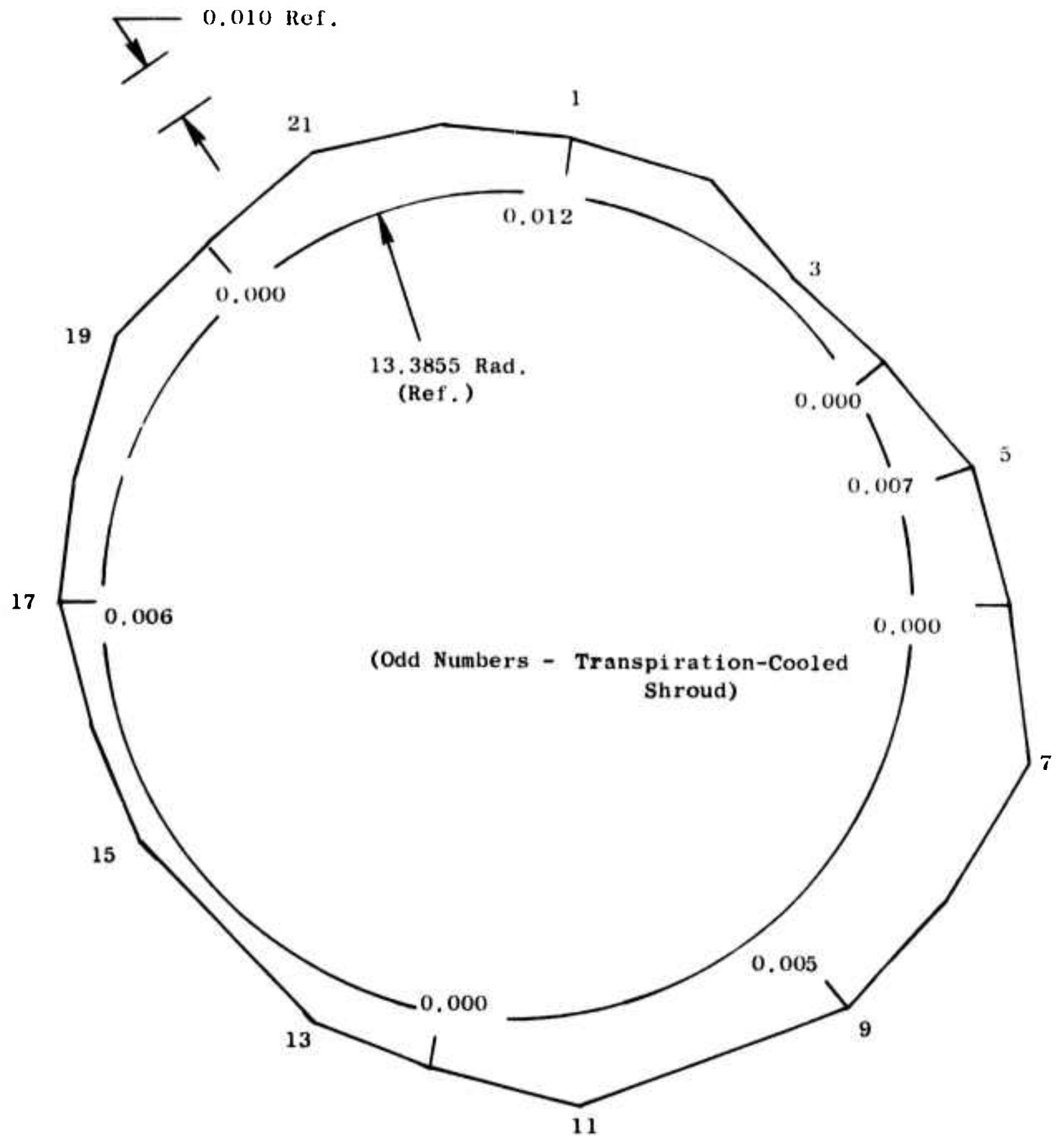

Figure 67. ATEST Shroud Rub Pin Heights and Mid-Chord Runout. 
Table 4. Comparison of Actual and Predicted Rotor-Shroud Clearances.

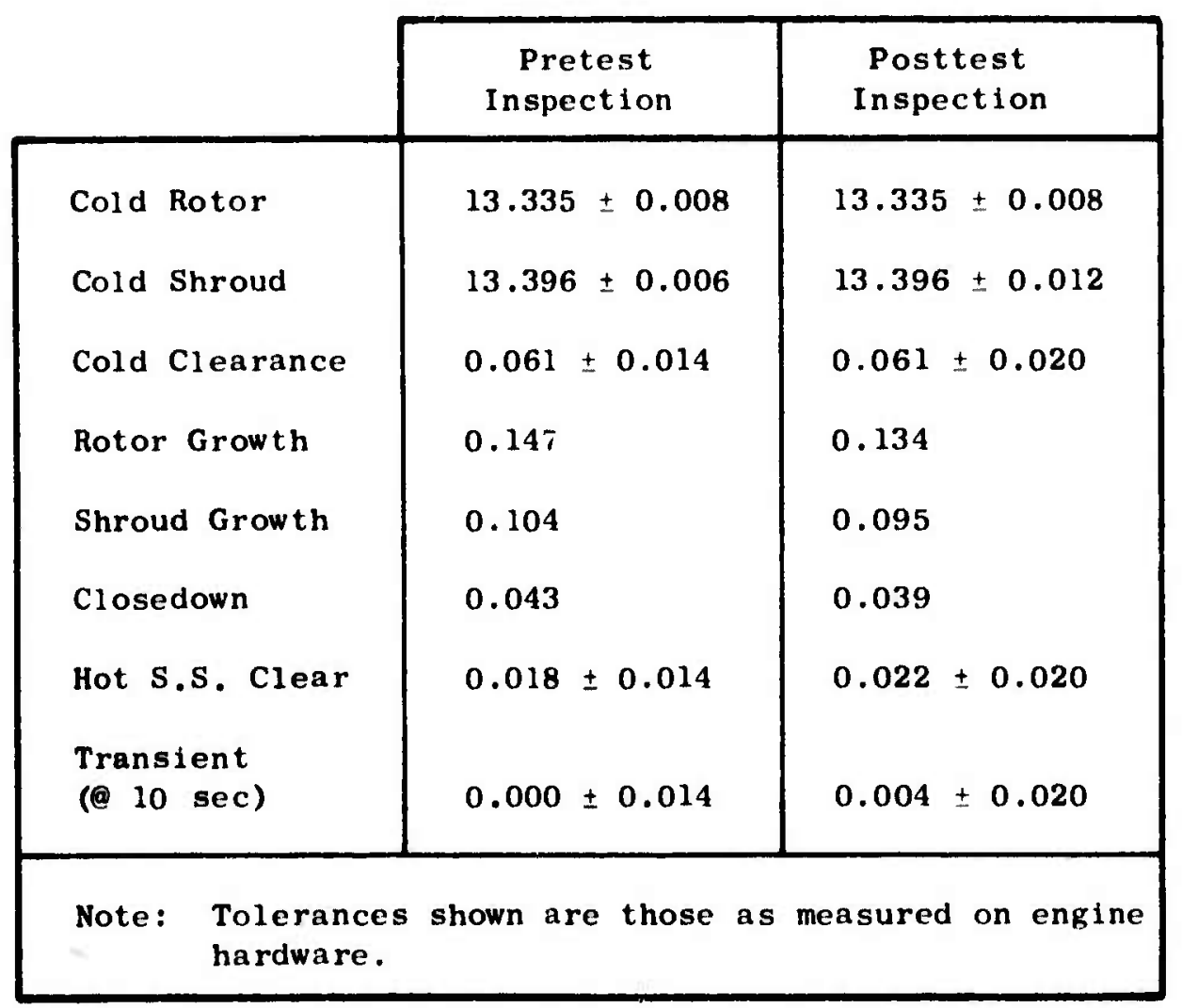


Postest runout inspections were taken on each shroud segment at nine places (Figure 68). These inspections were taken with the shroud system in the engine stack, and also in the free state. Figures 69 and 70 display the results of these two separate inspections at the leading edge and tralling edge of the segments, respectively. Also shown on these figures is the pretest runout. As can be seen, the shroud did go oval. The runout of the mid-chord of the segment is shown in Figure 67. The ovaling again is very obvious. The leading edge and trailing edge checked (in the posttest engine stack and in the free state) at 0.023 and 0.024 inch FIR (full indicator reading), respectively, while pretest measurements checked at 0.010 inch (L.E.) and 0.012 inch (T.E.) FIR. As explained earlier in this report, the shroud support was found to be oval at the time of buildup. Although the support was statically loaded to reduce this ovaling prior to engine testing and prior to obtaining pretest measurements, it appears that the support stress relieved back to the original oval during engine testing. This observation was confirmed by checking the runout of the forward and aft hangers of the shroud support. The FIR increased to 0.020 inch (posttest) and is shown in Figure 71 .

Before the shroud segments were cleaned and Zygloed, each was individually flow checked. Each flow zone (Figure 72), as well as the total segment, was flowed independently on the five instrumented segments. In general, the posttest flow on these five segments was higher than pretest measurements. About five percent of the difference can be explained by measuring error, small leaks, and instrument accuracy. The total flow of the remaining segments was measured and also compared to pretest data. The flow in the transpiration-cooled segments repeated pretest flow measurements within measuring accuracy. The film-convection-cooled segments flowed considerably higher than the pretest data. Extreme care was taken to check for leaks in the flow fixture to account for the large difference. Several segments wfre reflowed, but no difference was found. Upon examination of

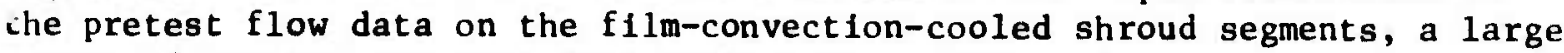
amount of scatter was seen from segment to segment. However, postest measurements indicated very little scatter in the flow data. This situation casts some doubt on the pretest flow measurements.

The flow in Zone 2 (Figure 72) of the film-convection-cooled shroud segment number 18 was individually flowed because it showed the heaviest indications of material smearing around the cooling holes. The flow was essentially identical to the pretest measurement. This would tend to indicate that the smearing caused no loss in flow. However, as noted above, the pretest flow checks are in question and, therefore, the effect of smearing on flow can not be determined with complete certainty. One observation that can be made is that there was no evidence of higher metal temperatures which would indicate significant reduced cooling in the rubbed area.

The cold blade tip-to-shroud clearance increased from pretest data based on runout inspections. This clearance ranged from 0.045 to 0.086 inch posttest, compared to 0.047 to 0.074 inch at pretest. However, about one 


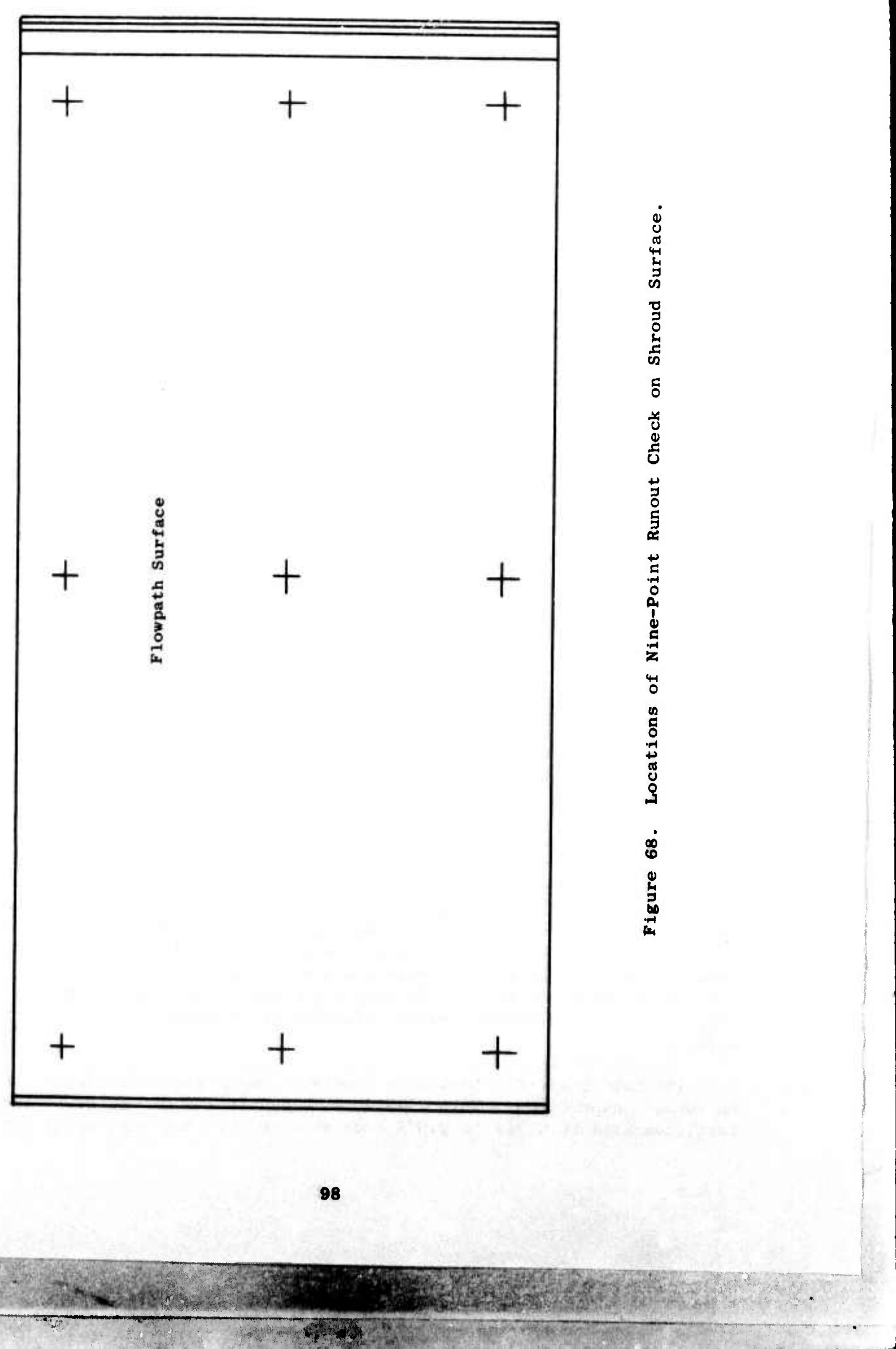




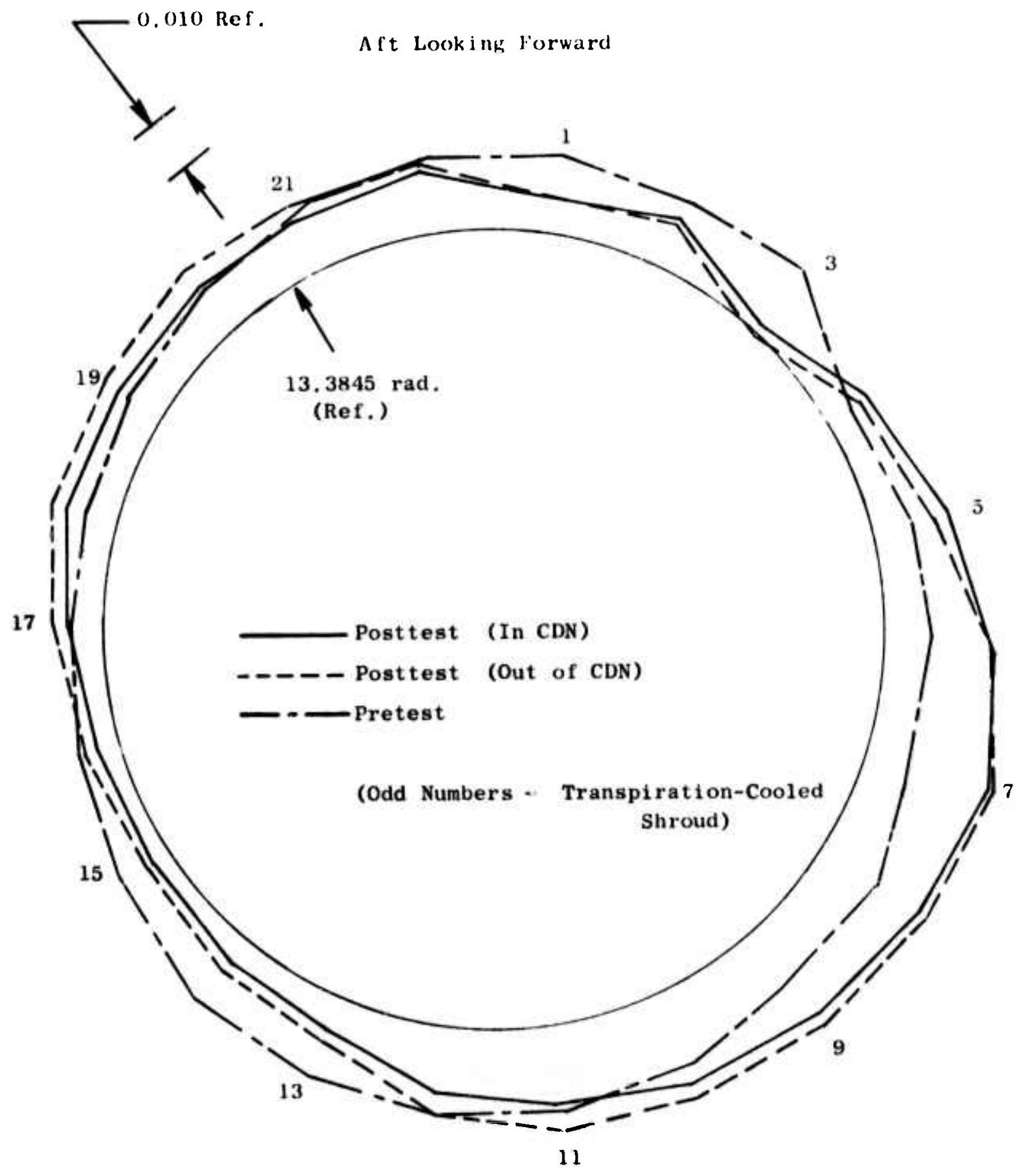

Figure 69. ATEST Shroud leading Edge Runout. 


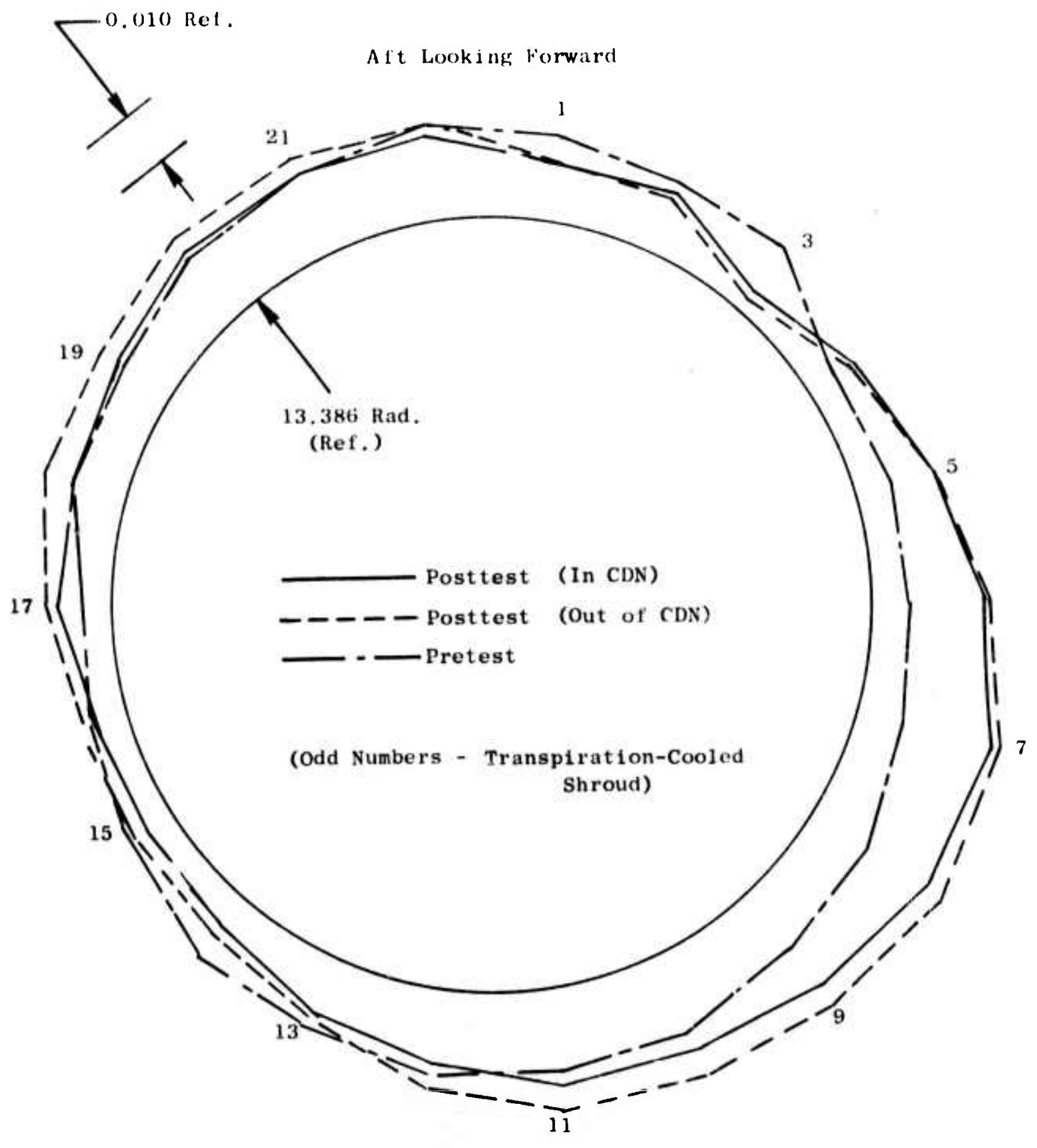

Figure 70, ATEST Shroud Trailing Edge Runout. 


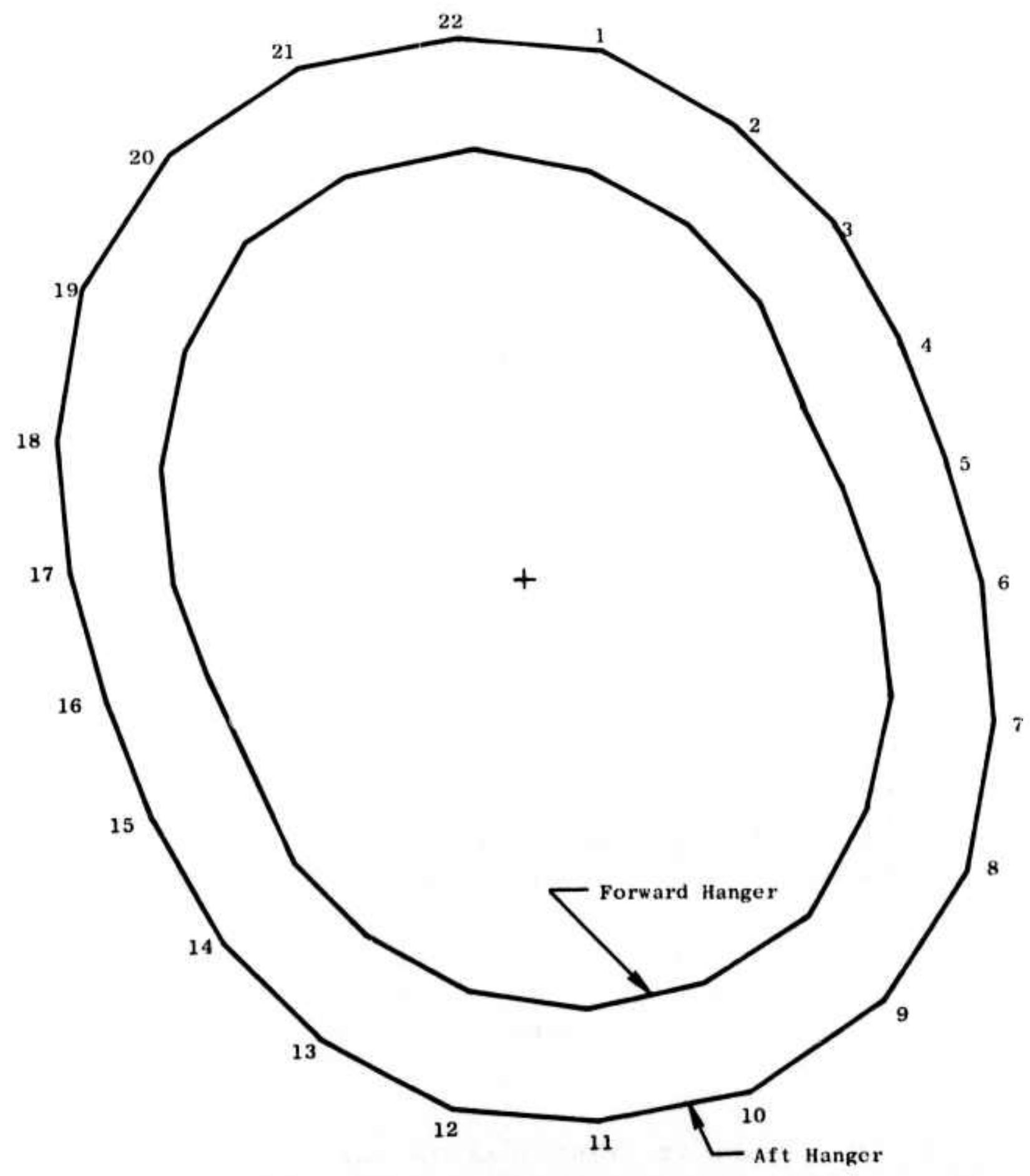

Figure 71. ATEST Shroud Support Posttest Runout. 

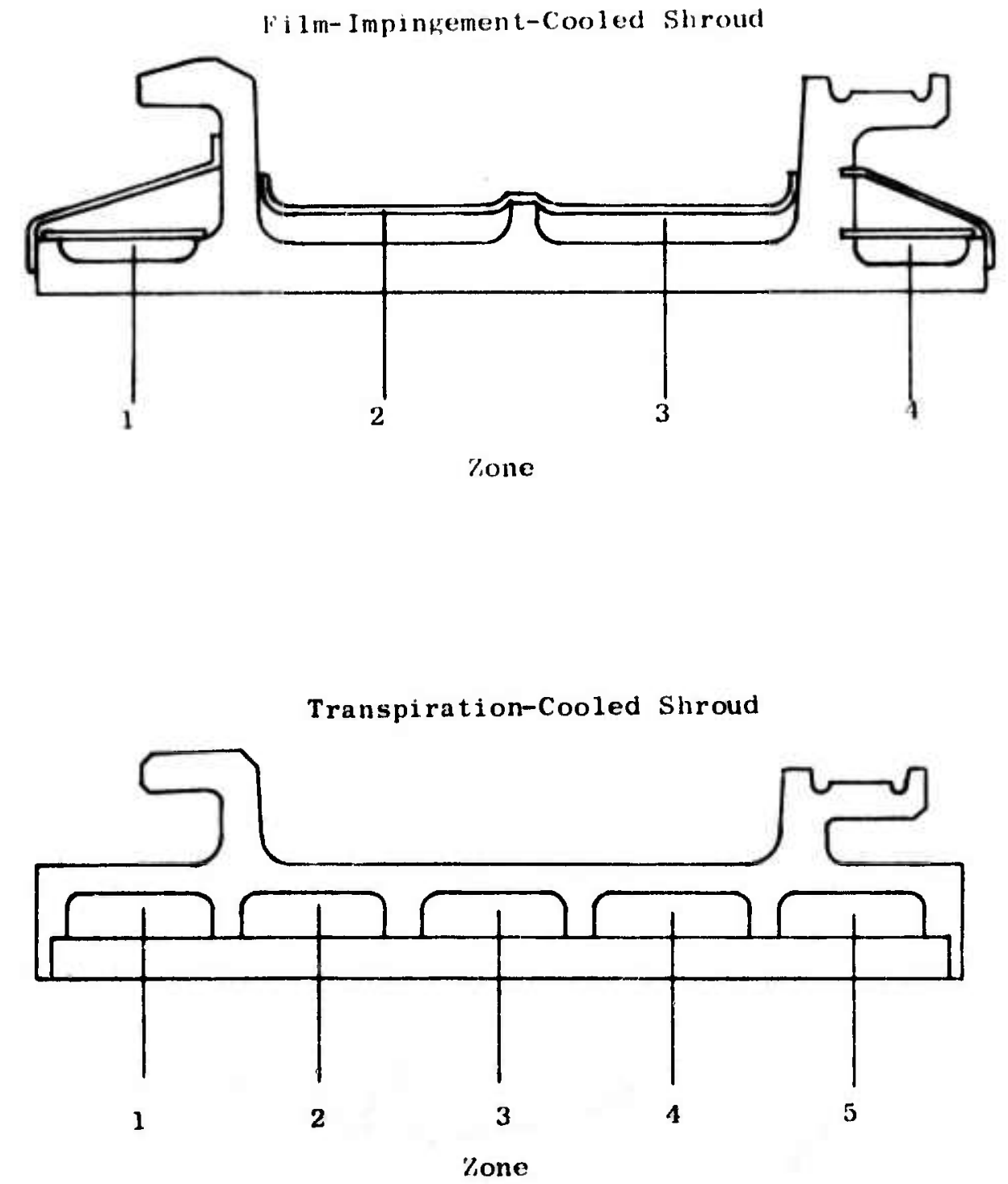

Figure 72. ATEST Shroud Flow Zones. 
half of the blades were loose in the disk, which accounts for a large portion of the difference. (Pretest runouts on the blade tips were made with the blades wedged out.) Based on these inspections, rub pin heights, and measured temperature data, the hot running clearances were calculated. The average steady-state tip clearance at rated TRIT (Turbine Rutor Inlet Temperature) was 0.022 inch at the shroud mid-chord. Because of rotation of the turbine rotor disk, an additional 0.004 inch of closedown was seen at the leading edge, while the average clearance at the trailing edge was 0.004 inch greater. The minimum clearance obtained occurred approximately 10 seconds into the transient accel to rated TRIT - $200^{\circ} \mathrm{F}$. Based on rub pin heights and rub indications, the average clearance at this 10-second point was 0.006 inch. Pretest hot clearances were predicted by setting zero average clearance at maximum transient conditions $\left(\mathrm{N}=15,300 \mathrm{rpm}, \mathrm{T}_{3}=\right.$ $\left.1080^{\circ} \mathrm{F}\right)$. However, the maximum condition encountered duing cyclic testing was $N=14,100 \mathrm{rpm}, \mathrm{T}_{3}=950^{\circ} \mathrm{F}$. Assuming that the low $\mathrm{T}_{3}$ affected the rotor and shroud equaliy, the difference in actual versus predicted average clearance can be explained by the rotor speed effect (approximately 0.005 inch less blade tip growth).

Table 4 summarizes these clearances compared to pretest. The table upholds the pretest calculations, and the conclusion can be made that the rotor-shroud system performed as designed. It should be noted in Table 4 that, under "From Test Data", the transient clearance $(0.004)$ is based on temperature data obtained during steady-state operation with 0.018 inch additional closedown as predicted. This agrees very well to the 0.006 inch average clearance based on rub pin helghts during transient operation.

As discussed earlier in this report, the pressure in the turbine shroud aft cavity was low during the test, leading to the theory that either the " $W$ " seal leaked or the shroud support-turbine frame flange leaked. Upon teardown, it was noted that a full. circumferential seal was obtained by the " $W$ " seal. However, local areas of oxide deposits were seen on the shroud support-turbine frame flange, indicating that sone amount of leakage was present. The leakage remained low enough to ensure proper coolant flow to the shroud segments. 


\subsection{CONCLUSIONS}

\subsection{MECHANICAL DES IGN PERFORMANCE}

The transpiration-cooled and film-impingement-cooled shroud segments were both in excellent condition upon teardown. Both types of shrouds were designed for 2000 high temperature cycles, but the transpiration-cooled shroud segment life was calculated to be 200 cycles, while the film-impingementconvection-cooled shroud segment life was calculated to be 500 cycles to crack initiation. Figure 73 shows the low cycle fatigue (LCF) life for both types of shroud segments at design conditions. The tëmperature data indicate that the critical locations on both shroud types ran cooler than design, thus greatly increasing the low cycle fatigue life, as can be seen on Figure 73 .

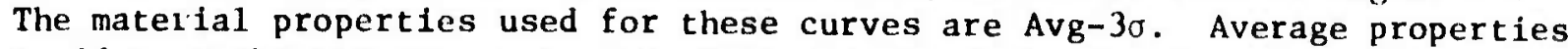
would move the LCF curves to the right and, thus, indicate greater life. The curves indicate that actual running conditions caused the film-impingementcooled shroud segments to be as limiting as the transpiration-cooled shroud segments in LCF. Thus, it becomes apparent that the greater predicted life in the film-impingement-cooled shroud ( 500 cycles versus 200 cycles) was not realized under engine conditions.

As stated previously, the film-impingement-cooled shrouds showed signs of material smearing due to a light blade tip rub. Although no hole plugging or loss in flow was seen, it is reasonable to assume that a heavier tip rub could cause serious problems in plugging holes. For this reason, a solid shroud of this type should have a rub surface which would absorb the tip rub and prevent smearing of material and blade metal transfer.

The mechanical design of the shroud support was unique to this program. The design theory was to use radial clearance slots in the shroud support to isolate it from surrounding engine structures. This design eliminates a large amount of out-of-roundness caused by circumferential temperature gradients and loads acting on the many casings and supports surrounding the shroud.

The ovaling problem found in the support at the time of buildup was due to improper manufacturing in meeting the roundness criteria specified in the detailed drawing. Taking this into account, it would appear that the slip joint feature performed as designed.

The inherent problems with this type of design must be closely considered. Because of the tight dimensioning of the clearance slots to avoid looseness and slop, a situation can occur where one or several bolts get hungup in the slots due to hardware out-of-roundness. When this occurs, the slip joint (a unique feacure of this design) loses its intended function since several locations of the shroud support bind-up with the surrounding structures and are forced to respond with them. This adversely effects roundness of the shroud and thus hinders tip clearance control. 


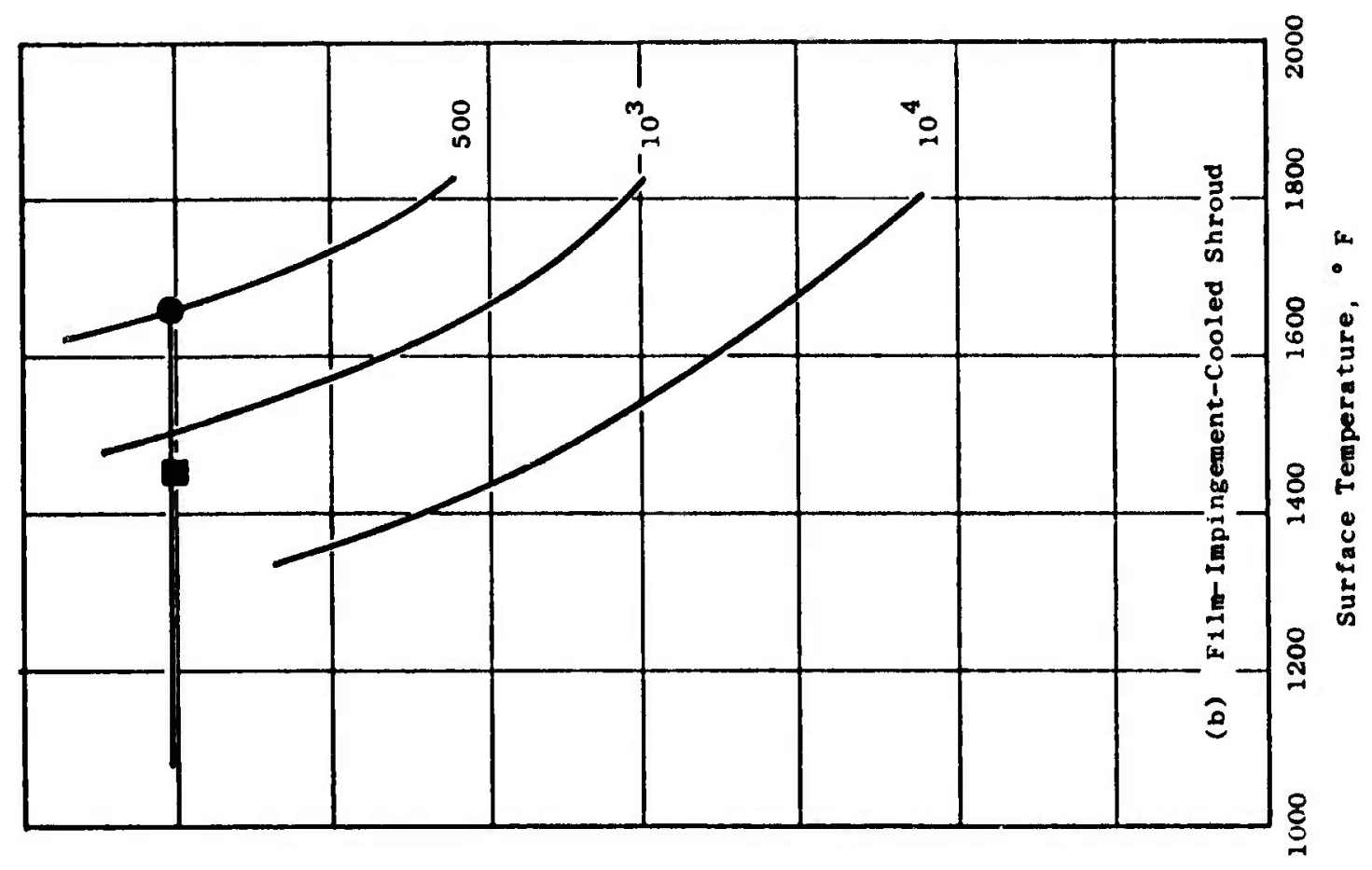

永

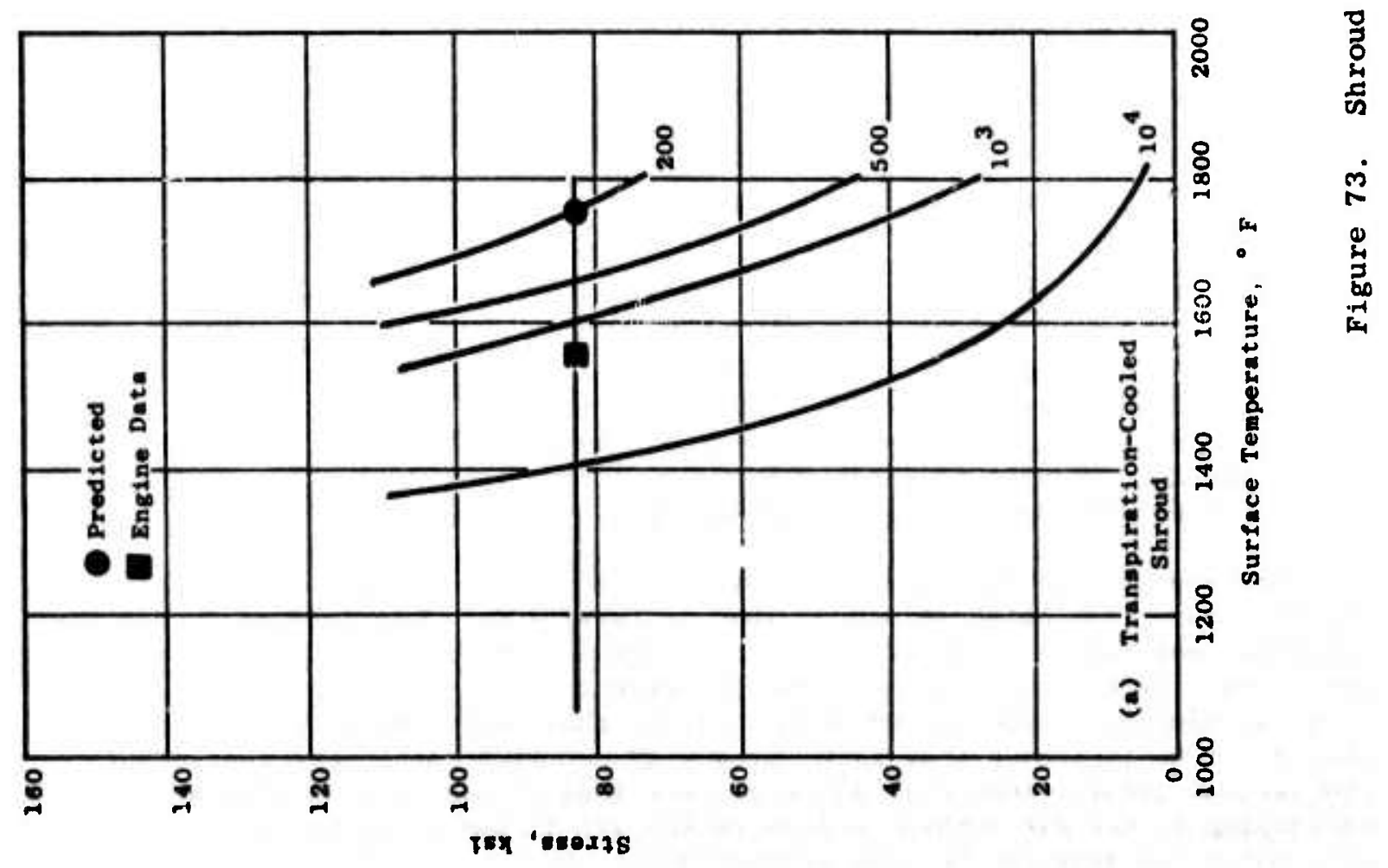


An important part of this program was not only a side-by-side comparison of two differently cooled shroud designs, but also a definition of a complete shroud system that would include transient and steady-state response characteristics for tip clearance control. The results of the tip clearance calculations shown in Table 4 indicate that this objective was met. The average steadystate clearance was as predicted, when taking into account the low rotor speed. Although the transient response of the shroud system was approximately 20 percent faster than predicted, it matched the rotor response well enough to provide $0.004-0.006$ inch average clearance during cyclic testing.

For the most part, the sealing of the shroud system was good. The "W" seal worked as designed as indicated by a full-circumferential wear mark seen upon disassembly. The forward spring seal attached in the shroud support did not yield and, thus, provided a continual seal throughout the test program. The spline seals used between segments did not perform satisfactorily. Upon engine teardown, over half of these seals were missing. The ones that were found showed signs of distress and wear attributable to vibration. It is felt that the falling out of these spline seals caused some blade damage, since many blades (towards the back of the blade snueeler tip suction side) showed signs of FOD. For future shroud designs, this type of seal should not be used. The seals between segments must be designed for low wear and for retainment under all englne operating conditions.

\subsection{COOLING PERFORMANCE}

In comparing cooling performance measurements with actual engine operating cooling performance predictions based on the turbine design procedures developed in Reference 1 , it is seen that the shrouds performed about as would be predicted. This means that the design procedures in Reference 1 from the air turbine test are valid for the most part.

Temperature measurements obtained during testing indicated lower temperatures on the transpiration-cooled shroud surface than on the $f 11 \mathrm{~m}$ impingenent-cooled segments. Relating measured temperatures to predicted temperatures indicated that uninstrumented sections of the segments ran at $1635^{\circ} \mathrm{F}$ on the transpiration-cooled shroud, and $1735^{\circ} \mathrm{F}$ on the f1lm-1mpingementcooled shroud. These temperatures are down $115^{\circ} \mathrm{F}$ from design due to the lower-than-design engine speed (thus $T_{3}$ ) obtained at the rated $T_{4}$.

One region that appeared to be overcooled was the forward two zones of the transpiration-cooled shrouds. The air turbine data had indicated that the apparent heat load in this area was very high. This led to increasing the heat loads for design by as much as 160 percent from the flat plate turbulent flow calculations. The eng ine data indicate that this forward heat load should not be increased that much for design. A flat plate heat load about 100 percent greater than flat plate calculations at the leading edge and decreasing to the air turbine values in the aft region as shown in Figure 74 w11l match the measured cooling performance. 


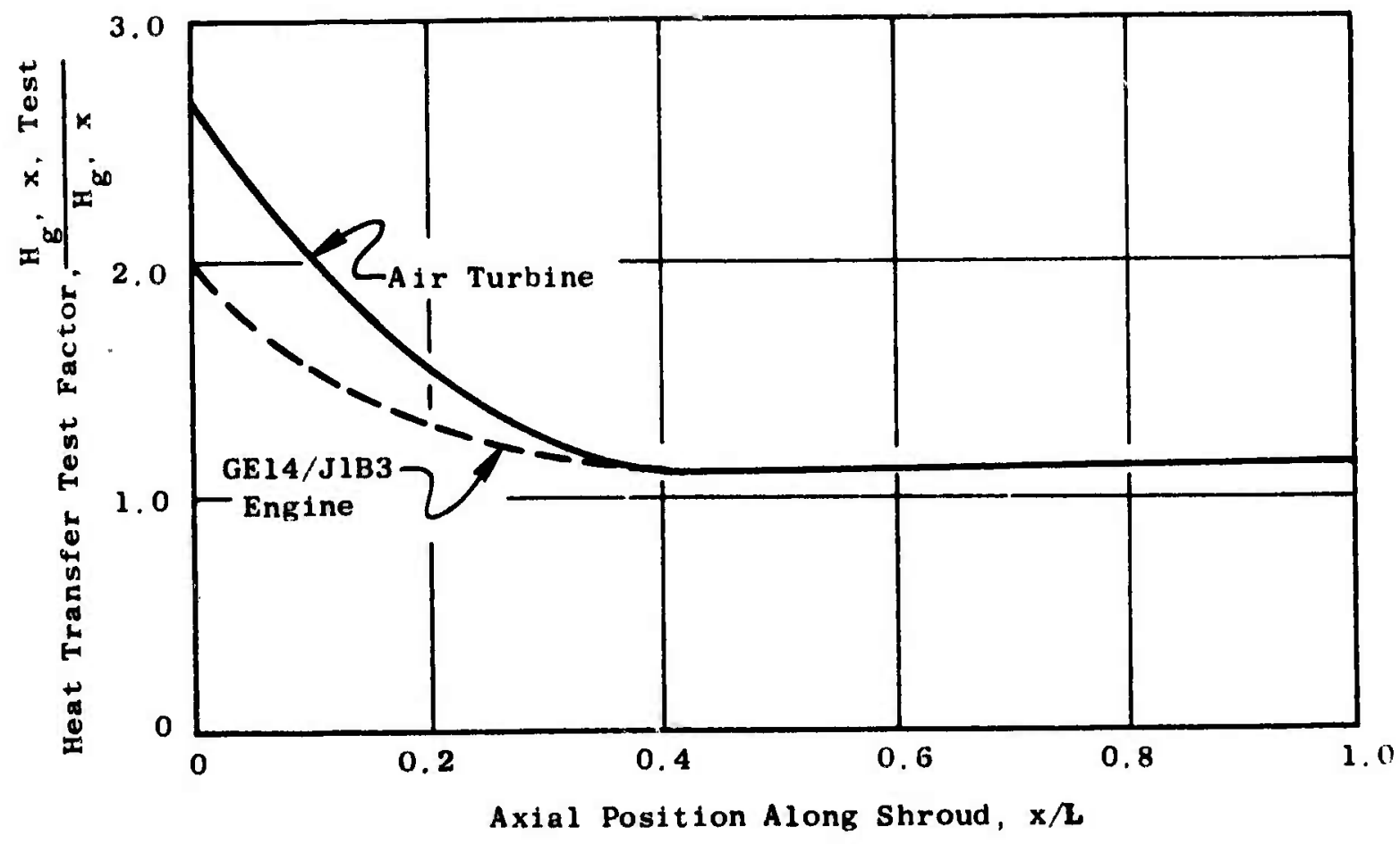

Figure 74. Heat Transfer Test Factor Versus Axial Position Along the Shroud. 
Reducing the design heat load in the forward region of the transpirationcooled shroud allows a reduction in the required cooling flow to maintain a given design metal temperature. The transpiration-cooled shroud flow for the GE14/J1B3 engine then could be reduced from 2.8 percent $W_{2 c}$ to 2.4 percent

$\mathrm{W}_{2 c}$. From a cooling-flow-only standpoint then, this reduction in $f$ low makes the transpiration-cooled shrouds more competitive with the film-impingementcooled shrouds. But even so, the transpiration-cooled shroud still uses about 40 percent more cooling air than the 1.67 percent $W_{2 c}$ required for the filmimpingement-cooled shroud.

The gas stream pressure distribution on the shroud surface is shifted aft from the design predictions as shown in Figure 57 . This shift has significnat effects in the aft regions of the shroud where the pressure gradient across the zones is significantly altered. If this gradient is not taken into account, some regions can be overcooled greatly and some undercooled with even the possibility of hot gas ingestion.

The shroud support operated at essentially the expected temperature levels, given the differences observed between the design and actual demonstrator engine environment. The transient response, however, was faster than predicted. This indicates that the heat transfer coefficients on the support surfaces are somewhat higher than predicted. These predictions are very difficult because the heat loads are not well defined, but the data indicate that the heat loads are 20 percent higher than assumed for the forced convection in the passages and the material convection on the exposed surfaces. 
1. Koffel, W.K. and Meyer, L.J.; "Advanced Turbine Engine Seal Design," Technical Report AFAPL-TR-73-46, May, 1973.

2. Hauser, A.A., Bryant, D.C. and Gardner, S.N.; "Advanced Turbine Engine Seal Test; Phase I - Design," Report R73AEG436, March, 1974. 
THIS REPORT HAS BEEN DELIMITED

AND CLEARED FOR PUDLIC RELQASE UNDER DOD DIRECTIVE 5200,20 AND

NO RESTRICTIONS ARE IMPOSED UPON

ITS USE AND DISCLOSURE.

DISTRIBUTION STATEMENT A

APPROVED FOR PUBLIC RELEASES

DISTRIBUTION UNLIMITED. 